\title{
Radioanalysis of ultra-low level radionuclides for environmental tracer studies and decommissioning of nuclear facilities
}

\author{
Hou, Xiaolin
}

Published in:

Journal of Radioanalytical and Nuclear Chemistry

Link to article, DOI:

10.1007/s10967-019-06908-9

Publication date:

2019

Document Version

Peer reviewed version

Link back to DTU Orbit

Citation (APA):

Hou, X. (2019). Radioanalysis of ultra-low level radionuclides for environmental tracer studies and

decommissioning of nuclear facilities. Journal of Radioanalytical and Nuclear Chemistry, 322(3), 1217-1245. https://doi.org/10.1007/s10967-019-06908-9

\section{General rights}

Copyright and moral rights for the publications made accessible in the public portal are retained by the authors and/or other copyright owners and it is a condition of accessing publications that users recognise and abide by the legal requirements associated with these rights.

- Users may download and print one copy of any publication from the public portal for the purpose of private study or research.

- You may not further distribute the material or use it for any profit-making activity or commercial gain

- You may freely distribute the URL identifying the publication in the public portal 


\section{Radioanalysis of ultra-low level radionuclides for} environmental tracer studies and decommissioning of

4 Names of the authors: Xiaolin Hou

5 Title: professor

6 Affiliation(s) and address(es) of the author(s): (1) Technical University of Denmark,

7 Center for Nuclear Technologies, Risø Campus, 4000, Roskilde, Denmark; (2) Lanzhou

8 University, School of Nuclear Science and Technology, 730000 Lanzhou, China; (3)

9 Xi'an AMS Center, Institute of Earth Environment, CAS, Xi'an 710061, China; E-mail

10 address of the corresponding author: xiho@dtu.dk 


\section{nuclear facilities}

\author{
Xiaolin $\mathrm{Hou}^{1,2,3}$ \\ ${ }^{1}$ Technical University of Denmark, Center for Nuclear Technologies, Risø Campus, \\ 4000, Roskilde, Denmark \\ ${ }^{2}$ Lanzhou University, School of Nuclear Science and Technology, China \\ ${ }^{3} X i^{\prime}$ an AMS Center, Institute of Earth Environment, CAS, Xi'an 710061, China
} environmental tracer studies and decommissioning of 
33 Radioanalytical methods for low-level radionuclides; mass spectrometry; speciation 34 analysis; environmental process tracing; decommissioning;

\section{Introduction}

36 Large amounts of anthropogenic radionuclides have been released to the environment by

37 human nuclear activities, meanwhile the industrial activities also significantly increased

38 the level of natural occurred radionuclides in regional environment. The impact of these

39 enhanced level of radionuclides to the environment and ecosystem has become a highly

40 concerned topic. Meanwhile, radionuclides entered into the environment also provide

41 good tracers for the investigation of environmental processes because of their unique

42 source terms. For these purposes, the accurate determination of these radionuclides in

43 various environmental media is needed. Because the concentrations of these

44 radionuclides in the environment are normally very low, highly sensitive measurement

45 techniques are important. Besides some gamma emitting radionuclides, most of long-

46 lived radionuclides are pure beta and alpha emitters, effective chemical separation of the

47 target radionuclides from the sample matrix and other interfering radionuclides and

48 elimination of the interference for the instrumental measurement are critical for their

49 reliable determination. In the recent years, our laboratory has developed, upgraded and

50 improved a number of analytical methods for the determination of long-lived

51 radionuclides and their chemical species in various environmental samples, e.g. ${ }^{99} \mathrm{Tc},{ }^{129} \mathrm{I}$,

$52{ }^{135} \mathrm{Cs},{ }^{210} \mathrm{Po},{ }^{226} \mathrm{Ra},{ }^{222} \mathrm{Rn},{ }^{239} \mathrm{Pu},{ }^{240} \mathrm{Pu},{ }^{237} \mathrm{~Np}$ and ${ }^{236} \mathrm{U}$, which have been used for

53 environmental trace studies, such as movement and interaction of water masses in the

54 seas/oceans, dispersion and deposition of radioactive substances and other air pollutions,

55 identification of the sources of radioactive substance and estimation of the contributions

56 of these sources to the corresponding environment, and tracing soil erosion and

57 sedimentation.

58 Since the application of atomic energy from 1940's, large number of nuclear facilities

59 have been established all over the world. Some of them have been closed, and many of 60 them are going to be closed in the coming years due to their life of 40-60 years. Fig. 1 
61 shows the number of nuclear power reactors closed and to be closed in the world [1]. 62 These closed nuclear facilities have to be well decommissioned to release the sites for 63 other purpose. In all processes of decommissioning, including preparation by background 64 radioactivity investigation of the site, cleanout by removal of spent nuclear fuel, 65 decontamination by removal of contaminant from the surface of the facilities and devices, 66 dismantling by cutting, demolition, waste removal and site clearance, waste depository by 67 classification of the produced waste and site release by measurement of the site, various 68 radionuclides in the relevant materials have to be determined for suitable treatment and 69 final repository of the produced wastes, management of the decommissioning process and 70 evaluation of the decommissioning quality. For these purposes, the analysis of various 71 decommissioning samples for their radiological and chemical characterization is the most 72 important issue. Among them, the determination of various difficult-to-measure 73 radionuclides is the major challenge, because of complicated and unknown composition 74 of sample matrix, significant difference in the radioactive level of radionuclides, 75 instability of some volatile radionuclides, and complicated chemical properties and 76 chemical species of some radionuclides. Since 2000, our laboratory has developed a 77 series of radioanalytical methods for determination of difficult-to-measure radionuclides 78 (e.g. ${ }^{3} \mathrm{H},{ }^{14} \mathrm{C},{ }^{36} \mathrm{Cl},{ }^{41} \mathrm{Ca},{ }^{55} \mathrm{Fe},{ }^{63} \mathrm{Ni},{ }^{93} \mathrm{Mo},{ }^{94} \mathrm{Nb},{ }^{99} \mathrm{Tc},{ }^{129} \mathrm{I},{ }^{135} \mathrm{Cs}$ and actinides) in various 79 decommissioning samples such as concrete, graphite, metals, resin, filters, etc. These 80 methods have been successfully applied in the characterization of decommissioning 81 waste of research and power reactors, hot cells and other nuclear facilities, as well as 82 wastes from the operational power reactors. 


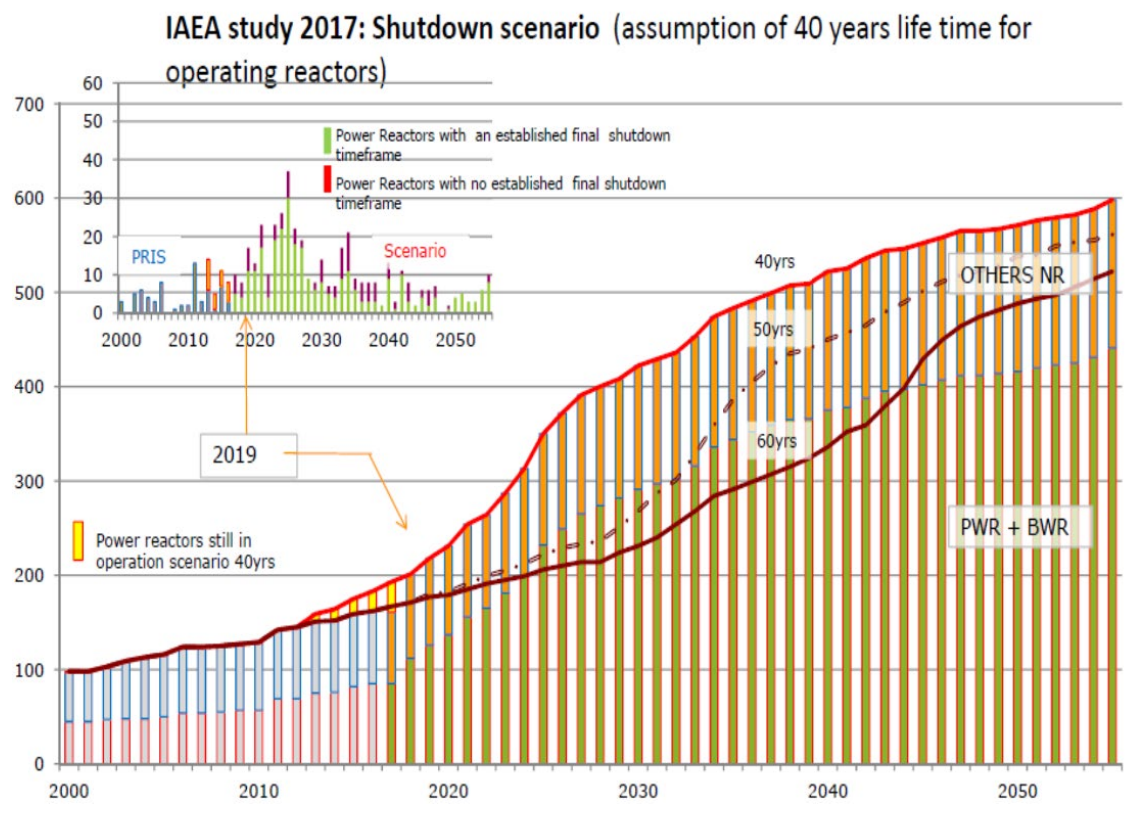

84 Fig.1 Number of power reactors closed and to be closed for decommissioning [1]

85 This paper aims to summarize the radioanalytical methods developed in our laboratories

86 in the past years for analysis of environmental samples and decommissioning waste. Both

87 chemical separation of various radionuclides from matrix and interferences and their

88 measurement techniques are presented.

89 Major sources of radionuclides in the environment

90 Since 1940's, large amount of anthropogenic radionuclides have been released to the 91 environment by human nuclear activities, mainly from atmospheric nuclear weapons test

92 before 1980, spent nuclear fuel reprocessing plants, nuclear accidents, and small amount

93 from operation of nuclear facilities and medical application of radionuclides in the

94 hospitals. United Nations Scientific Committee on Effects of Atomic Radiation

95 (UNSCEAR) has reported a comprehensive dataset on the radionuclides released from 
96 nuclear activities to the environment until 1998 [2]. Up to 2013, 2055 nuclear weapons

97 tests were conducted all over the world. Among them, 520 tests were conducted in the 98 atmosphere in 1945-1980. Large amount of radionuclides were released during the

99 weapons testing. Some of them were injected to the stratosphere and dispersed in large

100 scale and deposited all over the world, especially for those of high yield tests.

101 Meanwhile, some radionuclides were released to the troposphere and deposited

102 regionally.

103 Up to now, two large nuclear accidents happened in April 1986 in Chernobyl NPP and in 104 March 2011 in Fukushima Daiichi NPP (FDNPP) have released large amount of 105 radionuclides to the atmosphere, causing a relative high radioactive deposition in the 106 Europe during Chernobyl accident and in Japan during the Fukushima accident. FDNPP 107 has also discharged some fraction of liquid radioactive substance to the sea, caused 108 significantly increased radioactivity in the seawater off Fukushima [3]. In addition, some 109 relative small scale accidents were also occurred and released some radionuclides to the 110 environment. The accident of a graphite reactor fire at Windscale (UK) in 1957 had 111 released $1 \times 10^{15} \mathrm{~Bq}$ of ${ }^{131} \mathrm{I}, 9.4 \times 10^{13} \mathrm{~Bq}$ of ${ }^{90} \mathrm{Sr}$ to the atmosphere. An explosion in a 112 plutonium production plant in Kyshtym (USSR) in 1957 released $2 \times 10^{15} \mathrm{~Bq}$ of ${ }^{90} \mathrm{Sr}$ and $1133 \times 10^{13} \mathrm{~Bq}$ of ${ }^{137} \mathrm{Cs}$. Accidents of aircrafts carried nuclear weapons happened in 114 Palomares (Spain) in 1966 and in Thule (Greenland) in 1967 have released some amount 115 of plutonium and americium to the environment. A satellite (SNAP-9A) with ${ }^{238} \mathrm{Pu}$ as 116 fuel fell down and burned over Indian Ocean in 1964 and released $6.3 \times 10^{14} \mathrm{Ba}{ }^{238} \mathrm{Pu}$ to 117 the atmosphere, and another satellite fueled with a nuclear reactor fell down and burned 118 over Canada in 1978 and released $2 \times 10^{14} \mathrm{~Bq}$ of ${ }^{131} \mathrm{I}, 3 \times 10^{12} \mathrm{~Bq}$ of ${ }^{90} \mathrm{Sr}$ and ${ }^{137} \mathrm{Cs}$ to the 119 atmosphere.

120 Many spent fuel reprocessing plants have been in operation in USA, Russia, Japan, 121 Germany, France, India and China for separation of uranium and plutonium from the 122 used fuel, some radionuclides have been released to the atmosphere and to the seas 123 during their operation. Among them, the reprocessing plants at Sellafield (UK) and La 124 Hague (France) are the major ones which reprocessed large amount of nuclear fuel from 125 production and power reactors, meanwhile discharged large amount of radioactive 
126 substance to the seas and atmosphere $[4,5]$. Compared with the above three sources, the

127 amount of radionuclides discharged to the environment from the operation of nuclear 128 reactors, isotope production and medical application in the hospital is minor (UNSCEAR 129 2000). Table 1 presents the amount of major long-lived radionuclides released to the 130 environment from the nuclear weapons tests, reprocessing plants (Sellafield and La 131 Hague) and nuclear accidents in Chernobyl and Fukushima. It can be seen that the major 132 contribution of the anthropogenic radionuclides in the environment (excluding those 133 remained in the spent nuclear fuel and stored as nuclear waste) is the atmospheric nuclear 134 weapons tests, they caused a deposition of anthropogenic radionuclides all over the 135 world. Fig. 2 shows temporal variation of the measured ${ }^{137} \mathrm{Cs}$ and ${ }^{90} \mathrm{Sr}$ concentrations in 136 aerosol samples collected at Risø, Denmark from 1950's to the present. The highest 137 levels of ${ }^{137} \mathrm{Cs}$ and ${ }^{90} \mathrm{Sr}$ in the aerosol were observed in early 1960's when large numbers 138 of atmospheric nuclear weapons tests were conducted in 1961-1962 by USA and USRR. 139 Declined levels of ${ }^{137} \mathrm{Cs}$ and ${ }^{90} \mathrm{Sr}$ with some small peaks were observed afterwards 140 because some atmospheric nuclear weapons tests were conducted by UK, France and 141 China, which completely ceased in 1980. This caused a continuously decreased level of $142{ }^{90} \mathrm{Sr}$ in the aerosol. Two peaks of ${ }^{137} \mathrm{Cs}$ levels were clearly observed in 1986 and 2011, 143 which were attributed to the releases from Chernobyl and Fukushima accidents, 144 respectively.

146 Table 1. Amount of the major long-lived radionuclides released to the environment from 147 major human nuclear activities

\begin{tabular}{|c|c|c|c|c|}
\hline \multirow{2}{*}{ Nuclide } & \multicolumn{4}{|c|}{ Released activity, $10^{15} \mathrm{~Bq}$} \\
\cline { 2 - 5 } & $\begin{array}{l}\text { Nuclear } \\
\text { weapons tests }\end{array}$ & Reprocessing & $\begin{array}{l}\text { Chernobyl } \\
\text { accident }\end{array}$ & $\begin{array}{l}\text { Fukushima } \\
\text { accident }\end{array}$ \\
\hline${ }^{137} \mathrm{Cs}$ & 1280 & 17.45 & 85 & 15 \\
\hline${ }^{90} \mathrm{Sr}$ & 850 & 3.39 & 10 & 0.9 \\
\hline${ }^{144} \mathrm{Cs}$ & $1.04 \times 10^{6}$ & 0.51 & 116 & \\
\hline
\end{tabular}




\begin{tabular}{|c|c|c|c|c|}
\hline${ }^{106} \mathrm{Ru}$ & $4.25 \times 10^{5}$ & 7.47 & 73 & \\
\hline${ }^{131} \mathrm{I}$ & $2.3 \times 10^{7}$ & & 1760 & 160 \\
\hline${ }^{239} \mathrm{Pu}$ & 7.8 & 0.16 & 0.03 & \\
\hline${ }^{129} \mathrm{I}, \times 10^{12} \mathrm{~Bq}$ & 0.412 & 38.6 & 0.010 & 0.0086 \\
\hline${ }^{99} \mathrm{Tc}, \times 10^{12} \mathrm{~Bq}$ & 140 & 1872 & 0.75 & $<0.5$ \\
\hline
\end{tabular}

149 Although most of anthropogenic radionuclides in the environment were released from the 150 atmospheric nuclear weapons tests, some radionuclides such as ${ }^{129} \mathrm{I}$ and ${ }^{99} \mathrm{Tc}$ in the 151 environment were dominantly originated from the discharges of nuclear fuel reprocessing 152 plants at La Hague and Sellafield. Most of ${ }^{129} \mathrm{I}(>85 \%)$ and ${ }^{99} \mathrm{Tc}(>99 \%)$ originated from 153 the two reprocessing plants were discharged to the seas (Irish Sea and English Channel, 154 respectively). Fig. 3 shows the temporal variation of the amount of ${ }^{129} \mathrm{I}$ and ${ }^{99} \mathrm{Tc}$ 155 discharged to the seas from the two reprocessing plants [4, 5, 6]. Among them, Sellafield 156 reprocessing plant is the major source of ${ }^{99} \mathrm{Tc}$, while ${ }^{129} \mathrm{I}$ was mainly discharged from La 157 Hague reprocessing plants. The unique source terms and specific feature of discharge 158 profiles of the two reprocessing plants combined with the high water solubility and 159 conservative feature of iodine and technetium in the ocean make the reprocessing derived

$160{ }^{129} \mathrm{I}$ and ${ }^{99} \mathrm{Tc}$ very good oceanographic tracers for investigation of water mass movement 161 and interaction. Besides the marine discharges, about $800 \mathrm{~kg}$ of ${ }^{129} \mathrm{I}$ was also released to 162 the atmosphere from these reprocessing plants. Meanwhile ${ }^{129} \mathrm{I}$ discharged to the seas 163 might be also re-emitted to the atmosphere. Gaseous iodine (e.g. alkyl iodide) has a 164 relative long residence time in the atmosphere [6], the reprocessing derived ${ }^{129} \mathrm{I}$ in the 165 atmosphere can be also used to trace the atmospheric dispersion and deposition of 166 radioactive iodine and other air pollutions. 


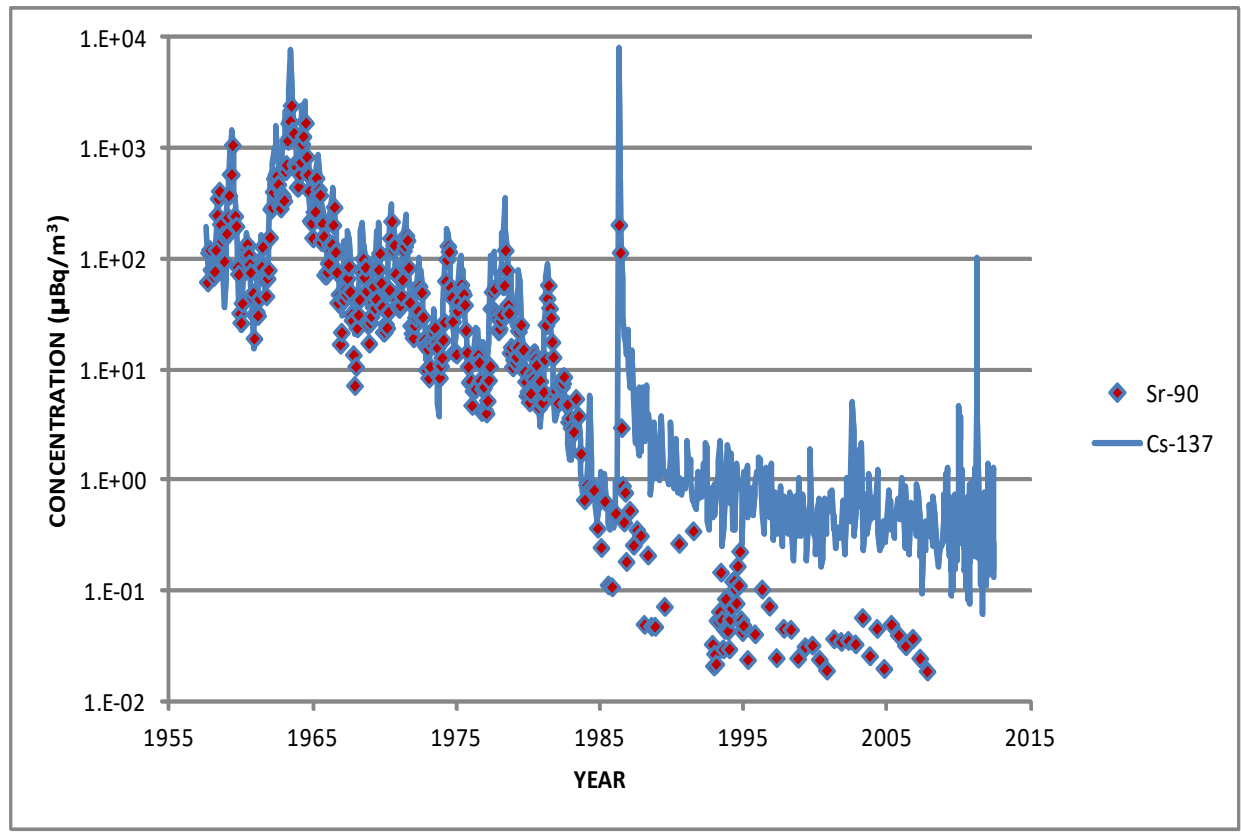

169 Fig. 2 Temporal variation of the concentration of aerosol associated ${ }^{137} \mathrm{Cs}$ and ${ }^{90} \mathrm{Sr}$ in air 170 collected at Risø, Denmark in 1957-2015
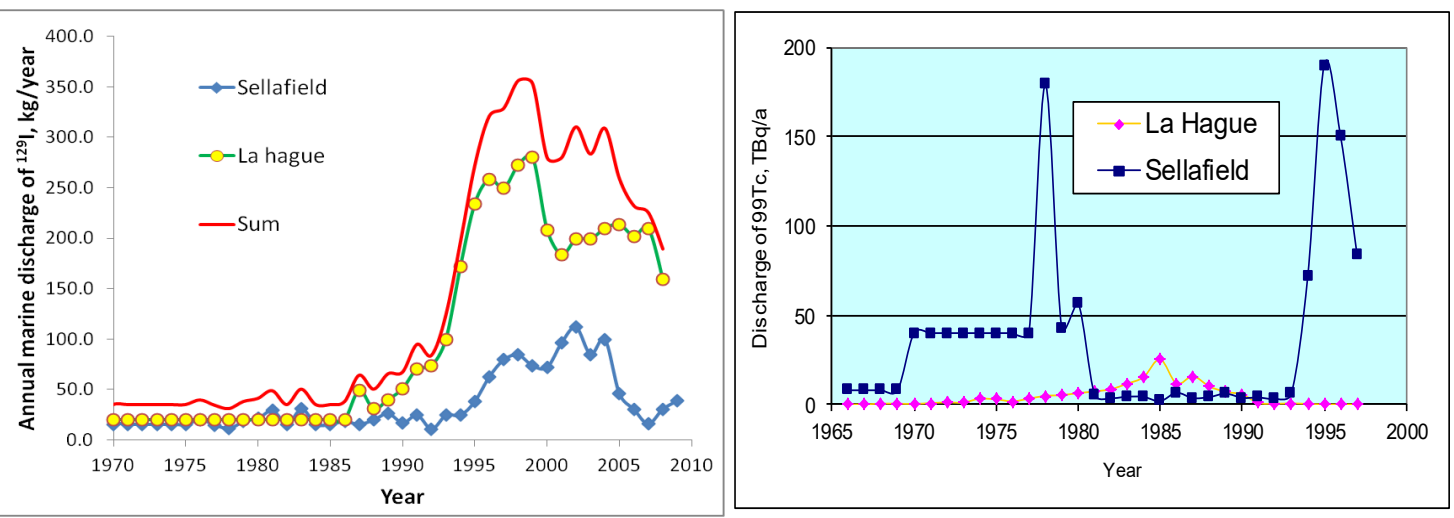

173 Fig. 3 Marine discharges of ${ }^{129} \mathrm{I}$ and ${ }^{99} \mathrm{Tc}$ from two European nuclear fuel reprocessing 174 plants at Sellafield (UK) and La Hague (France) 
177 For the environmental radioactivity and radioecology investigation and environmental 178 tracer studies using radionuclides, sensitive and reliable analytical methods are critical.

179 The major gamma emitting radionuclides (e.g. ${ }^{134} \mathrm{Cs},{ }^{137} \mathrm{Cs},{ }^{131} \mathrm{I},{ }^{210} \mathrm{~Pb},{ }^{241} \mathrm{Am}$, etc.) can be

180 directly measured using gamma spectrometry after some pre-treatment. However, many

181 long-lived radionuclides important for tracing environmental processes are pure beta or 182 alpha emitters and present in low or ultra-low concentration in the environment, they 183 have to be chemically separated from a large size of samples and all interfering isotopes 184 before measurement using radiometric or mass spectrometric methods. A series of 185 chemical separation procedures and sensitive methods for the measurement of the major 186 radionuclides in the environment were developed in our laboratory, which are briefly 187 presented in this paper. The chemical species of radionuclides is critical for their 188 behaviors in the environment and therefore important for estimation of their impact and 189 application of them for tracing environmental processes. A number of chemical 190 speciation methods have been developed in our laboratory. Here, the major methods for 191 speciation analysis of iodine isotopes in water, air, aerosol, soil and sediment samples are 192 briefly presented.

\section{Chemical separation of radionuclides from environmental samples}

194 Various methods can be used for separation of radionuclides from the samples depending 195 on the sample type and properties of the target radionuclides. Besides conventional 196 precipitation, solvent extraction, ion exchange chromatography, extraction 197 chromatography becomes a more often used method in the recent years. The solid 198 samples have to be first decomposed to release the target radionuclides to solution before 199 separation, and a pre-concentration such co-precipitation or exchange chromatography is 200 often applied for pre-concentration of target radionuclide from large size of water 201 samples. While, radionuclides in air have to be collected by selective adsorption or 202 filtration, and then treated as liquid or solid sample. A few chemical separation 203 procedures for determination of radioisotopes of cesium and strontium, ${ }^{99} \mathrm{Tc}$, isotopes of

204 plutonium neptunium and uranium developed in our laboratory are presented below. 
Separation of cesium from water samples for the determination of ${ }^{134} \mathrm{Cs},{ }^{135} \mathrm{Cs},{ }^{137} \mathrm{Cs}$.

206 Selective adsorption is the most often applied method for separation of cesium from big-

207 size water sample up to 1000 liters. Powder of ammonium molybdophosphate (AMP) and 208 potassium cupriferrocyanide $\left(\mathrm{K}_{2} \mathrm{CuFe}(\mathrm{CN})_{6}, \mathrm{KCuFC}\right)$ are the most often applied 209 adsorbents for this purpose [7, 8]. AMP was used to separate cesium from water 210 (seawater or fresh water) in acidic medium, the sample is often acidified to $\mathrm{pH} 2$ on-site 211 during sample collection using $\mathrm{HCl}$. AMP powder is directly added to the sample 212 solution (stable cesium or ${ }^{134} \mathrm{Cs}$ is added as chemical yield tracer) and mixed by stirring 213 for 1-2 hours. After settling for a few hours (or overnight), the AMP powder is separated 214 by discarding the supernatant, and collecting the sludge AMP on a filter paper. ${ }^{134} \mathrm{Cs}$ and $215{ }^{137} \mathrm{Cs}$ adsorbed on the AMP powder are then measured using an HPGe gamma detector. 216 The chemical yield is measured by determining stable cesium in the sample solution 217 before and after separation, or ${ }^{134} \mathrm{Cs}$ in the separated sample by gamma spectrometry and 218 compared with the spiked amount (if no ${ }^{134} \mathrm{Cs}$ is present in the samples). A high recovery 219 of more than $95 \%$ can be often obtained. ${ }^{135} \mathrm{Cs}$ as a long-lived $\left(2.3 \times 10^{6}\right.$ years $)$ pure beta 220 emitter is also adsorbed on the AMP, for its determination, a further separation from 221 interferences such as ${ }^{135} \mathrm{Ba}$ for ICP-MS measurement has to be implemented. For some 222 water samples, a pre-filtration through a filter is necessary for removal of any suspending 223 substance/colloids in the water sample, to obtain water soluble radiocesium concentration 224 and a better chemical yield.

225 For more than 100 liters water samples, the AMP method is not suitable for operation, 226 especially on board of a scientific vessel. In this case, a cartridge impregnated with 227 potassium cupriferrocyanide $\left(\mathrm{K}_{2} \mathrm{CuFe}(\mathrm{CN})_{6}\right)$ or other transition metal ferrocyanides (such 228 as $\mathrm{Cu}_{2} \mathrm{Fe}(\mathrm{CN})_{6}, \mathrm{KTiFe}(\mathrm{CN})_{6}$, etc.) can be used [9]. This type of material also has a very 229 high selectivity and capacity for adsorption of cesium $\left(\mathrm{Kd}\right.$ of $\left.10^{5}\right)$ in neutral or slight 230 acidic media. For preparation of potassium cupriferrocyanide cartridge, a polypropylene 231 cartridge is first impregnated to cupric sulfate solution, then to a solution of potassium 232 hexacyanoferrate (II), $\left.\mathrm{K}_{2} \mathrm{CuFe}(\mathrm{CN})_{6}\right)$ precipitate is formed on the cartridge, which can be 233 mounted to the cartridge holder (Fig. 4) after dried. Seawater sample can be directly 234 pumped through two sequentially connected cartridges after past through a pre-filtration 
235 cartridge for removal of suspended substance. The chemical recovery can be monitored 236 using stable cesium or ${ }^{134} \mathrm{Cs}$ spiked to the sample before separation, a recovery of more 237 than $80 \%$ is often obtained for two sequential cartridges. Radiocesium on the cartridge 238 can be measured using gamma spectrometry after dried and ashed at low temperature $(<$ $\left.239450{ }^{\circ} \mathrm{C}\right)$.

$240 \mathrm{AMP}$ and $\mathrm{KCuFC}$ were also prepared as resin material and commercialized by Triskem 241 International Company for chromatographic separation of cesium (AMP-PAN and 242 KNiFC-PAN). With these resins, a further separation of radiocesium from other 243 radionuclides of similar properties (e.g. $\mathrm{Rb}, \mathrm{Ba}$ ) can be implemented for improving the 244 detection limit of radiocesium. Fig. 4 shows an analytical procedure for determination of 245 radiocesium in water samples in our laboratory. Separation of strontium for determination of radiostrontium $\left({ }^{89} \mathrm{Sr}\right.$ and $\left.{ }^{90} \mathrm{Sr}\right)$. 248 Radiostrontium is one of the most important radionuclides in the environment, because of 249 the high fission yield of ${ }^{235} \mathrm{U}$ and ${ }^{239} \mathrm{Pu}$ and consequently high releases from human 250 nuclear activities. Both ${ }^{89} \mathrm{Sr}$ and ${ }^{90} \mathrm{Sr}$ are pure beta emitters, a complete separation of 251 strontium from sample matrix and all other radionuclides are needed for its measurement. 252 The traditional separation techniques for strontium from environmental samples and 253 interfering radionuclides mainly rely on the specific feature of strontium including low 254 solubility $\mathrm{Sr}\left(\mathrm{NO}_{3}\right)$ in high concentration of $\mathrm{HNO}_{3}$ solution $(>70 \%)$, and low solubility of $255 \mathrm{SrCrO}_{4}$ compared to chromate of $\mathrm{Ba}$ and $\mathrm{Ra}$, and precipitation of strontium rhodizonate 256 precipitation. Although these methods were successfully applied for determination of 257 radiostrontium in environmental samples for many decades, it is very tedious and time 258 consuming, and application of fuming nitric acid and chromate is also harmful and 259 expensive. 


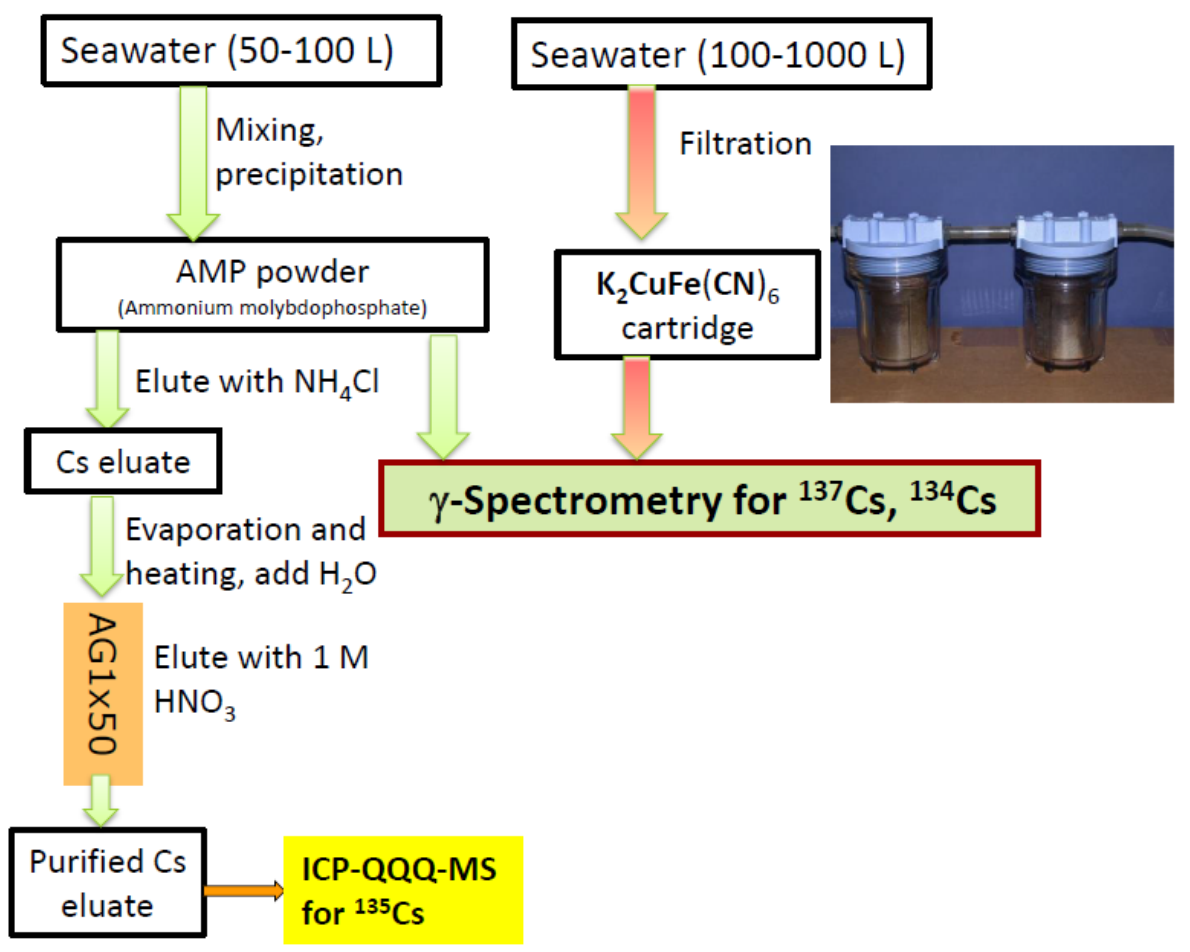

262 Fig. 4 Analytical procedure for determination of radiocesium $\left({ }^{134} \mathrm{Cs},{ }^{135} \mathrm{Cs},{ }^{137} \mathrm{Cs}\right)$ in 263 water samples

265 A number of methods have been developed to simplify the separation procedure and to 266 improve the detection limit. In our laboratory, an analytical procedure without application 267 of harmful fuming nitric acid and chromate was developed for analysis of large-size 268 water samples (seawater and fresh water) for determination of ${ }^{89} \mathrm{Sr}$ and ${ }^{90} \mathrm{Sr}$. Strontium 269 was first separated from large volume of water (up to 100 liter) by precipitation of 270 strontium as $\mathrm{SrCO}_{3}$ after addition of stable strontium as carrier, and then carbonate (e.g. $\left.271\left(\mathrm{NH}_{4}\right)_{2} \mathrm{CO}_{3}\right)$. Calcium in the sample in a high concentration was also precipitated as $272 \mathrm{CaCO}_{3}$ in this step. A precipitation of hydroxide step was therefore followed to remove 273 calcium based on lower solubility of $\mathrm{Ca}(\mathrm{OH})_{2}$ in a relative high concentration of $\mathrm{NaOH}$ 274 solution (0.2-0.5 mol/l) compared to $\mathrm{Sr}(\mathrm{OH})_{2} .{ }^{85} \mathrm{Sr}$ (a gamma emitter) can be used as 275 chemical yield tracer in this step. For removal of the interferences of radioisotopes of Ra, 276 the separated strontium solution was settled for 2-3 weeks for the ingrowth of its decay 277 daughter ${ }^{90} \mathrm{Y}$ after addition of stable yttrium. Sulfuric acid was then added to the sample 
278 solution, and the formed sulphate precipitate of $\mathrm{SrSO}_{4}, \mathrm{RaSO}_{4}$ and $\mathrm{BaSO}_{4}$ were removed 279 by filtration, and ${ }^{90} \mathrm{Y}$ remaining in the solution was then separated by precipitation of $280 \mathrm{Y}_{2}\left(\mathrm{C}_{2} \mathrm{O}_{4}\right)_{3}$ by addition of $\mathrm{H}_{2} \mathrm{C}_{2} \mathrm{O}_{4}$ under a slightly acidic condition. The chemical yield of 281 yttrium can be measured using yttrium spiked to the samples solution by gravimetry or 282 ICP-OES. ${ }^{90} \mathrm{Y}$ in the precipitation was measured using an ultra-low background GM 283 counter (Risø multi-counter), and ${ }^{90} \mathrm{Sr}$ concentration can be calculated according to the 284 ingrowth time and chemical yields. The overall chemical yield (including $\mathrm{Sr}$ and $\mathrm{Y}$ ) is 285 normally higher than 85\% [10]. Fig. 5 shows the analytical procedure of this method for 286 determination of ${ }^{90} \mathrm{Sr}$ in large volume of water samples. It should be mentioned that for 287 the analysis of fresh water samples, some amount of calcium needs to be added to 288 improve the chemical recovery of strontium in the first step. This procedure has been successfully applied in our laboratory for routine analysis of environmental samples for more than 15 years, and demonstrated to be robust and accurate method for determination of ultra-low level ${ }^{90} \mathrm{Sr}$ in large-size samples with high strontium content.

292 The method presented above is still time consuming and applicable only for ${ }^{90} \mathrm{Sr}$, 293 especially because of long waiting time for ingrowth of ${ }^{90} \mathrm{Y}$. Another method was also 294 developed for rapid determination of both ${ }^{89} \mathrm{Sr}$ and ${ }^{90} \mathrm{Sr}$ by using extraction 295 chromatographic separation. In this method, strontium in the sample leachate (from solid 296 samples, such as soil, sediment, and ash of vegetable and tissues) or small size of water 297 samples (<2 liters) was first separated from sample matrix by precipitation of $\mathrm{SrC}_{2} \mathrm{O}_{4}$ at $298 \mathrm{pH} 2$ after addition of small amount of stable strontium carrier. A $\mathrm{Sr}\left(\mathrm{NO}_{3}\right)_{2}$ precipitation 299 is followed to separate strontium from most of interfering radionuclides (e.g. radium and 300 barium isotopes) by addition of small amount of fumming nitric acidic $(<10 \mathrm{ml})$. The 301 separated $\mathrm{Sr}\left(\mathrm{NO}_{3}\right)_{2}$ was dissolved in water and prepared in $8 \mathrm{~mol} / 1 \mathrm{HNO}_{3}$ solution, which 302 was then loaded to a Sr-resin column (2-4 ml depending on the sample size and estimated 303 Sr content). After rinsing with $8 \mathrm{~mol} / 1 \mathrm{HNO}_{3}$, strontium on the column was eluted using $3040.01 \mathrm{~mol} / \mathrm{HNO}_{3}$, which was directly used for measurement of ${ }^{89} \mathrm{Sr}$ and ${ }^{90} \mathrm{Y}$ using liquid 305 scintillation counter by counting Cherenkov radiation of ${ }^{89} \mathrm{Sr}$ immediately after 306 separation, and then re-counting after 1-3 weeks for the Cherenkov radiation of ${ }^{90} \mathrm{Y}+{ }^{89} \mathrm{Sr}$, 307 to obtain both ${ }^{89} \mathrm{Sr}$ and ${ }^{90} \mathrm{Sr}$ concentrations. ${ }^{90} \mathrm{Sr}$ can be also measured by LSC with 308 addition of scintillation cocktail after the Cherenkov counting for ${ }^{89} \mathrm{Sr}$. In this case, no 
309 waiting time for ingrowth of ${ }^{90} \mathrm{Y}$ is needed and the results can be obtained in a short time

310 ( $<1$ day, including the chemical separation and measurement). The chemical yield of

311 strontium in all procedure was measured by determination of stable strontium before and

312 after separation using ICP-OES.

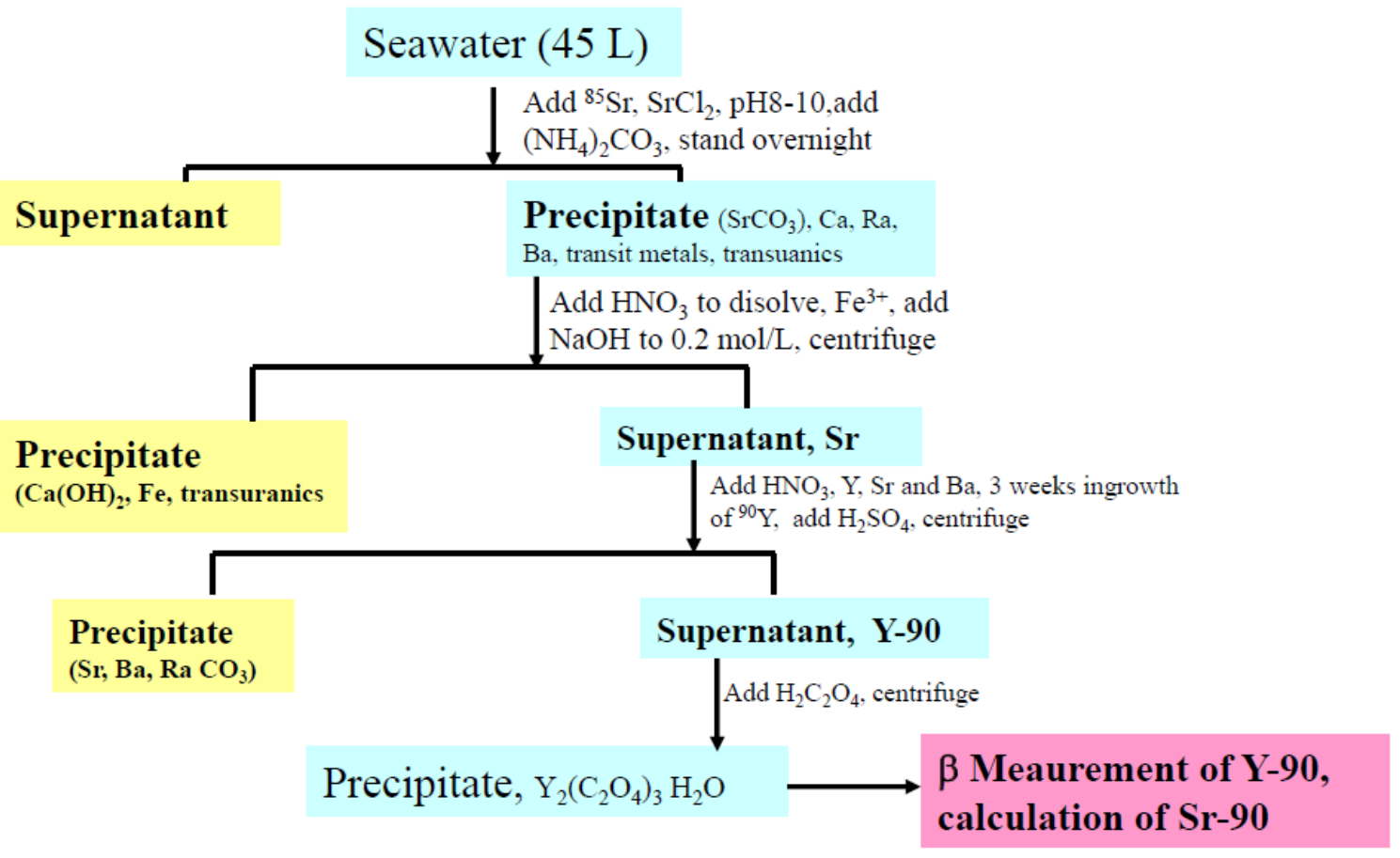

315 Fig. 5 Analytical procedure of ${ }^{90} \mathrm{Sr}$ in large volume of water samples

317 Fig. 6 shows the analytical procedure of this method. This method is relatively simple

318 and rapid, but not suitable for the analysis of large-size of samples (e.g. seawater). The

319 main reason is the relative low capacity of Sr-resin. For a $2 \mathrm{ml}$ column, normally $2 \mathrm{mg}$ of

320 stable strontium can be separated, high amount of stable strontium in the sample requires

321 a large column and large amount of resin, which will increase the expenses of the 322 analysis and prolong the analytical time. 


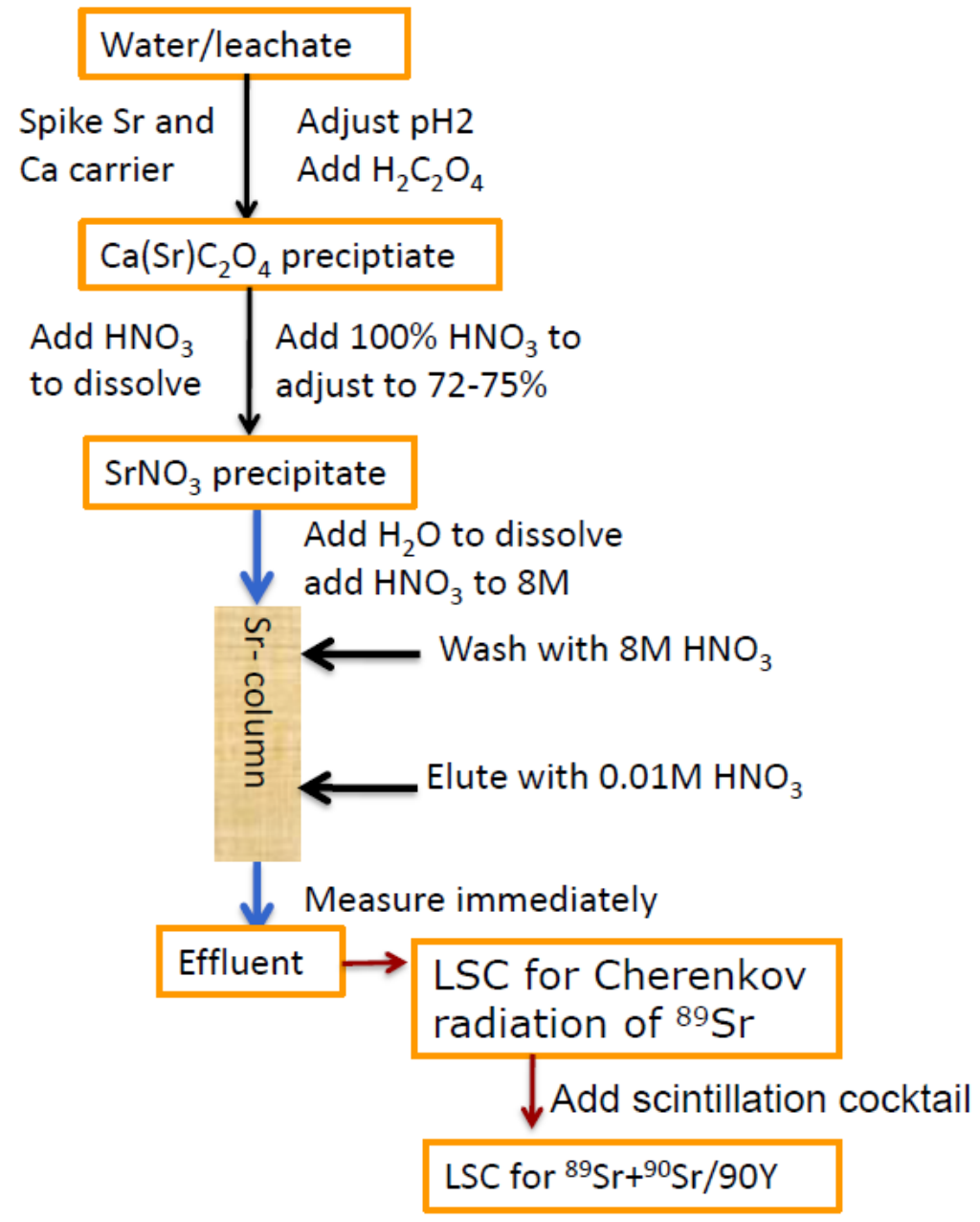

324 Fig. 6 Analytical procedure for determination of ${ }^{89} \mathrm{Sr}$ and ${ }^{90} \mathrm{Sr}$.

326 Separation of technetium for determination of ${ }^{99} \mathrm{Tc}$. Technetium is a radioactive element 327 without any stable isotope. ${ }^{99} \mathrm{Tc}$ is a long-lived $\left(2.1 \times 10^{5}\right.$ years $)$ radionuclide and the 328 major isotope of technetium occurred in the environment. Due to its high fission yield $329\left(6.1 \%\right.$ for $\left.{ }^{235} \mathrm{U}\right)$ and high mobility in the environment, it is one of the most important 330 radionuclides in the environmental radioactivity investigation and waste repository [11]. 331 Technetium is volatile at relative high temperature, its stability in the separation 332 procedure is critical for its determination. We have investigated the stability of 333 technetium in different sample matrices during ashing and heating [12]. It was found that 334 technetium is not stable in $\mathrm{HCl}$ medium during evaporation, while it is relative stable in 
$335 \mathrm{HNO}_{3}$ medium. Almost all technetium was lost when a technetium solution in $6 \mathrm{~mol} / \mathrm{l}$ $336 \mathrm{HCl}$ medium was evaporated to dryness even at $100^{\circ} \mathrm{C}$. While more than $95 \%$ technetium 337 was remained when technetium in a neutral, alkaline solution or $\mathrm{HNO}_{3}$ solution up to 8 $338 \mathrm{~mol} / \mathrm{l}$ was evaporated to dryness. Technetium is quite stable in brown seaweed (e.g. 339 fucus) during ashing even at $700{ }^{\circ} \mathrm{C}$ for 14 hours. While significant amount of technetium 340 was lost when it is present in soil and ashed at temperature more than $550{ }^{\circ} \mathrm{C}$. It was 341 observed that more than $60 \%$ of technetium in soil was lost when ashing at $700^{\circ} \mathrm{C}$ for 6 342 hours. It is therefore recommended that the soil sample should be ashed at less than 550 $343{ }^{\circ} \mathrm{C}$ for overnight (12-15 hours) to decompose organic substances before chemical 344 separation. Technetium mainly exists in $\mathrm{Tc}^{4+}$ and $\mathrm{TcO}_{4}^{-}$forms, $\mathrm{Tc}^{4+}$ is not stable in 345 solution and easily formed $\mathrm{TcO}_{2}$ to be associated with particles, while $\mathrm{TcO}_{4}^{-}$is quite 346 stable in both acidic and alkaline solutions, which is also the most often occurred species 347 of technetium in oxidative media.

348 Two methods have been used in our laboratory for separation and preconcentration of 349 technetium from large volume of water and leachate of solid samples, anion exchange 350 chromatography and co-precipitation of $\mathrm{TcO}_{2}$ with $\mathrm{Fe}(\mathrm{OH})_{2}$ in reductive condition. The 351 affinity of $\mathrm{TcO}_{4}^{-}$to strong basic anion exchange resin (e.g. Dowex 1 or Bio-Rad AG1, 352 and Eichrom TEVA) is very high compared to other anions in water. Seawater was 353 directly loaded to an anion exchange column (the size of the column is depended on the 354 volume of seawater, for 200 liters of seawater, a column of $50 \mathrm{~cm}$ length and $2.5 \mathrm{~cm}$ in 355 diameter was used), technetium was firmly adsorbed on the column. After rinsing with 356 water, $1.0 \mathrm{~mol} / 1$ of $\mathrm{NaOH}$ and $1.0 \mathrm{~mol} / 1$ of $\mathrm{HNO}_{3}, \mathrm{TcO}_{4}{ }^{-}$adsorbed on the column was 357 finally eluted with $10-14 \mathrm{~mol} / 1 \mathrm{HNO}_{3}$. Further purification for removal of $\mathrm{Ru}$ (for ${ }^{103} \mathrm{Ru}$,

$358{ }^{106} \mathrm{Ru}$ for radiometric measurement and ${ }^{99} \mathrm{Ru}$ for ICP-MS) was implemented by heating 359 technetium solution after addition 1-2 $\mathrm{ml}$ of concentrated $\mathrm{H}_{2} \mathrm{SO}_{4}$ and small amount of $360 \mathrm{NaClO}$ and $\mathrm{K}_{2} \mathrm{~S}_{2} \mathrm{O}_{8}$. The separated technetium was electrodeposited on a stainless steel 361 disc from a $2 \mathrm{~mol} / 1 \mathrm{NaOH}$ solution. ${ }^{99} \mathrm{Tc}$ was then measured using a low background GM 362 counter (Risø Multi-counter). The separated ${ }^{99} \mathrm{Tc}$ can be also measured by ICP-MS in a 363 small volume of diluted $\mathrm{HNO}_{3}$ solution (e.g. $2-5 \mathrm{ml}$ of $0.5 \mathrm{~mol} / 1 \mathrm{HNO}_{3}$ ) $[13,14]$. 
364 A separation procedure based on the co-precipitation of $\mathrm{TcO}_{2}$ with $\mathrm{Fe}(\mathrm{OH})_{2}$ in reductive 365 condition, combined with extraction chromatographic separation using TEVA column 366 has been developed for determination of ultra-low level ${ }^{99} \mathrm{Tc}$ in seawater [15]. Seawater 367 samples up to 200 liters were first acidified with $\mathrm{HCl}$ to $\mathrm{pH} 2$, and $\mathrm{FeCl}_{3}$ and ${ }^{99 \mathrm{~m}} \mathrm{Tc}$ tracer 368 were added. $\mathrm{K}_{2} \mathrm{~S}_{2} \mathrm{O}_{5}$ was then added to reduce $\mathrm{Tc}$ to $\mathrm{Tc}^{4+}$ and $\mathrm{Fe}^{3+}$ to $\mathrm{Fe}^{2+}$. $\mathrm{NaOH}$ was 369 added to adjust $\mathrm{pH} 9-10$, and the formed $\mathrm{TcO}_{2}-\mathrm{Fe}(\mathrm{OH})_{2}$ coprecipitate was then separated 370 by settling down for overnight followed by discarding the supernatant and filtrate the 371 precipitate. The precipitate was then dissolved with $\mathrm{HCl}$ and treated with $\mathrm{H}_{2} \mathrm{O}_{2}$ to convert 372 technetium to $\mathrm{TcO}_{4}{ }^{-}$. After removal iron by $\mathrm{Fe}(\mathrm{OH})_{3}$ precipitation with addition of $\mathrm{NaOH}$ 373 to $\mathrm{pH} 8-9$, the $\mathrm{TcO}_{4}{ }^{-}$in the supernatant was further purified using 2 sequentially connected 374 TEVA columns. The purpose of two TEVA columns was to improve the decontamination 375 factors to $\mathrm{Ru}$ and Mo, which cause high interferences for the ICP-MS measurement 376 through ${ }^{99} \mathrm{Ru}^{+}$isobar and ${ }^{98} \mathrm{Mo}^{1} \mathrm{H}^{+}$polyatomic ion. Fig. 7 shows the analytical procedure 377 for determination of ultra-low level ${ }^{99} \mathrm{Tc}$ in large volume of seawater samples.

378 For solid samples, such as soil, sediment and seaweed, they were first ashed at $550{ }^{\circ} \mathrm{C}$ or $379700{ }^{\circ} \mathrm{C}$ (for brown seaweed) to decompose all organic substance. Technetium was then 380 leached from the ashed samples using $\mathrm{HCl}$ and $\mathrm{H}_{2} \mathrm{O}_{2}$. Technetium in the leachate was 381 then separated by $\mathrm{TcO}_{2}-\mathrm{Fe}(\mathrm{OH})_{2}$ co-precipitation after addition of $\mathrm{K}_{2} \mathrm{~S}_{2} \mathrm{O}_{5}$ to reduce 382 technetium to $\mathrm{Tc}^{4+}$ and adjusted to $\mathrm{pH} 8-9$ to form $\mathrm{TcO}_{2}-\mathrm{Fe}(\mathrm{OH})_{2}$ precipitate. ${ }^{99} \mathrm{Tc}$ was 383 then further purified using chromatography with TEVA resin and measured using ICP384 MS. The short-lived ${ }^{99 \mathrm{~m}} \mathrm{Tc}$ obtained from ${ }^{99} \mathrm{Mo} /{ }^{99 \mathrm{~m}} \mathrm{Tc}$ generator was used as chemical 385 yield tracer. Since minor amount of ${ }^{99} \mathrm{Mo}$ and ${ }^{99} \mathrm{Tc}$ is might present in the ${ }^{99 \mathrm{~m}} \mathrm{Tc}$ eluate 386 from the ${ }^{99} \mathrm{Mo} /{ }^{99 \mathrm{~m}} \mathrm{Tc}$ generator, the generator needs to be pre-eluted 2-5 times to remove 387 accumulated ${ }^{99} \mathrm{Tc}$ from the generator, and the freshly eluted ${ }^{99 \mathrm{~m}} \mathrm{Tc}$ was further purified by 388 using a $\mathrm{Al}_{2} \mathrm{O}_{3}$ cartridge filter [16]. ${ }^{99 \mathrm{~m}} \mathrm{Tc}$ in the final solution was measured using gamma 389 spectrometry and chemical yield is calculated by comparing it to the amount of ${ }^{99 \mathrm{~m}} \mathrm{Tc}$ 390 spiked to the sample before separation. 


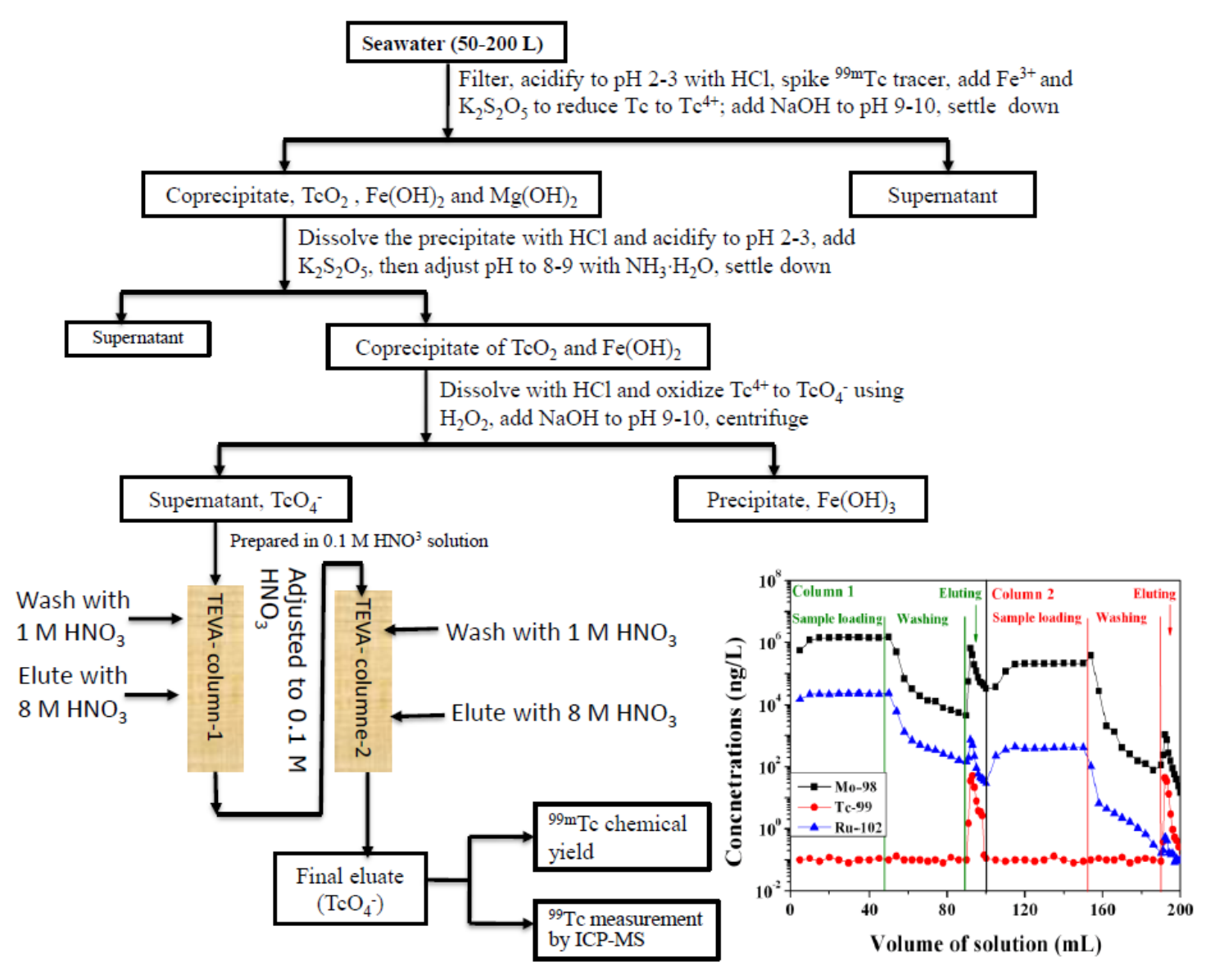

392 Fig. 7 Analytical procedure for determination of ${ }^{99} \mathrm{Tc}$ in large volume of seawater

394 Separation of plutonium and neptunium for the determination of their isotopes. The 395 concentrations of plutonium and neptunium isotopes are normally very low in 396 environmental samples, separation of plutonium and neptunium from big-size sample is 397 necessary to obtain reliable analytical results. Pre-concentration of plutonium and 398 neptunium from large volume of water (up to 200 liters) is often implemented by co399 precipitation with $\mathrm{Fe}(\mathrm{OH})_{2}, \mathrm{MnO}_{2}$, or lanthanide fluoride. After removal of the suspended 400 particles and acidification of the water to $\mathrm{pH} 2$ using $\mathrm{HCl}$, carrier (e.g. $\mathrm{Fe}^{2+}$ ) and chemical 401 yield tracer (e.g. ${ }^{242} \mathrm{Pu}$ ) were added, followed by addition of reductant (e.g. $\mathrm{K}_{2} \mathrm{~S}_{2} \mathrm{O}_{5}$ ) and 402 stirring to reduce species of plutonium and neptunium to $\mathrm{Pu}^{3+}$ and $\mathrm{Np}^{4+}$ to ensure a better 403 recovery. Ammonia was then added to adjust pH8-9 for co-precipitate $\mathrm{Pu}(\mathrm{OH})_{3}$ and $404 \mathrm{~Np}(\mathrm{OH})_{4}$ with $\mathrm{Fe}(\mathrm{OH})_{2}$, which were separated by settling down for overnight, discarding 
405 the supernatant and centrifuge. The precipitate was dissolved with $\mathrm{HCl}$, and co406 precipitation was repeated by addition of ammonia to $\mathrm{pH} 8-9$ to remove excess of $\mathrm{Ca}$ and $407 \mathrm{Mg}$. The precipitate was dissolved again using $\mathrm{HCl}$, and then concentrated $\mathrm{HNO}_{3}$ or $408 \mathrm{NaNO}_{2}$ was added to convert plutonium to $\mathrm{Pu}^{4+}$ and remain neptunium as $\mathrm{Np}^{4+}$ for further 409 separation and purification of $\mathrm{Pu}$ and $\mathrm{Np}[14,17,18]$.

410 For solid samples, such as soil, sediment, aerosol, food, bones, the samples were first 411 ashed to decompose the organic substances and convert organic associated plutonium and 412 neptunium to inorganic species. Ashing at low temperature (e.g. $450{ }^{\circ} \mathrm{C}$ ) was 413 recommended to avoid a low recovery of $\mathrm{Pu}$ and $\mathrm{Np}$ due to the formation of their 414 refractory species at high temperature [19]. Acid leaching (e.g. aquia regia) is an often 415 used method to release $\mathrm{Pu}$ and $\mathrm{Np}$ from the ashed sample to solution, but it might be not 416 suitable for the samples containing refractory species of $\mathrm{Pu}$ and $\mathrm{Np}$ such as the samples 417 collected from highly contaminated sites of nuclear weapons tests and nuclear accident 418 with hot particles. In this case, a full decomposition by acid dissolution in the presence of 419 HF or fusion are needed. Lithium metaborate fusion was demonstrated a suitable method 420 for decomposition of large size of samples (up to $20 \mathrm{~g}$ ), the formed cake can be easily 421 dissolved using aquia regia $[20,21]$. Separation of $\mathrm{Pu}$ and $\mathrm{Np}$ in the sample solution is 422 often implemented by coprecipitation of hydroxides or fluorides.

423 The chemical yield of plutonium is often monitored by spiking ${ }^{242} \mathrm{Pu}$ tracer before 424 separation, which can be measured in the separated samples by either alpha epectrometry 425 or mass spectrometry. However there is no suitable yield tracer for neptunium. A short426 live isotopes of neptunium, ${ }^{239} \mathrm{~Np}$ (2.35 days, beta emitter with gamma emission) has 427 been used for yield monitoring by gamma spectrometry measurement. However, its short 428 half- life makes its application not convenient. Because of similar chemical property of $429 \mathrm{~Np}$ and $\mathrm{Pu}$, yield tracer of plutonium was suggested also for neptunium [22, 23] and 430 simultaneous separation of both plutonium and neptunium for determination of their 431 isotopes [24, 25].

432 Solvent extraction, ion exchange and extraction chromatography are the major techniques 433 for the separation of plutonium and neptunium from interferences, among them ion 
434 exchange and extraction chromatography are becoming the most popular technique for

435 their separation in the recent years, which is mainly based on the formation of anion 436 complexes of $\mathrm{Pu}$ and $\mathrm{Np}$ with $\mathrm{NO}_{3}{ }^{-}$and $\mathrm{Cl}^{-}$and further formation of complexes with the 437 organic function group on the extraction chromatographic resin (e.g. TRU, DGA). The 438 pre-concentrated $\mathrm{Pu}$ and $\mathrm{Np}$ in $\mathrm{HCl}$ solution were first converted to $\mathrm{Pu}^{4+}$ and $\mathrm{Np}^{4+}$ using $439 \mathrm{NaNO}_{2}$ or concentrated $\mathrm{HNO}_{3}$, and prepared in $8 \mathrm{~mol} / 1 \mathrm{HNO}_{3}$ for separation using anion 440 exchange chromatography or in $3 \mathrm{~mol} / 1 \mathrm{HNO}_{3}$ using TEVA resin for extraction 441 chromatographic separation. The column was rinsed using $\mathrm{HNO}_{3}$ and $\mathrm{HCl}$ solution to 442 remove matrix elements and interferences such as uranium. $\mathrm{Pu}$ and $\mathrm{Np}$ on the column 443 were finally eluted using diluted $\mathrm{HCl}$ or diluted $\mathrm{HCl}-\mathrm{NH}_{2} \mathrm{OH} \cdot \mathrm{HCl}$ solution. AGMP-1 444 (Bio-Rad company) was confirmed to be the best anion exchange resin for simultaneous 445 separation of plutonium and neptunium because of their same behaviors in 446 chromatographic separation [24]. TEVA resin was also confirmed to be suitable for the 447 separation of both plutonium and neptunium [25]. Fig. 8 shows an analytical procedure 448 used in our laboratory for determination of plutonium isotopes and ${ }^{237} \mathrm{~Np}$ in the 449 environmental samples. For the measurement of ${ }^{239} \mathrm{Pu}$ and ${ }^{237} \mathrm{~Np}$ using ICP-MS, the 450 major interference is ${ }^{238} \mathrm{U}$ through tailing to $\mathrm{m} / \mathrm{z}=237$ and 239 , and forming ${ }^{238} \mathrm{U}^{1} \mathrm{H}^{+}$ 451 polyatomic ions. The decontamination factor of uranium is a critical feature of the 452 separation procedure, it was noticed that TEVA resin showed a better decontamination 453 factor compared to anion exchange resin. This might be attributed to the relative high 454 uranium content in the anion exchange resin than that in TEVA resin and a larger size 455 anion exchange resin was used compared to TEVA resin (5-10 times larger). A 456 decontamination factor up to $10^{7}$ was reported by using a sequential extraction 457 chromatographic separation using TEVA-UTEVA and DGA resins in the analysis of soil 458 and sediment samples for plutonium isotopes [26]. 


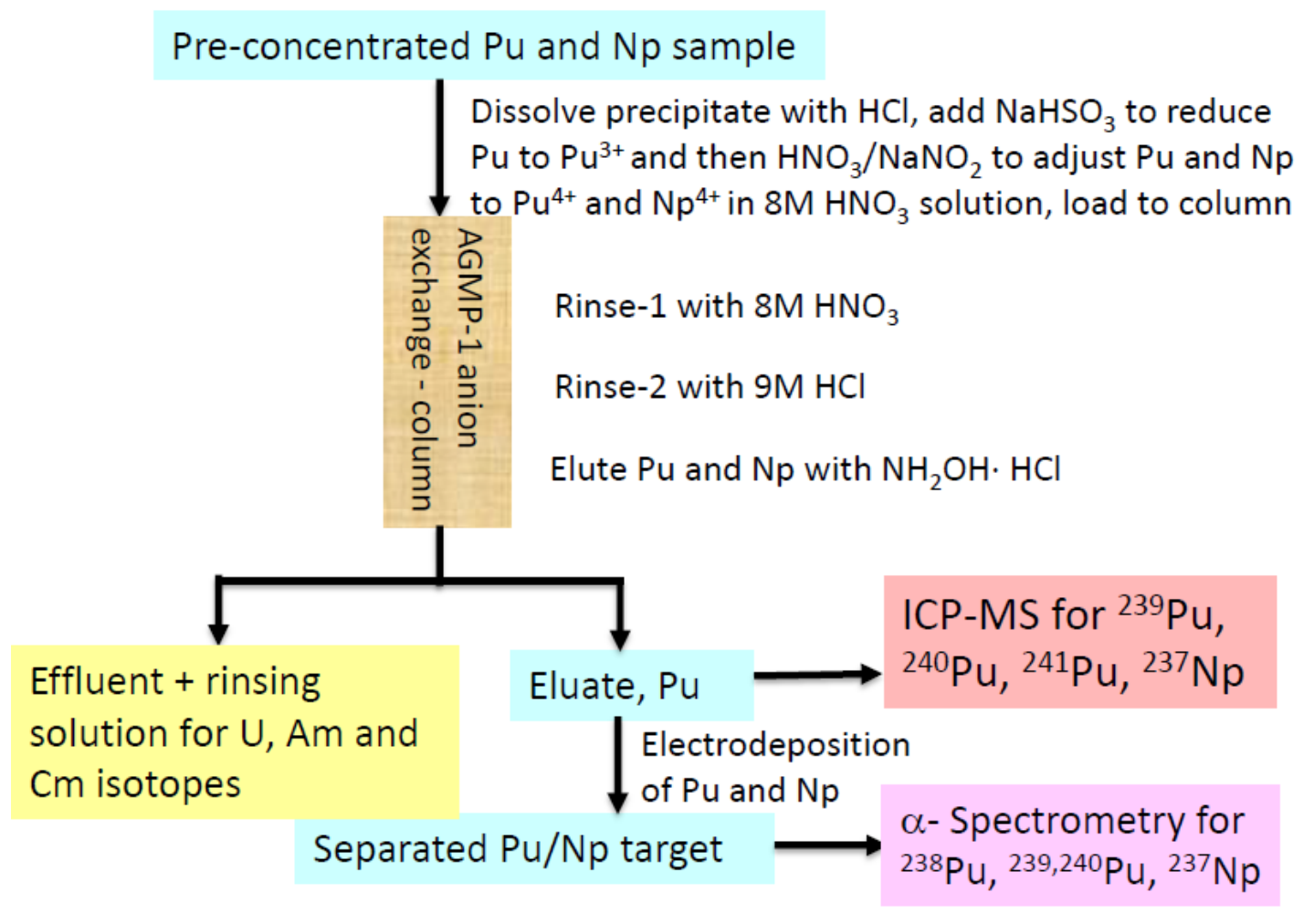

460 Fig. 8 Analytical procedure for determination of isotopes of plutonium and ${ }^{237} \mathrm{~Np}$ in 461 environmental samples.

\section{Determination of iodine-129 and its chemical species in environmental samples}

463 Iodine is a volatile and redox sensitive element, anthropogenic ${ }^{129} \mathrm{I}$ is a very useful 464 oceanographic and environmental process tracer, determination of the concentration and 465 chemical species of ${ }^{129} \mathrm{I}$ and stable iodine are needed for this purpose [6]. In the past 466 years, we have developed a series of methods for determination ultra-trace amount of ${ }^{129} \mathrm{I}$ 467 in various environmental samples, meanwhile some methods for speciation analysis of $468{ }^{129} \mathrm{I}$ in water, air, aerosol, sediment and soil were also developed.

469 Because of the long half-life $\left(1.57 \times 10^{7}\right.$ years $)$, beta decay, low intensive and energy of 470 gamma ray and the ultra-low concentration of ${ }^{129} \mathrm{I}$ in environmental samples $\left(<10^{-12} \mathrm{~g} / \mathrm{g}\right)$, 471 separation of iodine from large sample is needed before its measurement, even using high 472 sensitive accelerator mass spectrometry (AMS). Based on the volatile feature of iodine, 473 an oxidative combustion method has been developed for separation of iodine from 
474 various solid samples such as soil, sediment, vegetation and aerosol [27, 28]. By 475 employing a modified 4-tubes Pyrolyse system (RADDEC International), four samples 476 can be treated in the same time. In this method, ${ }^{125} \mathrm{I}$ chemical yield tracer was first mixed 477 with sample in a quartz boat, up to 20 sample (soil/sediment) can be analyzed. The 478 sample boat was inserted to a quartz tube in a three zones furnace, the temperature and 479 heating sequence were programmed and precisely controlled. When the temperature of 480 the furnace was increased up to $800^{\circ} \mathrm{C}$, all iodine was released as gaseous iodine, and 481 trapped in a bubbler filled with diluted $\mathrm{NaOH}$ solution. The chemical yield in this process 482 was more than $95 \%$ depending on sample type. The most critical step is the 483 burning/carbonization in the analysis of samples of large amount of organic matter, such 484 as vegetation, wood, aerosol/filter and high organic sediment. The rapidly increased 485 temperature might cause quick burning of large amount of organic substance and create 486 large amount of $\mathrm{CO}_{2}$ and other gasses in a short time. As a consequence, un-decomposed 487 materials (carbon particles) will be transported to the bubbler by the flowing gasses $\left(\mathrm{N}_{2}+\right.$ $488 \mathrm{O}_{2}$ ), even a splashing of the trap solution in the bubbler and small explosion of the quartz 489 tube may occur. Slowly increased temperature in the carbonization step of the sample 490 combustion was found to be an effective approach for solving this problem. A $2{ }^{\circ} \mathrm{C} / \mathrm{min}$ 491 temperature increasing rate in $250-400^{\circ} \mathrm{C}$ for soil/sediment samples, and $1{ }^{\circ} \mathrm{C} / \mathrm{min}$ rate in $492230-300^{\circ} \mathrm{C}$ for vegetation/wood samples were confirmed to be suitable [27, 28].

493 Alkaline fusion was also used for the separation of iodine from solid sample. This is 494 based on the relative high stability of iodine in alkaline media [29]. Besides soil, 495 sediment and vegetation sample, tissue and aerosol samples were also treated by this 496 method [30]. In this method, sample was mixed with $\mathrm{NaOH}$ and ashed at $600-650^{\circ} \mathrm{C}$, 497 iodine in the fused sample was leached with water for further separation, the recovery of 498 iodine in this method was normally $70-85 \%$ depending on the sample type. Due to the un499 completed ash/decomposition of vegetation/aerosol including filter, iodine could not be 500 completely leached out from the treated samples, caused a non-quantitative recovery of 501 iodine. For soil and sediment samples, the fused silicate was soluble in water, but became 502 silica gel when the solution was acidified, some iodine might be wrapped in the gel, 
503 caused a low recovery. Therefore, the oxidative combustion was confirmed to be a more

504 effective method for releasing iodine from solid sample matrix.

505 Solvent extraction using $\mathrm{CCl}_{4}$ or $\mathrm{CHCl}_{3}$ is the most often used method for separation of 506 iodine from water samples (including the trap solution and water leachate of the fused 507 sample). The most critical step in this procedure is to adjust all iodine species to $\mathrm{I}_{2}$ to be 508 extracted to organic phase. For inorganic iodine, iodate can be reduced to $\mathrm{I}_{2}$ by $\mathrm{NH}_{2} \mathrm{OH}$ $509 \mathrm{HCl}$ in acidic media, and iodide can be oxidized to $\mathrm{I}_{2}$ using $\mathrm{NaNO}_{2}$ in acidic solution. For 510 simplifying the separation process, all inorganic iodine was first reduced to iodide using 511 sulfite in acidic media, and then oxidized to $\mathrm{I}_{2}$ using $\mathrm{NaNO}_{2}$ in acidic media for 512 extraction. The most critical parameter is $\mathrm{pH}$ of the media, reduction of iodate and 513 oxidation of iodide need to be implemented at $\mathrm{pH}<2$, the higher $\mathrm{pH}$ might cause slow 514 reaction rate and low recovery of iodine. $\mathrm{H}_{2} \mathrm{O}_{2}$ has also been used to oxidize iodide to $\mathrm{I}_{2}$, 515 but repeated extractions were used to get better recovery, this might be attributed to the 516 low reaction rate of $\mathrm{H}_{2} \mathrm{O}_{2}$ with iodide.

517 The major disadvantage of the solvent extraction method is the production of toxic 518 organic waste, a direct precipitation method was developed to separate iodine from 519 water/aqueous samples. In this case, all inorganic iodine was converted to iodide, and 520 excessive amount of $\mathrm{AgNO}_{3}$ was added to form $\mathrm{AgI}$ precipitate, which was separated 521 from sample matrix by centrifuging. Since chloride, bromide, sulfide, sulfite can also 522 form precipitates with $\mathrm{Ag}^{+}$, a large amount of precipitate might be formed. Acidification 523 of sample to $\mathrm{pH}<2$ before addition of $\mathrm{Ag}^{+}$and washing the precipitate with $\mathrm{HNO}_{3}$ and 524 ammonia could remove these precipitates and remained only AgI. The separated AgI 525 could be directly used for AMS measurement of ${ }^{129}$ I [31]. Fig. 9 shows a schematic 526 diagram of analytical procedure for determination of ${ }^{129} \mathrm{I}$ in environmental samples.

527 Iodine is also present in organic form in water samples [6], direct solvent extraction and 528 AgI precipitation only separate inorganic iodine (mainly iodide and iodate). For 529 determination of total ${ }^{129}$ I or organic associated ${ }^{129} \mathrm{I}$, an oxidative decomposition method 530 was developed using strong oxidant $\mathrm{K}_{2} \mathrm{~S}_{2} \mathrm{O}_{8}$ at an increased temperature. It was found 531 that organic iodine in water samples can be converted to inorganic forms by addition of 
$532 \mathrm{~K}_{2} \mathrm{~S}_{2} \mathrm{O}_{8}$ to a concentration of $30 \mathrm{mg} / \mathrm{g}$, adjusting $\mathrm{pH} 0.5-1$ and digesting at about $60{ }^{\circ} \mathrm{C}$ for 53320 hours [32]. Afterwards all iodine is separated using the method presented above for 534 determination of total ${ }^{129} \mathrm{I}$.

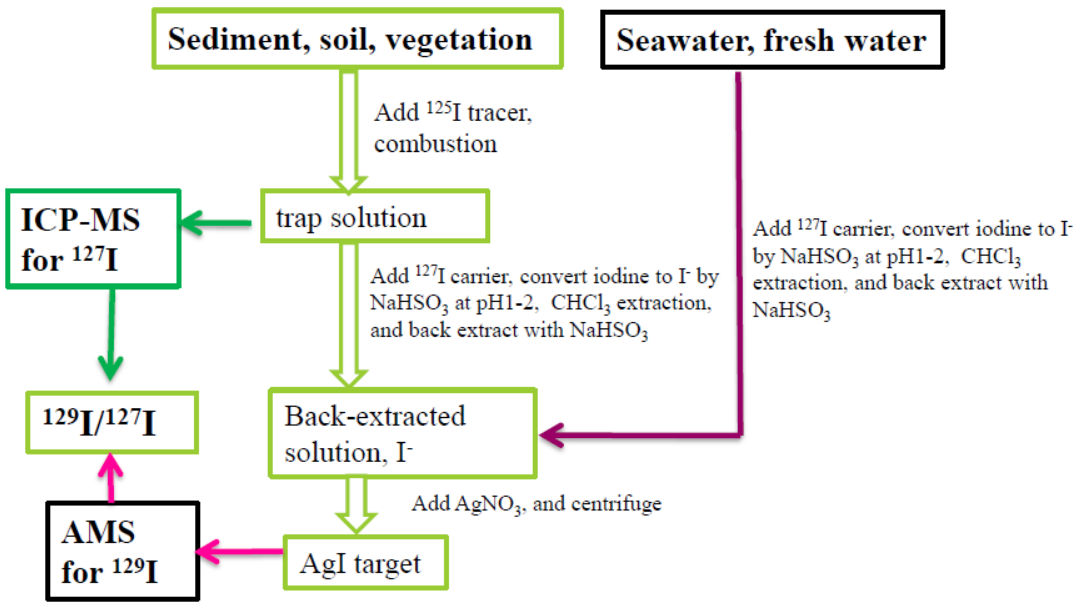

536 Fig. 9 Schematic diagram of analytical procedure for determination of ${ }^{129} \mathrm{I}$ in 537 environmental samples

539 For easy separation of iodine for ${ }^{129}$ I determination, stable carrier containing very low 540 level ${ }^{129} \mathrm{I}$ (e.g. iodine from Woodward company with original ${ }^{129} \mathrm{I} /{ }^{127} \mathrm{I}$ ratio of $2 \times 10^{-14}$ ) is 541 often added. To avoid the contribution of stable iodine carrier in the determination of 542 ultra-low level ${ }^{129}$ I (natural occurred), a carrier free method was developed for the 543 separation of iodine from samples and preparation of measurement target [31]. In this 544 method, iodine released from the sample and trapped into a solution was directly 545 precipitated as $\mathrm{AgI}-\mathrm{AgCl}-\mathrm{Ag}_{2} \mathrm{SO}_{3}$ co-precipitate after reduction of all iodine to iodide 546 and addition of excessive amount of $\mathrm{Ag}^{+}$. Addition of sulfite was important in the 547 separation of carrier free iodide by coprecipitation because of the similar particle size of $548 \mathrm{AgI}$ and $\mathrm{Ag}_{2} \mathrm{SO}_{3}$ precipitate [33]. $\mathrm{Ag}_{2} \mathrm{SO}_{3}$ can be removed by washing the co-precipitate 549 with $\mathrm{HNO}_{3}$, and the excessive amount of $\mathrm{AgCl}$ was removed by washing with diluted 550 concentrations of ammonia, and only $\mathrm{AgI}$ and small amount of $\mathrm{AgCl}$ (in total 2-4 mg) 551 were remained for preparation of AgI target for measurement of ${ }^{129} \mathrm{I}$ by AMS. 
552 In seawater, iodine is present as iodide, iodate and minor amount of organic iodine 553 depending on the marine environment. While in fresh water samples, organic iodine 554 might accounts for a relative large fraction. In the atmosphere, iodine is present as both 555 gaseous forms and particle associate forms. The specific species of gaseous iodine in the 556 atmosphere are very complicated [34], but can be classified as gaseous inorganic iodine 557 (mainly $\mathrm{I}_{2}, \mathrm{HI}, \mathrm{HIO}$, etc.) and gaseous organic iodine (mainly alkyl iodide). In aerosol, 558 soil and sediment, iodine is mainly associated to different components of the sample, 559 therefore often separated into different fractions such as water soluble, exchangeable, 560 carbonate, oxides, organic and mineral associated forms. While, in biological samples 561 including vegetation and animal tissues, iodine is mainly bound to different organic 562 compounds [6].

563 We have developed a series of methods for speciation analysis of ${ }^{129} \mathrm{I}$ in different 564 environmental samples. Separation method based on anion exchange chromatography 565 [35], co-precipitation [33], and solvent extraction were developed for separation of iodide 566 and iodate for the speciation analysis of iodine in water samples. The anion exchange 567 chromatographic procedure is based on the high affinity of iodide compared with iodate 568 on strong base anion exchange resin (e.g. Dowex 1 or AG1). Water samples were directly 569 loaded to an anion exchange column filled with Bio-Rad AG1- $\times 4$ resin in $\mathrm{NO}_{3}{ }^{-}$form. 570 Iodide was adsorbed on the column, while iodate and organic iodine passed through. 571 Small fraction of iodate remained on the column was removed by rinsing with diluted $572(0.5 \mathrm{~mol} / \mathrm{l}) \mathrm{KNO}_{3}$, iodide on the column was finally eluted with $2 \mathrm{~mol} / 1 \mathrm{KNO}_{3}$. For 573 separation of iodate, the effluent and rinsing solution were combined, acidified to $\mathrm{pH}<2$ 574 using $\mathrm{HCl}$. Iodate in the sample was reduced to iodide by addition of $\mathrm{KHSO}_{3}$ solution 575 and separated using the same procedure as for iodide (Fig. 10). The eluted iodine from 576 the column was further separated from matrix using solvent extraction and prepared as 577 AgI for AMS measurement [35]. A simple co-precipitation method was developed to 578 separate iodide and iodate from seawater for speciation analysis of ${ }^{129} \mathrm{I}$, which is more 579 suitable for application on board of a ship. This method is based on the selective 580 coprecipitation of $\mathrm{AgI}$ with $\mathrm{Ag}_{2} \mathrm{SO}_{3}$ and $\mathrm{AgCl}$ at $\mathrm{pH} 4-6$, the $\mathrm{Ag}_{2} \mathrm{~S}_{2} \mathrm{O}_{3}$ and excessive 581 amount of $\mathrm{AgI}$ could be removed by washing with $\mathrm{HNO}_{3}$ and ammonium. Addition of 
$582 \mathrm{KHSO}_{3}$ and controlling $\mathrm{pH}$ 4-6 are critical for selective precipitation of iodide, lower $\mathrm{pH}$ 583 will cause the reduction of iodate and therefore split over iodate to iodide fraction [33]. 584 This method has been successfully applied for speciation analysis of ${ }^{129} \mathrm{I}$ in seawater 585 samples [36, 37], but not suitable for fresh water samples, because of less chloride in the

586 fresh water. A selective solvent extraction method was therefore developed for separation 587 of iodide and iodate from water samples. This method is based on the oxidation of iodide 588 to $\mathrm{I}_{2}$ by low concentration of $\mathrm{NaClO}(1 \%)$ at $\mathrm{pH} 4-7$, followed by solvent extraction of the

589 formed $\mathrm{I}_{2}$ into organic phase $\left(\mathrm{CHCl}_{3}\right.$ or $\left.\mathrm{CCl}_{4}\right)$. It is well known that $\mathrm{NaClO}$ is a strong 590 oxidant, which can oxidize iodide directly to iodate. However, our experiment showed 591 that $\mathrm{NaClO}$ of low concentration can only oxidize iodide to $\mathrm{I}_{2}$ if the $\mathrm{pH}$ of solution is

592 higher than 4. The key parameters in this method are the concentration of $\mathrm{NaClO}$ and the $593 \mathrm{pH}$ value of the sample solution. The total inorganic iodine (iodide plus iodate) can be 594 obtained by first reducing iodate to iodide at $\mathrm{pH}<2$, and then oxidizing iodide to $\mathrm{I}_{2}$ by $595 \mathrm{NaNO}_{2}$, and extract $\mathrm{I}_{2}$ to the organic phase. In this method, stable carrier needs to be 596 added before solvent extraction, because the recovery of solvent extraction is related to 597 the concentration of iodide and the other salt. The very low concentration of iodine in 598 fresh water and high salt content in seawater cause a low recovery of iodine in the 599 extraction step if no stable iodine carrier is added.

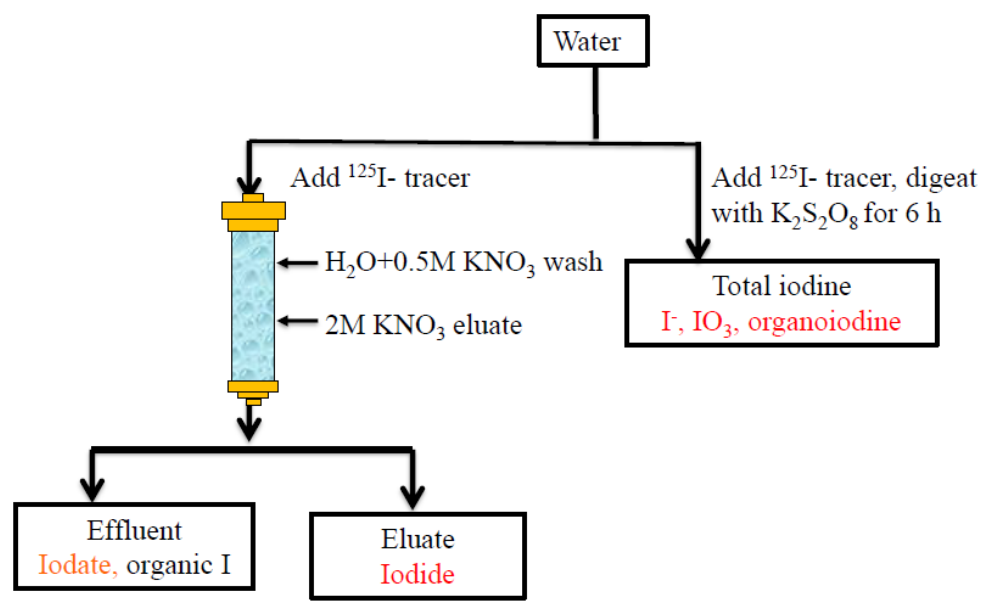

600

601 Fig. 10 Schematic diagram of separation procedure for speciation analysis of ${ }^{129} \mathrm{I}$ in 602 water samples using anion exchange chromatography 
603 A three-fraction air iodine collector was developed for separation of particle associate, 604 inorganic gaseous iodine and organic gaseous iodine from air, the collector was 605 connected to an air pump [6]. In this collector, particle associate iodine (aerosol) was first 606 collected on a glass fiber filter of $0.45 \mu \mathrm{m}$ pore size, followed by two layer cellulous 607 filter impregnated with $\mathrm{NaOH}$ for collecting inorganic gaseous iodine (HI, $\mathrm{I}_{2}, \mathrm{HOI}$, etc.), 608 and the organic gaseous iodine (alkyl iodide) was finally collected by an active carbon 609 cartridge, in which the active charcoal was purified by washing with $\mathrm{NaClO}$ and $\mathrm{NaOH}$, 610 and impregnated with triethylenediamine. Iodine collected in the filter or cartridge was 611 then separated by combustion using tube furnace, and prepared as AgI for determination 612 of ${ }^{129} \mathrm{I}$.

613 For speciation analysis of ${ }^{129} \mathrm{I}$ in aerosol, a sequential extraction followed by anion 614 exchange chromatographic method was developed in our laboratory. Iodide, iodate, water 615 soluble iodine organic and mineral associated iodine were sequentially separated, each 616 fraction of iodine was then purified and finally prepared as AgI for measurement of ${ }^{129} \mathrm{I}$ 617 using AMS [30]. In this method, aerosol samples cut into small pieces was first leached 618 with deionized water, and the leachate was divided into two parts, one was used for 619 determination of total water soluble ${ }^{129} \mathrm{I}$ by digestion with $\mathrm{K}_{2} \mathrm{~S}_{2} \mathrm{O}_{8}$ in acidic condition and 620 heating followed by solvent extraction. Iodide and iodate in another part of water leachate 621 were separated using anion exchange chromatographic method as described above for 622 water samples, and used to determine ${ }^{129} \mathrm{I}$ in iodide and iodate form. The residue filter 623 after water leaching was leached with $0.5 \mathrm{~mol} / 1 \mathrm{NaOH}$ at $45^{\circ} \mathrm{C}$. The leachate was treated 624 using the same method as that for determination of the total ${ }^{129} \mathrm{I}$, i.e. digestion with $625 \mathrm{~K}_{2} \mathrm{~S}_{2} \mathrm{O}_{8}$ followed by solvent extraction, this fraction of ${ }^{129} \mathrm{I}$ was considered as organic 626 associated ${ }^{129}$ I. Iodine still remained in the remained residue was separated by oxidative 627 combustion using tube furnace, followed by purification by solvent extraction or direct 628 AgI precipitation for determination of ${ }^{129} \mathrm{I}$ in the mineral fraction of aerosol. The analysis 629 of aerosol collected in Denmark showed that most ${ }^{129} \mathrm{I}$ is present as organic associate 630 iodine, and the water soluble ${ }^{129} \mathrm{I}$ is mainly present as iodide [30].

631 Speciation analysis of ${ }^{129} \mathrm{I}$ in soil and sediment was performed using sequential extraction 632 (Fig. 11). In consideration of the volatile feature of iodine, the ordinary sequential 
633 fractionation method was modified to avoid the loss of the iodine during the separation $634[38,39,40]$.

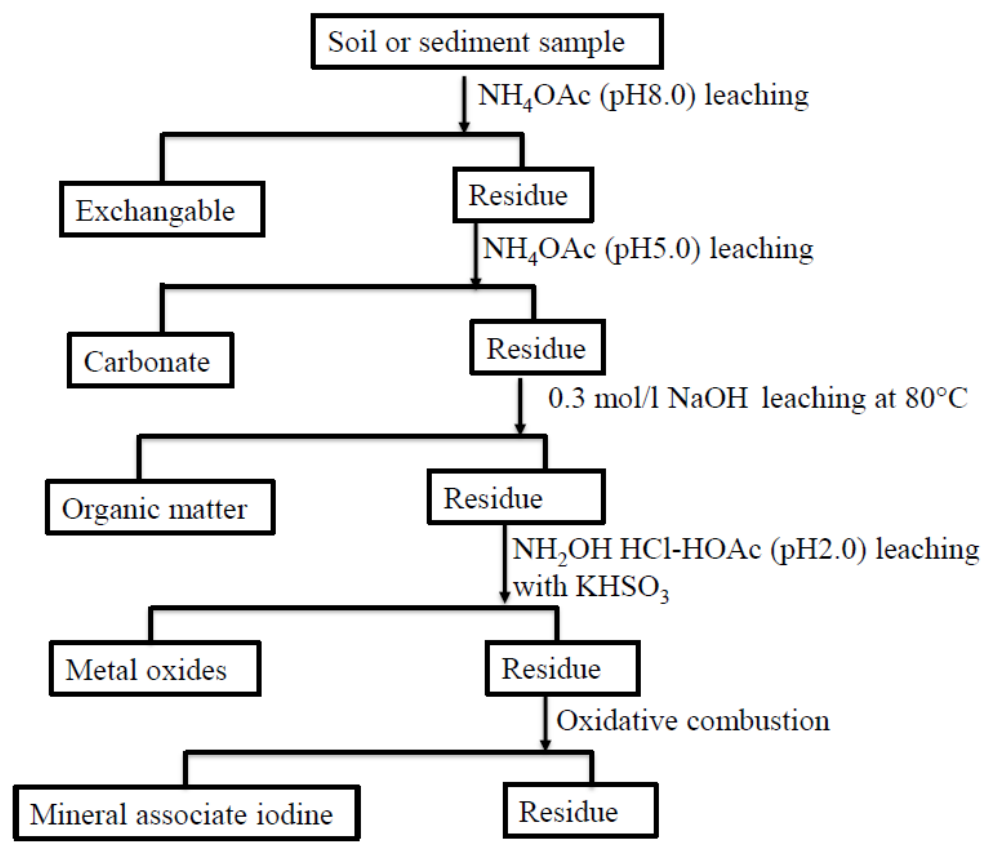

636 Fig. 11 Schematic procedure for speciation analysis of ${ }^{129}$ I in soil and sediment samples.

637 In this procedure (Fig. 11), the ground sample was leached with $1.0 \mathrm{~mol} / \mathrm{L} \mathrm{NH}_{4} \mathrm{OAc}-$ $638 \mathrm{NH}_{3}(\mathrm{pH} 8)$ at room temperature to obtain water soluble and exchangeable iodine, the 639 residue was then leached with $1.0 \mathrm{~mol} / \mathrm{L} \mathrm{NH}_{4} \mathrm{OAc}$ (ammonium acetate) in 25\% HOAc 640 (acetic acid) $(\mathrm{v} / \mathrm{v})(\mathrm{pH}$ of 5$)$ for $4 \mathrm{~h}$ at room temperature to obtain carbonate associate 641 iodine. The residue was further leached with $0.3 \mathrm{~mol} / \mathrm{L} \mathrm{NaOH}$ at $80{ }^{\circ} \mathrm{C}$ for $8 \mathrm{~h}$ to obtain 642 organic substance associated iodine. The residue was then leached with $0.04 \mathrm{~mol} / \mathrm{L}$ $643\left(\mathrm{NH}_{2} \mathrm{OH}\right)_{2} \cdot \mathrm{H}_{2} \mathrm{SO}_{4}$ in $25 \%(\mathrm{v} / \mathrm{v}) \mathrm{HOAc}$ at $80^{\circ} \mathrm{Cfor} 8$ hours, and $0.1 \mathrm{~mL} 1 \mathrm{~mol} / \mathrm{L} \mathrm{NaHSO}_{3}$ 644 was added every hour to prevent the loss of iodine by reducing the leached iodine to 645 iodide form. The remained residue was dried and transferred to a quartz boat for 646 separation of iodine by combustion using a Pyrolyser furnace to obtain the mineral 647 associated iodine. The analysis of soil and sediment showed that most of ${ }^{129} \mathrm{I}$ was 648 associated with organic substances and metal oxides [38-41]. 
Journal of Radioanalytical and Nuclear Chemistry

\section{Measurement of ultra-low level radionuclides using mass spectrometry}

651 Depending on the decay model, radionuclides are conventionally measured by 652 radiometric methods through their radioactive decay [42]. Gamma spectrometry using 653 HPGe detector is the often used technique for measurement of gamma emitting 654 radionuclides in environmental samples because of its high resolution and single energy 655 feature of gamma rays. By employing anti-Compton electronic setup to suppress the 656 spectrum background, installing spectrometry instrument in underground laboratory of 657 few hundreds to a few thousands meters depth to shield the cosmic rays causing 658 background radiation, lining the wall of the laboratory with pure copper and instrument 659 with high purity shielding materials to reduce the background radiation from the 660 surrounding environment, and using big germanium crystal detector to increase the 661 detection efficiency, the gamma spectrometry can be used for measurement of ultra-low 662 level gamma radionuclides in the environment. The major advantage of this technique is 663 its direct measurement without chemical separation. Liquid scintillation counting (LSC)

664 is the most often used techniques for measurement of pure beta emitting radionuclides 665 (including those decay by internal conversion) [43], and low background GM counter 666 especially those equipped with anti-coincidence device is also an often used technique for 667 measurement of radionuclides emitting high energy beta particles at low level in the 668 environment. Alpha spectrometry is still the dominant technique for measurement of the 669 alpha emitting radionuclides, especially the relative short lived alpha radionuclides (e.g. $\left.670{ }^{210} \mathrm{Po},{ }^{238} \mathrm{Pu},{ }^{241} \mathrm{Am},{ }^{242} \mathrm{Cm},{ }^{243,244} \mathrm{Cm}\right)$. Before the measurement, beta and alpha emitting 671 radionuclides, the target radionuclides have to be separated from the sample matrix and 672 interfering radionuclides. Inorganic mass spectrometry as an instrument for isotope 673 measurement is becoming an attractive measurement technique of radionuclides. 674 Compared with radiometric measurement techniques, mass spectrometry is used to 675 measure the number of atoms of the target isotope. Based on the decay equation: $\mathrm{A}=$ $676 \mathrm{~N}^{*} \operatorname{Ln}(2) / \mathrm{t}^{1} / 2$ (A is the activity of radionuclide; $\mathrm{N}$ is the numbers of atoms and $\mathrm{t}^{1 / 2}$ is the 677 half-life of radionuclide), the mass spectrometry is suitable for the measurement of long678 lived radionuclides. Assuming a detection limit of $2 \mathrm{mBq}$ for radiometric techniques and $67910^{6}$ atoms for mass spectrometry, the mass spectrometry technique will become more 
680 sensitive than radiometric method if the half-life of radionuclide is longer than 10 years. 681 However, the detection limit of a measurement technique depends on many parameters, 682 including the interferences, specific instrument setup and property of the specific 683 radionuclide. A selection of measurement technique has to consider all these factors.

684 Many mass spectrometry techniques can be used to measure radionuclides, such as 685 inductively coupled plasma mass spectrometry (ICP-MS), accelerator mass spectrometry 686 (AMS), thermal ionization mass spectrometry (TIMS), resonance ionization mass 687 spectrometry (RIMS), secondary ion mass spectrometry (SIMS) and glow discharge mass 688 spectrometry (GDMS) [42]. Among these mass spectrometry techniques, ICP-MS and 689 AMS are the most attractive and popular mass spectrometry techniques for measurement 690 of long-lived radionuclides because of the rapid development/improvement of these two 691 mass spectrometry techniques in the past years. The major challenges in the measurement 692 of radionuclides by mass spectrometry techniques are sensitivity (including ionization, 693 transmission and detection efficiency), spectral interferences (mainly from isobars, 694 molecular/polyatomic ions and matrix), and instrumental limitations (e.g. abundance 695 sensitivity, sample introduction, and possibility of ionization). The most efforts on the 696 development of instrument and measurement methods are dedicated to solve these 697 problems to get accurate and sensitive measurement of the target radionuclides. In the 698 past years, we have developed a number of measurement methods for the determination 699 of ${ }^{99} \mathrm{Tc},{ }^{135} \mathrm{Cs}$, isotopes of plutonium and uranium and ${ }^{237} \mathrm{~Np}$ using ICP-MS, and ${ }^{129} \mathrm{I}$ using 700 AMS. Some of these methods are briefly presented below.

701 Measurement of isotopes of plutonium using ICP-MS. The major isotopes of plutonium in 702 the environment are ${ }^{238} \mathrm{Pu},{ }^{239} \mathrm{Pu},{ }^{240} \mathrm{Pu}$ and ${ }^{241} \mathrm{Pu}$. It is almost impossible to measure ${ }^{238} \mathrm{Pu}$ 703 using mass spectrometry (except RIMS) because of isobaric interference of ${ }^{238} \mathrm{U}$, the 704 difference of the atomic mass of ${ }^{238} \mathrm{U}$ and ${ }^{238} \mathrm{Pu}$ of $5.2 \times 10^{-6}(\Delta \mathrm{m} / \mathrm{m})$ is too small to be 705 discriminated by mass spectrometry, even for high resolution instrument. Measurement 706 of plutonium isotopes using mass spectrometry is therefore mainly dedicate to the 707 measurement of ${ }^{239} \mathrm{Pu},{ }^{240} \mathrm{Pu}$ and ${ }^{241} \mathrm{Pu}$. The major challenges on the ICP-MS 708 measurement of these isotopes of plutonium are abundance sensitivity of the instrument 709 and the interferences of molecular ions (e.g. ${ }^{238} \mathrm{U}^{1} \mathrm{H}^{+},{ }^{238} \mathrm{U}^{1} \mathrm{H}_{2}{ }^{+},{ }^{205} \mathrm{Hg}^{35} \mathrm{Cl}^{+},{ }^{202} \mathrm{Hg}^{37} \mathrm{Cl}^{+}$, 
$710{ }^{200} \mathrm{Hg}^{40} \mathrm{Ar}^{+}$, etc.). Uranium is an abundant element on the earth, the concentration of 711 uranium in the environment is normally more than 6 orders of magnitude higher than that 712 of plutonium, causing ${ }^{238} \mathrm{U}$ the major interferences in the ICP-MS measurement of ${ }^{239} \mathrm{Pu}$ 713 and ${ }^{240} \mathrm{Pu}$. To eliminate the interference of uranium hydrides $\left({ }^{238} \mathrm{U}^{1} \mathrm{H}^{+},{ }^{238} \mathrm{U}^{1} \mathrm{H}_{2}{ }^{+}\right)$, 714 different dynamic reaction gases were investigated in our lab. It was found that simple 715 collision reaction using He cannot effectively destroy hydrides of uranium, therefore 716 could not remove its interference. By introducing $\mathrm{O}_{2}$ as reaction gas, $\mathrm{UH}^{+}$and $\mathrm{U}^{+}$were 717 converted to oxides $\left(\mathrm{UO}^{+}, \mathrm{UHO}^{+}, \mathrm{UO}_{2}{ }^{+}\right.$or $\mathrm{UHO}_{2}{ }^{+}$), meanwhile $\mathrm{Pu}$ was also converted to 718 oxides $\left(\mathrm{PuO}^{+}, \mathrm{PuO}_{2}^{+}\right)$, the interference of uranium hydrides could not be effectively 719 eliminated in the measurement of ${ }^{239} \mathrm{Pu}$ and ${ }^{240} \mathrm{Pu}$. Injection of ammonium into the 720 reaction cell could significantly suppress the signal of $\mathrm{UH}^{+}$by 2 orders of magnitude, 721 while the intensities of $\mathrm{Pu}^{+}$keep constant. Meanwhile, the intensity of $\mathrm{U}^{+}$signal was 722 reduced 3-4 orders of magnitude (Fig. 12). This indicated that ammonium as reaction gas 723 could effectively eliminate the interference of hydrides of uranium to the measurement of $724{ }^{239} \mathrm{Pu}$ and ${ }^{240} \mathrm{Pu}$. This was attributed that $\mathrm{U}^{+}$and $\mathrm{UH}^{+}$reacted with $\mathrm{NH}_{3}$ and formed $725 \mathrm{UNH}_{2}^{+}$, but $\mathrm{Pu}^{+}$does not react with $\mathrm{NH}_{3}$ [44]. This method could reduce the contribution 726 of ${ }^{238} \mathrm{U}$ to the ${ }^{239} \mathrm{Pu}$ to $1 \times 10^{-7} . \mathrm{CO}_{2}$ as reaction gas was also investigated, it was found that $727 \mathrm{CO}_{2}$ can effectively react with $\mathrm{UH}^{+}$to form $\mathrm{UO}^{+}$ions, while $\mathrm{Pu}$ partly react with $\mathrm{CO}_{2}$ to 728 form $\mathrm{PuO}^{+}$. At optimal condition, this method can reduce the contribution of ${ }^{238} \mathrm{U}$ to ${ }^{239} \mathrm{Pu}$ 729 to $1 \times 10^{-8}$, one order of magnitude better than $\mathrm{NH}_{3}$. It was also observed that injection of $730 \mathrm{He}$ with $\mathrm{NH}_{3}$ or $\mathrm{CO}_{2}$ in to reaction/collision cell could significantly improve the 731 measurement sensitivity of plutonium isotopes by a factor of 3 . This was attributed to the 732 collision focusing of $\mathrm{He}$ through reducing and narrowing the energy distribution of $\mathrm{Pu}^{+}$ 733 ion during transmission to the detector from the quadrupole.

734 By employing two quadrupole mass separators in the Agilent 8800 ICP-MS, the 735 abundance sensitivity (tailing) of the ${ }^{238} \mathrm{U}$ was significantly improved. It was observed 736 that the contribution of ${ }^{238} \mathrm{U}$ to $\mathrm{m} / \mathrm{z}=237$ was significantly reduced to $<10^{-9}$ when two 737 quadrupole mass separators were applied, which is 4 orders of magnitude better 738 compared with the conventional signal quadrupole mass separator instrument. 739 Introducing collision/reaction gases can further improve the abundance sensitivity. The 
740 contribution of ${ }^{238} \mathrm{U}$ to $\mathrm{m} / \mathrm{z}=237$ was reduced to $<2 \times 10^{-11}$ when $\mathrm{CO}_{2}-\mathrm{He}$ gasses were 741 injected into the reaction/collision cell. Besides the double separation by two 742 quadrupoles, removal of ${ }^{238} \mathrm{U}^{+}$ions by converting $\mathrm{U}^{+}$to $\mathrm{UO}_{2}{ }^{+}$or $\mathrm{UO}_{2}{ }^{+}$ions in the reaction 743 cell also reduced its contribution to $\mathrm{m} / \mathrm{z}=237$ and 239 . In addition, collision focusing of $744{ }^{238} \mathrm{U}^{+}$by helium atoms in the DRC also helps to reduce the tailing contribution to $745 \mathrm{~m} / \mathrm{z}=237$ and 239. A schematic mechanism of the triple quadrupole ICP-MS with $\mathrm{NH}_{3}$ 746 He as reaction gasses is illustrated in Fig. 13.

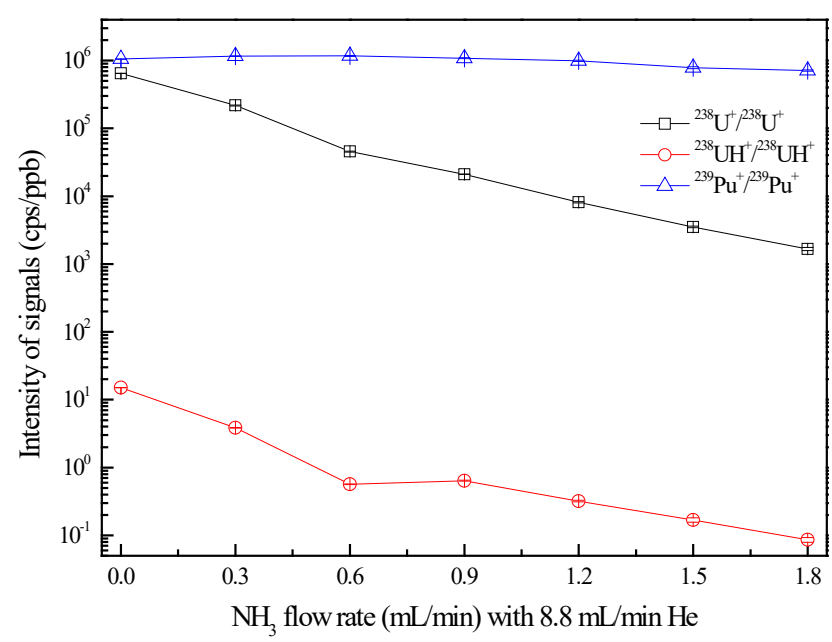

748 Fig. 12 Variation of the signal intensities of ${ }^{238} \mathrm{U}^{+},{ }^{238} \mathrm{U}^{1} \mathrm{H}^{+}$and ${ }^{239} \mathrm{Pu}^{+}$with the flow rate 749 of $\mathrm{NH}_{3}$ (mixed with $8.8 \mathrm{ml} / \mathrm{min} \mathrm{He}$ ) as reaction gas measured in uranium standard 750 solution $\left({ }^{238} \mathrm{U}\right)$ and ${ }^{239} \mathrm{Pu}$ standard solution using ICP-MS/MS

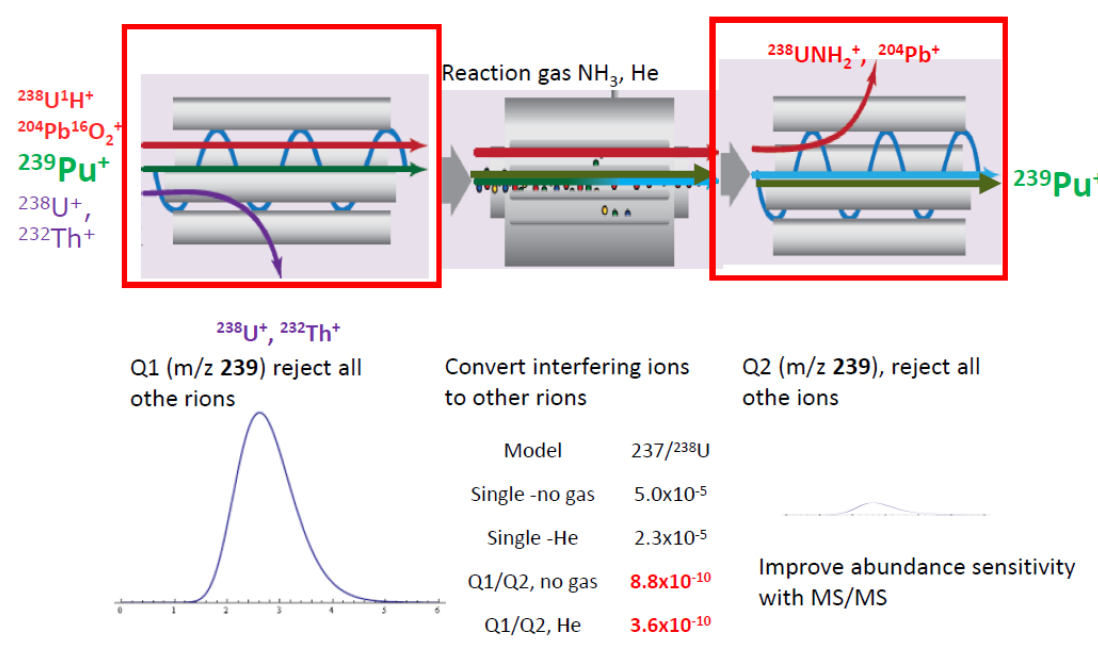


752 Fig.13 Diagram illustrating the mechanism of triple-quadrupole ICP-MS with $\mathrm{NH}_{3}-\mathrm{He}$ as 753 reaction gas to eliminate interferences for measurement of ${ }^{239} \mathrm{Pu}$

754 Accelerator mass spectrometry for measurement of ${ }^{129} I$. AMS can well overcome the 755 isobaric and spectral interferences occurred in ICP-MS measurement of radionuclides, 756 therefore achieve very low background and ultra-low detection limit, it is the most 757 powerful method for the measurement of many long-lived radionuclides such as ${ }^{14} \mathrm{C},{ }^{10} \mathrm{Be}$, $758{ }^{26} \mathrm{Al},{ }^{36} \mathrm{Cl},{ }^{41} \mathrm{Ca},{ }^{79} \mathrm{Se},{ }^{129} \mathrm{I},{ }^{236} \mathrm{U},{ }^{239} \mathrm{Pu},{ }^{240} \mathrm{Pu}$, etc. Fig. 14 illustrates the major features of 759 AMS in the measurement of radionuclides (e.g. $\left.{ }^{129} \mathrm{I}\right)$.

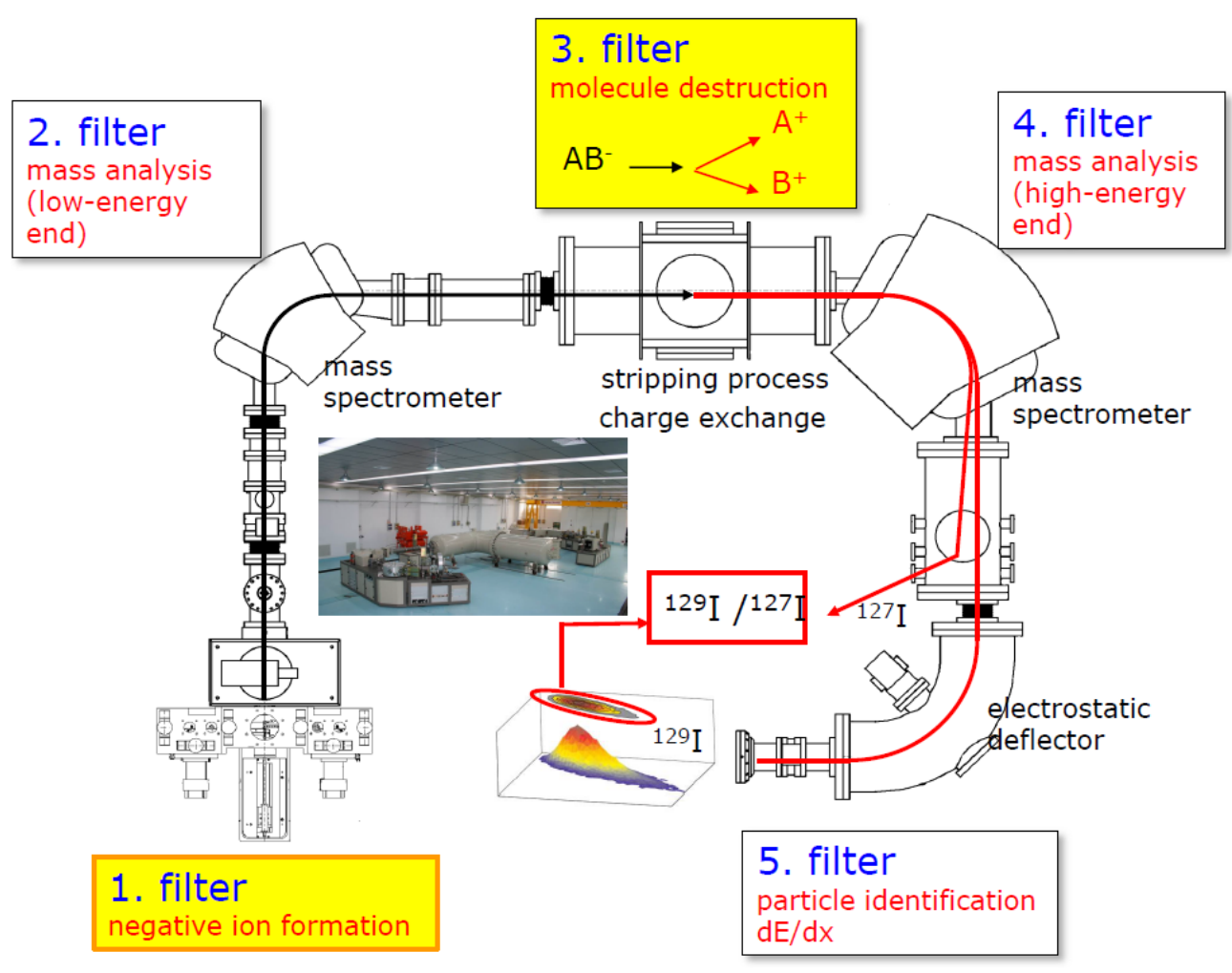

761 Fig. 14 Schematic diagram illustrating the mechanism of AMS measurement of 762 radionuclides

763 In the AMS, negative ions are selected to be injected to the system, most of isobaric 764 interferences can be excluded in this step, because many elements cannot form negative 765 ions in the ion source. The most serious isobaric interference for the measurement of ${ }^{129} \mathrm{I}$ 766 can be completely eliminated in AMS because ${ }^{129} \mathrm{Xe}$ cannot form negative ions. The first 767 mass analyzer at low energy part selects the target $\mathrm{m} / \mathrm{z}$ (e.g. 129 for ${ }^{129} \mathrm{I}^{-}$, and 127 for ${ }^{127} \mathrm{I}^{-}$) 
768 to be injected to the system. For the measurement of ${ }^{129} \mathrm{I}$, both ${ }^{127} \mathrm{I}^{-}$and ${ }^{129} \mathrm{I}^{-}$are 769 sequentially injected to the accelerator through the first mass analyzer, meanwhile other 770 ions are excluded. All ions entered into the accelerator are accelerated through an electric 771 field, and out layer electrons of the ion are then stripped through a film or gas filled in the 772 middle of the accelerator. The formed positive ions are further accelerated in the second 773 part of the accelerator. By this way, all molecular ions (e.g. ${ }^{127} \mathrm{I}^{1} \mathrm{H}_{2}$ for ${ }^{129} \mathrm{I}$ measurement) 774 are destroyed and eliminated. Afterwards, the target ions (e.g. ${ }^{129} \mathrm{I}^{3+}$ or ${ }^{127} \mathrm{I}^{3+}$ ) are selected 775 and entered to the second mass analyzer (high energy part) to further eliminate other 776 interference. By these ways, almost all interferences can be eliminated and a very low 777 background can be achieved. The major isotope ions (e.g. ${ }^{127} \mathrm{I}^{3+}$ ) are measured by a 778 Faraday cup, and the minor isotope ions (e.g. ${ }^{129} \mathrm{I}^{3+}$ ) are measured by a more sensitive 779 detector, e.g. ionization chamber. An electrostatic analyzer is normally installed before 780 the detector to further eliminate some interference, e.g. ${ }^{10} \mathrm{~B}$ in the measurement of ${ }^{10} \mathrm{Be}$, 781 which cannot be sufficiently removed in the previous steps.

782 We have developed a numbers of AMS measurement methods for ${ }^{129}$ I using a 3MV AMS 783 system in the Xi'an AMS center. An instrumental background of $2 \times 10^{-14}$ for ${ }^{129} \mathrm{I} /{ }^{127} \mathrm{I}$ 784 atomic ratio was obtained by direct measurement of a target prepared by directly pressed $785 \mathrm{NaI}$ and niobium powder into a copper holder. The procedure blanks were measured to be 786 lower than $1 \times 10^{-13}$ for ${ }^{129} \mathrm{I} /{ }^{127} \mathrm{I}$ ratio in AgI targets containing 0.2-1.0 mg iodine carrier, 787 which is corresponding to a detection limit of $3 \times 10^{6}$ atoms ( 3 times of blank count rate).

788 For the measurement of ${ }^{129} \mathrm{I}$ in surface environmental samples (with ${ }^{129} \mathrm{I} /{ }^{127} \mathrm{I}$ ratio $>10^{-9}$ ), $789 \quad 0.5-2.0 \mathrm{mg}$ of stable iodine carrier prepared from a low-background iodine crystal 790 (Woodward Company) was spiked to the sample after separation using combustion, or 791 directly to the water samples. The separated iodine in iodide form was precipitated as AgI 792 by addition of $\mathrm{AgNO}_{3}$. After dried at $70-75^{\circ} \mathrm{C}$ in a $1.5 \mathrm{ml}$ centrifuge tube, the $\mathrm{AgI}$ 793 precipitate was ground to fine powder and mixed with niobium powder of 3-5 times by 794 mass, which was then pressed in a copper holder for AMS measurement of ${ }^{129} \mathrm{I}$. In 795 general, $10 \mathrm{mg}$ of mixture can be pressed into target holder, i.e. maximum $2 \mathrm{mg}$ of AgI 796 can be pressed into the holder. In practice, only small fraction of sample in the target 797 holder was used for measurement due to a relative short analytical time ( $<20 \mathrm{~min}$.). 
798 Therefore, for the analysis of low-level samples, it is better to reduce the final mass of 799 samples, to enable more samples were used for measurement. In this case, $0.2 \mathrm{mg}$ iodine 800 carrier was used and the final mass of the precipitate of 0.5-1.0 mg was mixed with 2-3 $801 \mathrm{mg}$ of niobium to be fully pressed into the target holder and used for measurement of ${ }^{129} \mathrm{I}$.

802 An AMS method using carrier free iodine target was developed for the determination of

$803{ }^{129}$ I in ultra-low level samples. In this method, no stable iodine was spiked to the sample 804 to avoid the ${ }^{129} \mathrm{I}$ background resulted from iodine carrier. Because the concentration of 805 iodine in environmental samples (except seaweed, thyroid, brine, etc.) is normally very 806 low, only small amount of iodine $(<0.05 \mathrm{mg})$ can be separated from the sample, e.g. $20 \mathrm{~g}$ 807 soil), which is not sufficient to prepare AgI precipitate, therefore an AgI-AgCl co808 precipitation method was developed to prepare the target. The final $\mathrm{AgI}-\mathrm{AgCl}$ precipitate 809 of 0.5-1 mg was prepared, ground, mixed with 2-5 $\mathrm{mg}$ of niobium powder, and pressed 810 into a niobium holder for measurement of ${ }^{129} \mathrm{I}$ using AMS. The main challenge in this 811 method is stabilization, control and precise measurement of the beam current of iodine 812 ions, because of very low current of $<100 \mathrm{nA}$. With this method, samples with ${ }^{129} \mathrm{I} /{ }^{127} \mathrm{I}$ 813 atomic ratio of $2.0 \times 10^{-13}$ can be measured when $0.05 \mathrm{mg}$ iodine is separated and used for 814 measurement. This method is therefore useful for analysis of ultra-low level ${ }^{129}$ I samples, 815 e.g. deep soil, seawater, or pre-nuclear samples. For a sample with ${ }^{129} \mathrm{I} /{ }^{127} \mathrm{I}$ ratio of $1 \times 10^{-}$ $81{ }^{10}$, this method only needs $3 \mu \mathrm{g}$ iodine for measurement, i.e. a small size sample is needed, 817 which is very useful for the application in which only small sample is available [31].

818 In the AMS measurement of ${ }^{129} \mathrm{I}$, the $\mathrm{AgI}$ or $\mathrm{AgI}-\mathrm{AgCl}$ precipitate is often pressed into a 819 copper (or titanium, stainless steel) holder. The aluminum target holder often used for 820 measurement of ${ }^{14} \mathrm{C}$ is not suitable for this type of target. A violent reaction (bubbles) 821 was observed shortly (< 10 minutes) after $\mathrm{AgI}-\mathrm{AgCl}$ was pressed into an aluminum 822 holder and exposed to air. A similar but weaker reaction was observed for AgI precipitate 823 when it was pressed into an aluminum holder, and liquid bubbles on the surface of the 824 sample were observed. No visible reaction was observed when they were pressed in 825 holders made of copper for both $\mathrm{AgI}$ and $\mathrm{AgI}-\mathrm{AgCl}$ precipitate, even after exposure to air 826 for more than 7 days. This might be attributed to a solid phase reaction: $3 \mathrm{AgI}+\mathrm{Al}=3 \mathrm{Ag}$ 
$827+\mathrm{AlI}_{3}$ and $3 \mathrm{AgCl}+\mathrm{Al}=3 \mathrm{Ag}+\mathrm{AlCl}_{3}$, these reactions take place when water vapor and

828 water soluble iodide/chloride are present [45].

829 In the AMS measurement, the target radionuclide is always separated from the sample 830 matrix and purified from other impurity before measurement. This procedure is normally 831 time consuming and not suitable for rapid analysis. We have developed a direct AMS 832 measurement method without chemical separation. The sample was only ground to

833 powder and directly pressed into target holder after mixed with niobium powder. The 834 prepared target was measured for ${ }^{129} \mathrm{I}$ in the $3 \mathrm{MV}$ AMS. The analytical results indicate 835 that this method is valid for the measurement of ${ }^{129} \mathrm{I}$ in environmental solid samples (e.g. 836 vegetation, soil, aerosol /dust) in a level of $0.1 \mu \mathrm{Bq} / \mathrm{mg}^{129} \mathrm{I}$ with an analytical uncertainty 837 of less than $20 \%$. For normal environmental sample with low concentration of iodine $(<5$ $838 \mu \mathrm{g} / \mathrm{g}$ ), stable iodine carrier pre-mixed with niobium was used, which can significantly 839 improve the stability of the measurement and accuracy of the analytical result [46]. This 840 method is very useful for emergency analysis, the analytical time is only less than 5 min 841 per sample. In consideration of sample preparation, a batch of 40 samples can be 842 analyzed in 5 hours.

843 Determination of difficult-to-measure radionuclides for 844 decommissioning of nuclear facilities and emergency preparedness

845 Since 2002, our laboratory at DTU Nutech has developed serious analytical methods for 846 the determination of radionuclides of difficult to measure (mainly long-lived beta and 847 alpha emitters and some low-level gamma emitters), including ${ }^{3} \mathrm{H},{ }^{14} \mathrm{C},{ }^{36} \mathrm{Cl},{ }^{41} \mathrm{Ca},{ }^{55} \mathrm{Fe}$, $848{ }^{63} \mathrm{Ni},{ }^{90} \mathrm{Sr},{ }^{93} \mathrm{Mo},{ }^{99} \mathrm{Tc},{ }^{129} \mathrm{I},{ }^{237} \mathrm{~Np},{ }^{238} \mathrm{U},{ }^{239} \mathrm{Pu},{ }^{240} \mathrm{Pu},{ }^{241} \mathrm{Pu},{ }^{241} \mathrm{Am}$ and ${ }^{244} \mathrm{Cm}$. Various

849 types of materials have been analyzed for decommissioning of nuclear facilities, 850 including concrete, graphite, metals, stainless steel, exchange resin, liquid waste 851 concentrate, ordinary water, heavy water, silicate gels, paint, oil, soil/sand, 852 sediment/slurry, etc. The analytical results have been used to characterize these materials 853 and treatment of the produced wastes for the decommissioning of research and power 854 reactors and other nuclear facilities in Denmark, Sweden. 
855 The main challenges in the radiological characterization of decommissioning waste 856 includes instability of some radionuclides (e.g. ${ }^{3} \mathrm{H},{ }^{14} \mathrm{C},{ }^{36} \mathrm{Cl},{ }^{99} \mathrm{Tc},{ }^{129} \mathrm{I}$, etc.) during 857 sampling, storage and chemical separation, complicated and unknown components of 858 sample matrix, difficulties in decomposition and pre-treatment of some samples, high 859 radiation exposure for some samples. Fig.15 shows an overall sequential separation 860 procedure for determination of various radionuclides in different samples. Brief 861 description of analytical methods for individual radionuclide are also presented below.

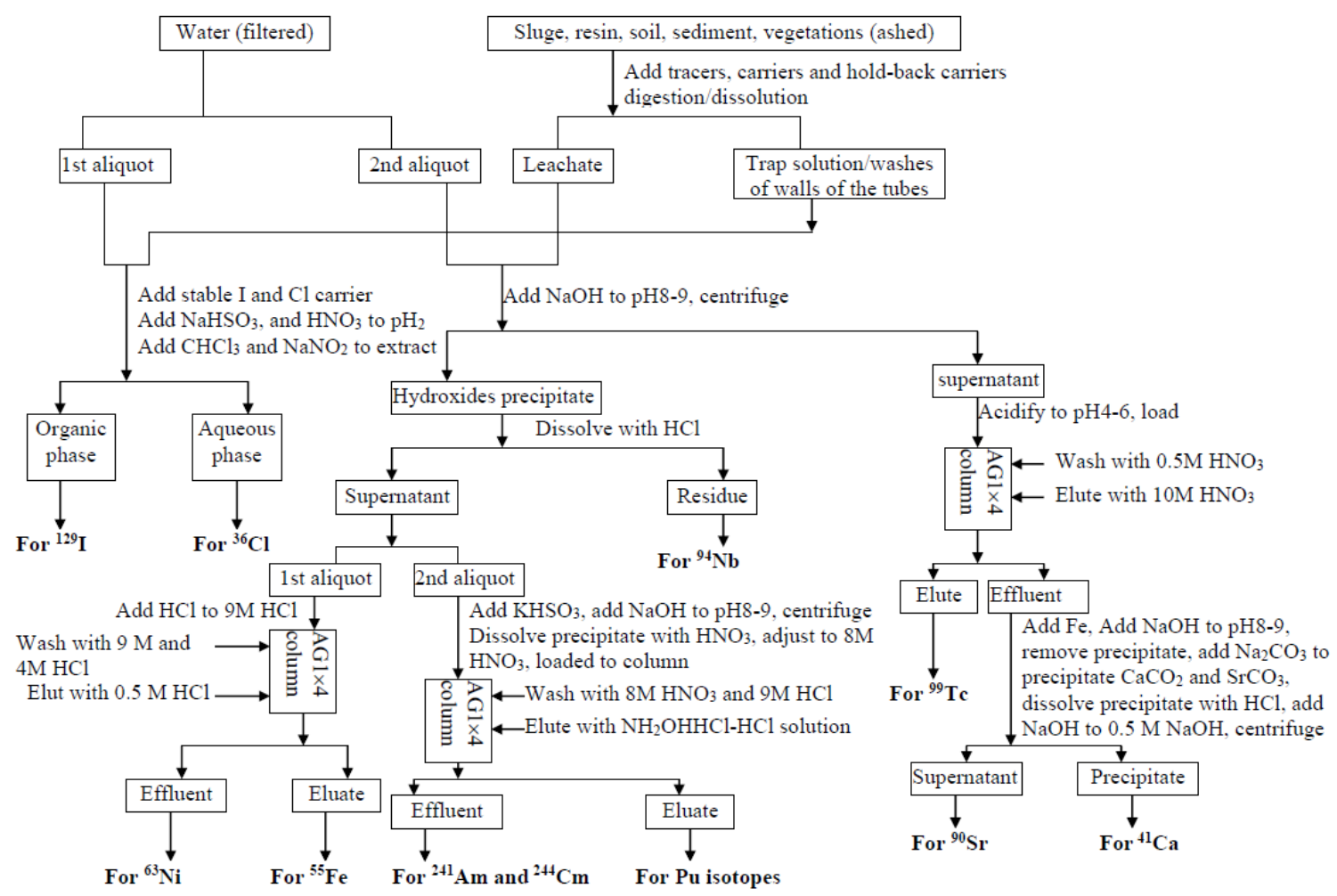

863 Fig. 15 Schematic diagram of overall separation procedure of radionuclides for 864 characterization of radioactive waste

867 Tritium and ${ }^{14} \mathrm{C}$ are major radionuclides in both contaminated or neutron activated 868 samples due to their high concentration. For water samples, tritium normally present as 869 tritated water (HTO), a simple distillation and direct measurement of tritium in the 
870 distilled water using LSC is sufficient. However, for some water, tritium is present both

871 as water and organic tritium. The organic associated tritium can be separated by active

872 charcoal adsorption first, and then tritium is determined in water form. Organic tritium

873 adsorbed on active charcoal can be determined using the same method as for solid

874 samples (see below). ${ }^{14} \mathrm{C}$ might also present as inorganic (mainly carbonate) and organic

875 associated form [47]. The organic ${ }^{14} \mathrm{C}$ can be also adsorbed on active charcoal and

876 analyzed as for solid samples (see below). While inorganic ${ }^{14} \mathrm{C}$ in the sample can be

877 separated by digestion of sample in a closed system (Fig. 16), in which gasses released

878 from the samples are adsorbed in a bubbler filled with alkaline solution (e.g. CarboSorb).

879 Acid (e.g. $\mathrm{H}_{2} \mathrm{SO}_{4}$ ) is added to the sample, and $\mathrm{N}_{2}$ flows to the sample solution, all

880 inorganic carbon is converted to $\mathrm{CO}_{2}$ and released from sample, which is trapped in

881 bubbler filled with CarboSorb, and ${ }^{14} \mathrm{C}$ in the separated samples was measured by LSC

882 after mixed with scintillation cocktail [48, 49]. A simple method was also applied to

883 measure total ${ }^{14} \mathrm{C}$ in water samples. In this method, water sample was first neutralized to

$884 \mathrm{pH} 7-8$, small amount of $\mathrm{Na}_{2} \mathrm{CO}_{3}(0.1 \mathrm{mmol})$ was spiked to the sample as carrier. The

885 sample was then evaporated to small volume $(>0.5 \mathrm{ml})$, and then transferred to a cellulose

886 pad filled with cellulose powder and analyzed as solid sample (see below).

887 A combustion method using Sample Oxidizer has been developed for determination of ${ }^{3} \mathrm{H}$

888 and ${ }^{14} \mathrm{C}$ in solid samples [49]. Solid samples in powder such as graphite, concrete, active

889 charcoal, soil, sediment, metal pieces $(<2 \mathrm{~mm})$, resin, etc. were mixed with cellulose

890 powder in a cellulose pad of about $2.5 \mathrm{ml}$, which was put into a Sample Oxidizer. In the

891 Sample Oxidizer, the sample was combusted at $1200^{\circ} \mathrm{C}$ with oxygen flow. All tritium in

892 the samples was converted to $\mathrm{H}_{2} \mathrm{O}$ vapor during combustion with oxygen, which was

893 flushed with nitrogen gas through a closed system, and condensed in an air condenser,

894 and the condensed tritiated water was collected in a LSC vial after the combustion. The

895 scintillation cocktail stored in a reservoir was used to flush the tubes and combined to the

896 vials with tritiated water. All ${ }^{14} \mathrm{C}$ in the samples including carbon, carbonate and organic

897 carbon were converted to $\mathrm{CO}_{2}$, and flowed through the system with the input $\mathrm{N}_{2} / \mathrm{O}_{2}$

898 gasses, and finally absorbed in CarboSorb (an amine solution) filled into a column. The

899 absorbed ${ }^{14} \mathrm{C}$ in the CarboSorb solution was collected in a LSC vial after the combustion, 
900 and the column was washed with a scintillation cocktail which was stored in a reservoir

901 to remove any remaining CarboSorb in the tubes, and the CarboSorb, and scintillation

902 cocktail are then directly collected in the vial and mixed. The separated tritium and ${ }^{14} \mathrm{C}$ in

903 the vials were directly measured using LSC. The whole procedure of combustion takes

904 about 2 minutes. No any suitable radioisotopes for tritium and ${ }^{14} \mathrm{C}$ can be used in this

905 procedure for monitoring the chemical yield of tritium and ${ }^{14} \mathrm{C}$ in the whole procedure.

906 Standard addition methods were used by analysis the same samples with or without spike

907 tritium (both organic tritium and tritated water) or ${ }^{14} \mathrm{C}$ (both organic and inorganic ${ }^{14} \mathrm{C}$ ),

908 the results indicate a quantitative recovery of both tritium and ${ }^{14} \mathrm{C}$ in this method [50].

\section{Determination of ${ }^{36} \mathrm{Cl}$ and ${ }^{129} \mathrm{I}$}

910 Both iodine and chlorine are volatile elements, and instable during sample treatment and

911 analysis. For water sample, solvent extraction was directly used for the separation of

912 iodine from matrix; the aqueous phase from the extraction was used for separation of ${ }^{36} \mathrm{Cl}$

913 by $\mathrm{AgCl}$ precipitate. While for solid sample, a special attention has to be given to avoid

914 loss of ${ }^{129} \mathrm{I}$ and ${ }^{36} \mathrm{Cl}$ during analysis. An acid digestion method in a closed system was

915 developed to decompose graphite, iron, aluminum, stainless steel and ion exchange resin

916 for the determination of ${ }^{129} \mathrm{I}$ and ${ }^{36} \mathrm{Cl}$ (Fig. 16). In this method, the sample was first put

917 into the flask, yield carriers (stable $\mathrm{Cl}$ and I) were added. All apparatus in the system

918 were connected and leakage was checked. Acid or mixed acids were added through the

919 funnel (No. 5) to avoid the loss of the produced gasses. Afterwards, the sample with acid

920 was heated to dissolve the sample and release iodine and chlorine to the solution.

921 Different acid or acid mixture were used depending on the sample types. It was found

922 that mixed acids of $\mathrm{H}_{2} \mathrm{SO}_{4}: \mathrm{HNO}_{3}: \mathrm{HClO}_{4}=15: 4: 1$ were effective for completely dissolve

923 graphite, $5-8 \mathrm{~mol} / 1$ of $\mathrm{H}_{2} \mathrm{SO}_{4}$ was effective for completely dissolve stainless steel and iron

924 without addition of any chlorine, while $\mathrm{HNO}_{3}$ is sufficient for dissolution of aluminum,

925 lead, copper. For soil and sediment, $\mathrm{HNO}_{3}$ can be used to leach iodine and chlorine out

926 [51]. Alkaline fusion was also used to release iodine and chlorine from soil, sediment and

927 vegetation samples [29]. For releasing iodine from ion exchange resin, $\mathrm{NaOH}$ and $\mathrm{NaClO}$

928 leaching was a simple and sufficient method. In this case, the closed digestion system

929 was not necessary, because iodine was stable in alkaline solution in the present of $\mathrm{NaClO}$. 
930 After the acid digestion of the sample, the iodine was released from the sample solution 931 and remained in the trapping solution and on the condenser walls. The trap solution and 932 washes of the tubes and condenser are combined as iodine trap solution. Solid samples 933 (soil, sediment and vegetation) decomposed by an alkali fusion method were leached 934 with water, and filtered through a filter paper. ${ }^{129} \mathrm{I}$ in the filtrate/trap solution and water 935 samples was then separated by solvent extraction.

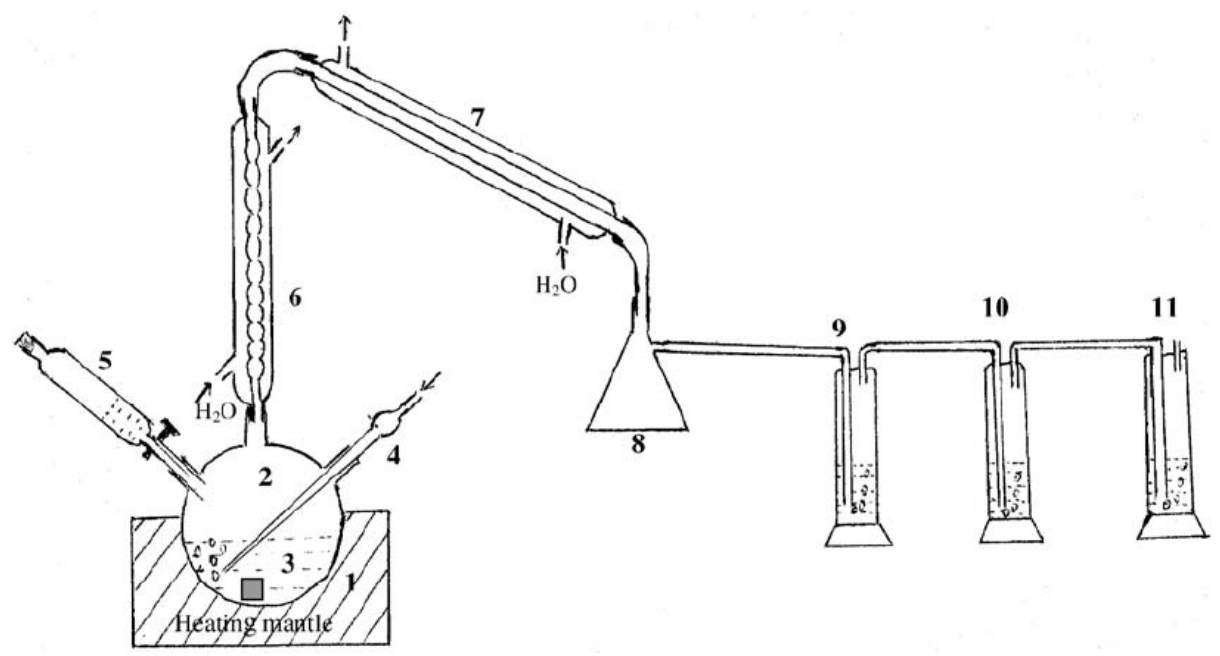

937 Fig. 16 Schematic diagram of acid digestion system for decomposition of graphite,

938 metals, concrete, soil and sediment samples. 1-Heating mantle; 2-three-neck-flask; 3-

939 sample and digestion acids; 4-bubbling tube; 5-separation funnel for adding acids; 6,7-

940 reflux cooler; 8-condenser receiver; 9-washing bottle with diluted acid; 10, 11-absorption

941 bottle with $\mathrm{NaOH}$

943 Chlorine released from the sample during the acid dissolution/digestion remained in the 944 sample solution, and small fraction on the condenser walls and diluted acid/water trap 945 solution. These solution and washes of the tubes and condenser were combined, ${ }^{36} \mathrm{Cl}$ was 946 then separated by precipitation and ion exchange methods after the separation of iodine 947 using solvent extraction. To the aqueous phase from the solvent extraction of iodine, 948 some more $\mathrm{NaNO}_{2}$ solution was added to convert all chlorine to chloride. $\mathrm{AgNO}_{3}$ was 949 then added to precipitate chloride as $\mathrm{AgCl}$, which was then separated by centrifuging. 
950 The $\mathrm{AgCl}$ precipitate was dissolved with $\mathrm{NH}_{4} \mathrm{OH}$ and then $\mathrm{Cl}^{-}$was re-precipitated as $951 \mathrm{AgCl}$ by addition of $\mathrm{HNO}_{3}$ to $\mathrm{pH} \mathrm{1-2}$. The formed $\mathrm{AgCl}$ was dissolved in $5 \mathrm{ml} \mathrm{NH} 4 \mathrm{OH}$ 952 and loaded to an anion exchange column which has been conditioned with $\mathrm{NH}_{4} \mathrm{OH}$ 953 solution. After washing with $\mathrm{NH}_{4} \mathrm{OH}$ to remove all $\mathrm{Ag}^{+}, \mathrm{Cl}^{-}$adsorbed on the column was 954 finally eluted with $\mathrm{NH}_{4} \mathrm{NO}_{3}-\mathrm{NH}_{4} \mathrm{OH}$ solution. The eluate was evaporated to dryness and 955 the residue was dissolved with 2-3 $\mathrm{ml}$ water and transferred to a vial for LSC 956 measurement of ${ }^{36} \mathrm{Cl}$ [51]. Fig. 17 shows a combined analytical procedure for 957 determination of ${ }^{129} \mathrm{I}$ and ${ }^{36} \mathrm{Cl}$ in decommissioning samples.

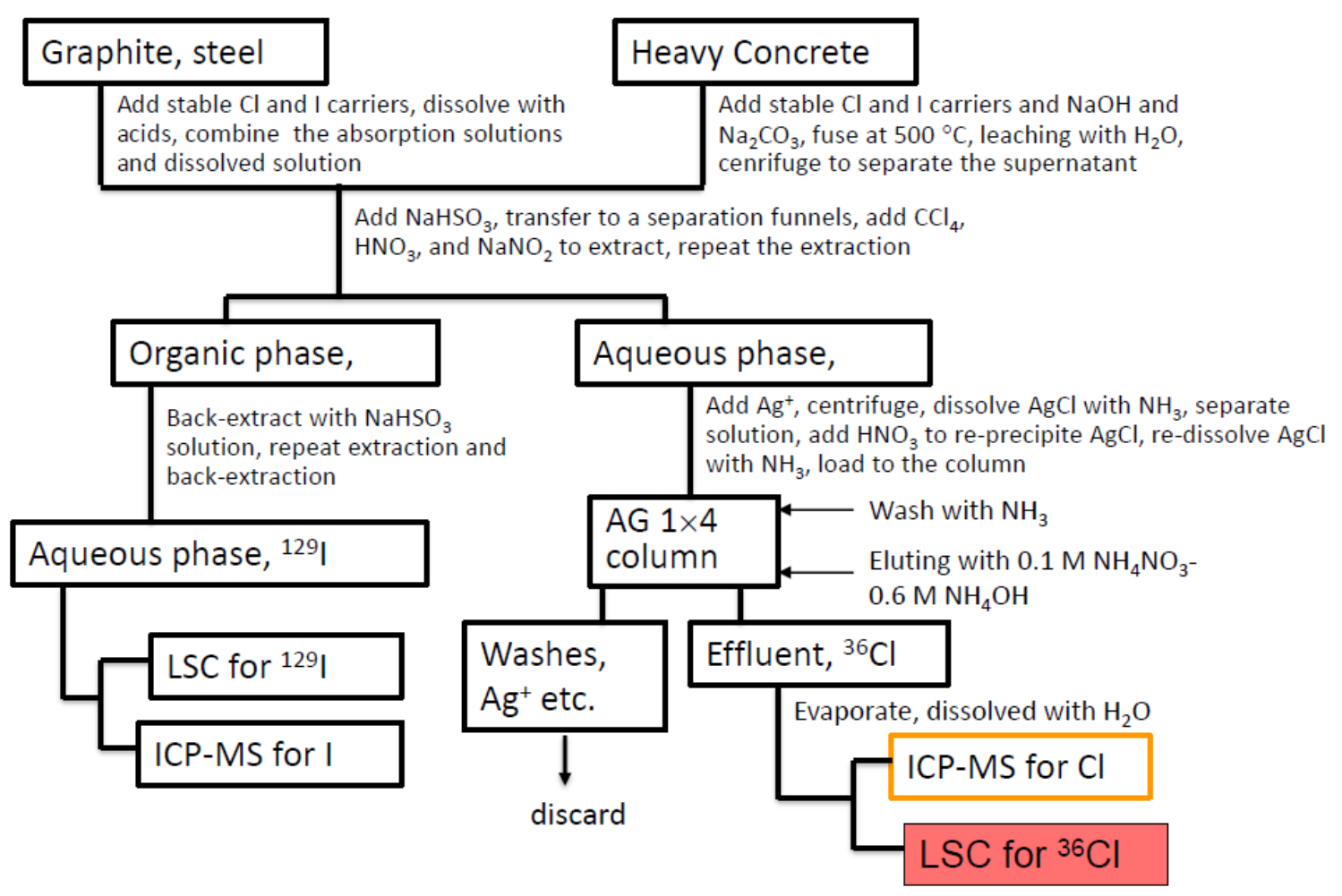

959 Fig. 17 Schematic diagram of a combined analytical procedure for the determination of $960{ }^{36} \mathrm{Cl}$ and ${ }^{129} \mathrm{I}$ in decommissioning samples

962 Determination of ${ }^{99} \mathrm{Tc}$.

963 In oxidative condition, ${ }^{99} \mathrm{Tc}$ is mainly present as $\mathrm{TcO}_{4}^{-}$, therefore can be separated from 964 matrix by anion exchange chromatography. Based on the high affinity of $\mathrm{TcO}_{4}^{-}$on anion 
965 exchange resin, ${ }^{99} \mathrm{Tc}$ was separated from most of interfering radionuclides. ${ }^{99} \mathrm{Tc}$ in water

966 or leachate of sample was first oxidized to $\mathrm{TcO}_{4}{ }^{-}$using $\mathrm{H}_{2} \mathrm{O}_{2}$, then the solution was 967 neutralized to $\mathrm{pH} 8 \mathrm{-9}$ to separate the transit metals and actinides by hydroxides

968 precipitation. The supernatant was loaded to an anion exchange column (e.g. $\mathrm{AG} 1 \times 4, \mathrm{Cl}^{-}$ 969 form) after acidified to $\mathrm{pH} 4-5$. The column was washed with $1.0 \mathrm{~mol} / \mathrm{l} \mathrm{NaOH}, \mathrm{H}_{2} \mathrm{O}$ and

$9700.5-1.0 \mathrm{~mol} / 1 \mathrm{HNO}_{3},{ }^{99} \mathrm{Tc}$ on the column was finally eluted using $10 \mathrm{~mol} / 1 \mathrm{HNO}_{3}$. The 971 eluate was evaporated to $0.5-1.0 \mathrm{ml}$ on a hotplate, and then diluted with $20 \mathrm{ml} \mathrm{H}_{2} \mathrm{O}$. The 972 prepared solution was loaded to a $2 \mathrm{ml}$ TEVA extraction chromatographic column, the 973 column is washed with $2 \mathrm{~mol} / 1 \mathrm{HNO}_{3},{ }^{99} \mathrm{Tc}$ on the column was finally eluted with 10 $974 \mathrm{~mol} / \mathrm{HNO}_{3}$. The eluate was evaporated to $0.5-1.0 \mathrm{ml}$ and diluted to $5 \mathrm{ml}$ with $\mathrm{H}_{2} \mathrm{O}$.

975 Chemical yield was measured by gamma counting of ${ }^{99 \mathrm{~m}} \mathrm{Tc}$ spiked to the sample before 976 separation, and ${ }^{99} \mathrm{Tc}$ in the separated sample solution was finally measured using ICP-MS $977[12,15]$. LSC can be also used for measurement of ${ }^{99} \mathrm{Tc}$. In this case, the eluate can be 978 evaporated to near dryness at $<100{ }^{\circ} \mathrm{C}$, and transferred to $20 \mathrm{ml}$ vial with $2-3 \mathrm{ml}$ water. 979 After addition of scintillation cocktail, ${ }^{99} \mathrm{Tc}$ can be measured using LSC. However, the 980 detection limit of ICP-MS for ${ }^{99} \mathrm{Tc}$ is generally better than LSC by more than one order of 981 magnitude [42].

\section{Determination of ${ }^{55} \mathrm{Fe}$ and ${ }^{63} \mathrm{Ni}$.}

983 Based on hydroxides precipitation, anion exchange chromatography, and extraction 984 chromatography using Ni specific resin, we have developed an analytical procedure for 985 determination of both ${ }^{55} \mathrm{Fe}$ and ${ }^{63} \mathrm{Ni}[52]$. To the water samples or leachates of solid 986 samples, stable iron (4 mg) and nickel $(2 \mathrm{mg})$ and hold-back carriers (Co, Eu, etc.) were 987 spiked, the solution was adjust to $\mathrm{pH} 8-9$ by addition of $\mathrm{NaOH}$ solution. The formed 988 hydroxides precipitate was separated by centrifuging, and afterward was dissolved in $989 \mathrm{HCl}$, and the sample solution was adjusted to $9.0 \mathrm{~mol} / \mathrm{l} \mathrm{HCl}$ by addition of concentrated $990 \mathrm{HCl}$. The prepared sample solution was loaded to an anion exchange column $\left(\mathrm{AG} 1 \times 4, \mathrm{Cl}^{-}\right.$ 991 form), the column was rinsed using $30-40 \mathrm{ml}$ of $9.0 \mathrm{~mol} / 1 \mathrm{HCl}$. The effluent and rinse 992 solution were collected for ${ }^{63} \mathrm{Ni}$ determination. The column was rinsed with $5-6 \mathrm{~mol} / 1$ $993 \mathrm{HCl}$ to remove ${ }^{60} \mathrm{Co},{ }^{58} \mathrm{Co}$ and other transition metals (e.g. $\left.\mathrm{Cu}\right) .{ }^{55} \mathrm{Fe}$ on the column was 994 eluted with $0.5 \mathrm{~mol} / \mathrm{l} \mathrm{HCl}$. The eluate was evaporated to dryness. For the sample 
995 containing high iron or radioactive cobalt, a further purification step was added. The

996 dried ${ }^{55} \mathrm{Fe}$ fraction was dissolved with $9 \mathrm{~mol} / \mathrm{l} \mathrm{HCl}$, hold-back carriers (e.g. $\mathrm{Co}^{2+}$ ) were

997 spiked. The solution was loaded to a new anion exchange column. The column was

998 rinsed with $5-6 \mathrm{~mol} / 1 \mathrm{HCl}$, and ${ }^{55} \mathrm{Fe}$ on the column was finally eluted with $0.5 \mathrm{~mol} / \mathrm{l} \mathrm{HCl}$.

999 The eluate was evaporated to dryness, and dissolved with $1 \mathrm{~mol} / 1 \mathrm{H}_{3} \mathrm{PO}_{4}$ to obtain a

1000 colorless solution (Fig. 18). The second anion exchange chromatographic purification is

1001 needed when ${ }^{60} \mathrm{Co}$ and ${ }^{58} \mathrm{Co}$ concentration are high and/or the iron content is high in the

1002 sample to get a high decontamination factors for ${ }^{58} \mathrm{Co}$ and ${ }^{60} \mathrm{Co}$. The iron in the final

1003 solution and the original solution was measured by ICP-OES to calculate the chemical

1004 yield. In this procedure, ${ }^{55} \mathrm{Fe}$ is normally quantitatively recovered, a chemical yield of

1005 more than $98 \%$ was often achieved. The remaining solution was used to measure ${ }^{55} \mathrm{Fe}$ by 1006 LSC.

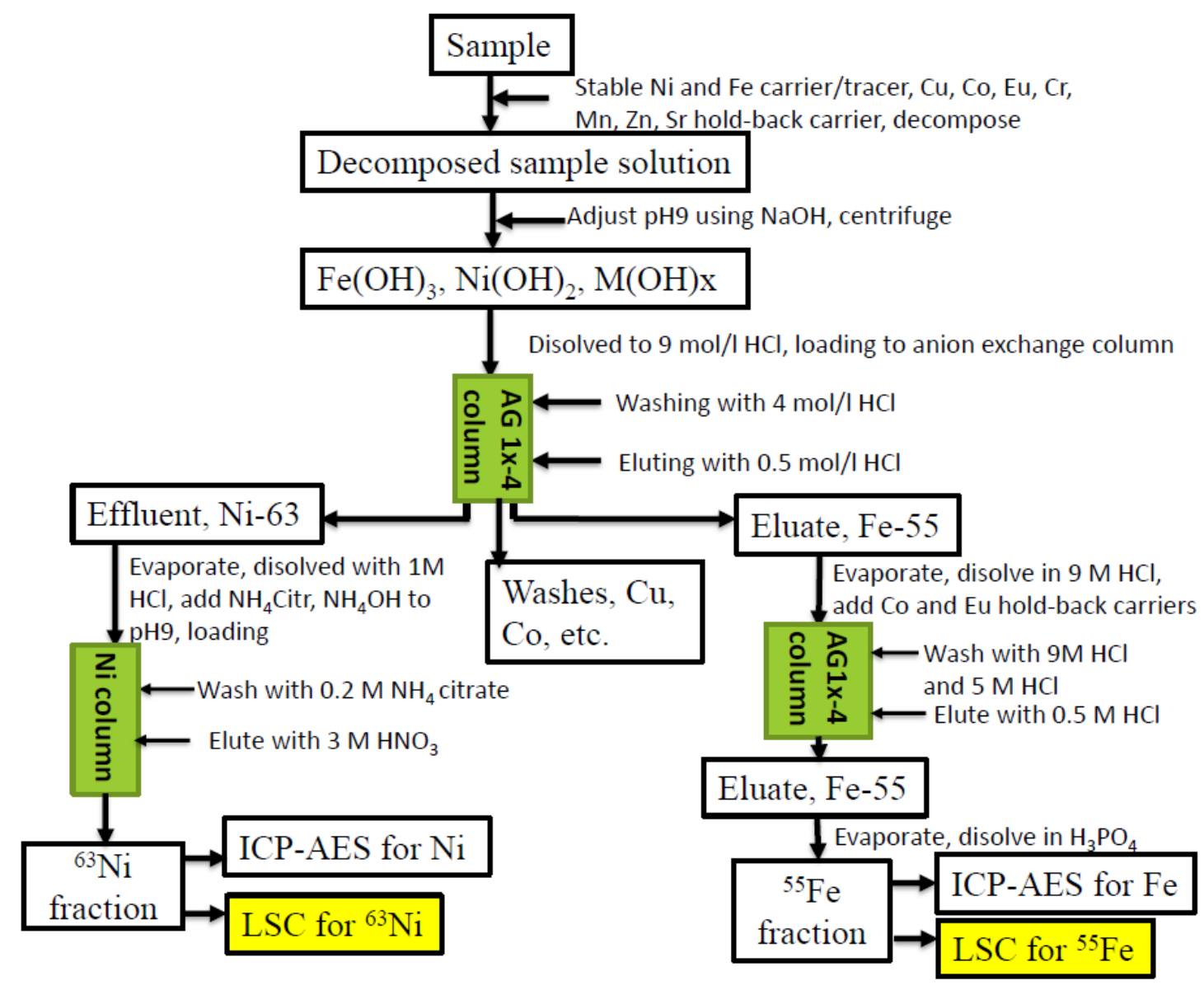

1008 Fig. 18 Diagram of analytical procedure for determination of ${ }^{55} \mathrm{Fe}$ and ${ }^{63} \mathrm{Ni}$ 
1009 It should be mentioned, application of $\mathrm{H}_{3} \mathrm{PO}_{4}$ to dissolve $\mathrm{Fe}(\mathrm{OH})_{3}$ or $\mathrm{Fe}_{2} \mathrm{O}_{3}$ is important, 1010 otherwise a high quench color (yellow/brown) solution is obtained, causing a low LSC 1011 counting efficiency of ${ }^{55} \mathrm{Fe} . \mathrm{H}_{3} \mathrm{PO}_{4}$ can not only dissolve $\mathrm{Fe}(\mathrm{OH})_{3}$ and $\mathrm{Fe}_{2} \mathrm{O}_{3}$, but also 1012 form a colorless solution of complex of iron with $\mathrm{H}_{3} \mathrm{PO}_{4}$, Fig. 19 shows quench curve of $1013{ }^{55} \mathrm{Fe}$ in different amount of $\mathrm{Fe}$ solution and at different media $\left(\mathrm{FeCl}_{3}, \mathrm{Fe}-\mathrm{H}_{3} \mathrm{PO}_{4}\right.$ or $1014 \mathrm{FeSO}_{4}$ ), a significantly improved quench level and high counting efficiency of ${ }^{55} \mathrm{Fe}$ was 1015 achieved by using $\mathrm{H}_{3} \mathrm{PO}_{4}$.
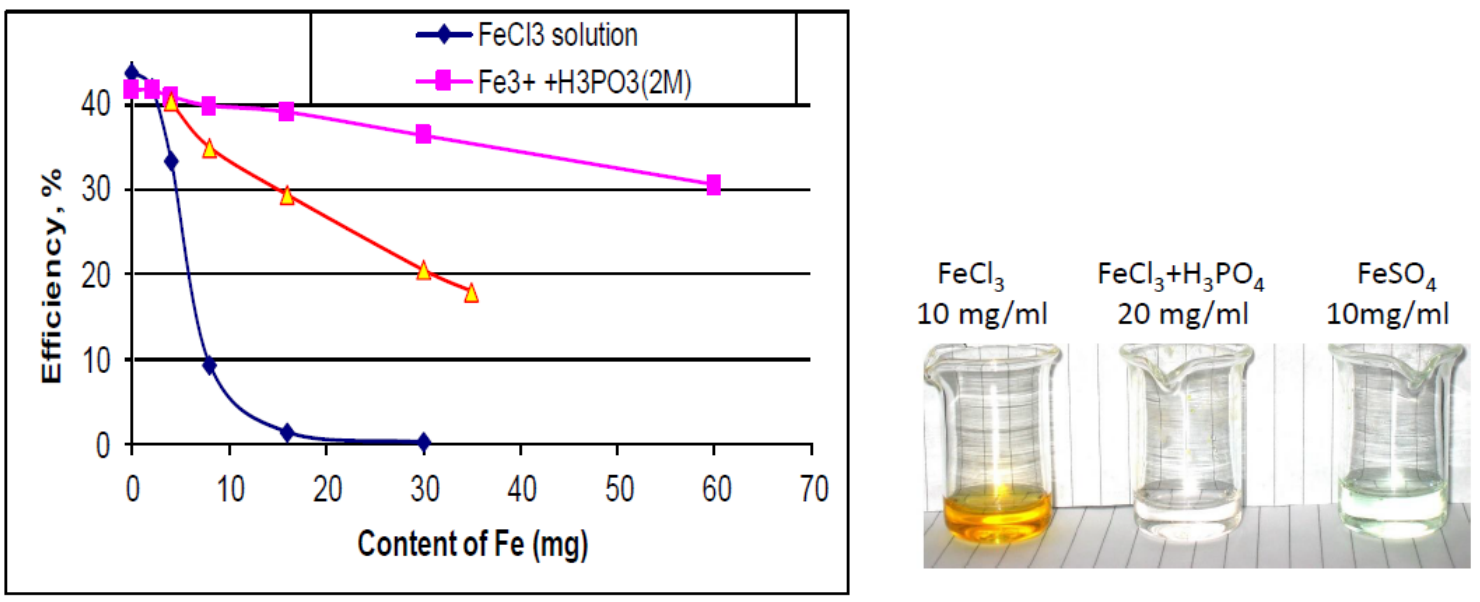

1017 Fig. 19 Quench curves of ${ }^{55} \mathrm{Fe}$ in different media against the iron content in the sample.

1019 For the separation of nickel, a specific extraction resin based on dimethylglyoxime 1020 (DMG) as function group was used. Nickel can form a stable complex with DMG, $\mathrm{Ni}^{2+}$ 1021 loaded to the Ni-resin column can be adsorbed on the resin. However, other transition 1022 metal ions (e.g. $\mathrm{Fe}^{3+}, \mathrm{Co}^{2+}, \mathrm{Cu}^{2+}$, etc.) can also form complexes to be adsorbed on the 1023 column. Because the complex of other transition metal with DMG are not stable, which 1024 can be removed by rinsing. For obtaining a better decontamination factor for some high 1025 radioactive radionuclides (e.g. ${ }^{60} \mathrm{Co},{ }^{58} \mathrm{Co}$ ), a further separation of these transition metals 1026 is necessary. Therefore, ${ }^{63} \mathrm{Ni}$ was first separated from many other transition metals using 1027 anion exchange chromatography, most of ${ }^{60} \mathrm{Co}$ and ${ }^{58} \mathrm{Co}\left(\mathrm{DF}>10^{3}\right)$ can be removed in this 1028 step. However, rare earth elements could not form anions in $\mathrm{HCl}$ solution and entered the 
1029 effluence with Ni. Since rare earth elements could not form complex with DMG, they

1030 could be well removed in the Ni-resin extraction chromatographic separation step. The

1031 effluent from the anion exchange column was evaporated to dryness, the residue was

1032 dissolved using $1.0 \mathrm{~mol} / 1 \mathrm{HCl} .1-2 \mathrm{ml}$ of $1 \mathrm{~mol} / \mathrm{l}$ ammonium citrate (depending on the

1033 amount of residue) was added to the solution to complex most of metals. Then ammonia

1034 solution was added to the solution to $\mathrm{pH} 8-9$. The prepared sample solution was then

1035 loaded to an extraction chromatographic column (Eichrom Ni-column, $2 \mathrm{ml}$ ). The column

1036 was rinsed with $0.2 \mathrm{~mol} / \mathrm{l}$ ammonium citrate at $\mathrm{pH} 9$ to remove all possible interfering

1037 radionuclides. $\mathrm{Ni}$ adsorbed on the column (red band) was finally eluted using $3.0 \mathrm{~mol} / \mathrm{l}$

$1038 \mathrm{HNO}_{3}$. The eluate was evaporated to $0.1-0.3 \mathrm{ml}$ on a hotplate, and transferred to a vial

1039 with $2 \mathrm{ml}$ water. $0.1 \mathrm{ml}$ of the final solution, as well as the original solution, were taken

1040 for the determination of Ni using ICP-OES for the chemical yield measurement. It was

1041 observed that nickel can be quantitatively recovered in this procedure with a chemical

1042 yield of $>98 \%$. ${ }^{63} \mathrm{Ni}$ in the remaining solution was measured by LSC [52]. The pre-

1043 separation of nickel from iron and cobalt was confirmed very necessary for the samples

1044 with high ${ }^{60} \mathrm{Co}$ and ${ }^{58} \mathrm{Co}$, because the decontamination factor of Ni-column is not

1045 sufficient high to remove all radioactive isotopes of cobalt, which can cause a high 1046 interference in the measurement of ${ }^{63} \mathrm{Ni}[53]$.

\section{Determination of ${ }^{41} \mathrm{Ca}$ and ${ }^{90} \mathrm{Sr}$.}

1049 Calcium-41 is a long-lived $\left(1.3 \times 10^{5}\right.$ years $)$ radionuclide decaying by electron capture, 1050 without any gamma or beta rays emission. LSC is the most suitable method for its 1051 measurement by counting its low-energy Auger electrons. ${ }^{41} \mathrm{Ca}$ is a neutron activation 1052 product, mainly produced in concrete biological shield, which contains high 1053 concentration of calcium and is exposed to neutrons. ${ }^{90} \mathrm{Sr}$ is one of the important fission 1054 products because of its high fission yield, and therefore an important radionuclide in the 1055 decommissioning of nuclear facilities. ${ }^{90} \mathrm{Sr}$ is a pure beta emitter, and therefore needs to 1056 be separated from all other radionuclides before measurement, especially from 1057 radioisotopes of alkaline earth metals (e.g. ${ }^{131} \mathrm{Ba},{ }^{228,}{ }^{226} \mathrm{Ra}$ ). In some heavy concrete used 
1058 in nuclear reactors, $\mathrm{BaSO}_{4}$ was added to obtain a better shield of radiation, the separation 1059 of ${ }^{131} \mathrm{Ba}$ is one of major challenge in the analysis of such type of samples. We have 1060 developed a simple precipitation method for separation of calcium from matrix and 1061 interfering radionuclides, as well as to separate calcium from strontium [54]. In this 1062 method, calcium and strontium were first released from concrete to solution. Both acid 1063 leaching and alkaline fusion were investigated, and found acid leaching using aquia regia 1064 can release almost all calcium and strontium from concrete, and more simple compared to 1065 alkaline fusion. Meanwhile, most of $\mathrm{BaSO}_{4}$ can be removed because of its insolubility in 1066 acid solution. $\mathrm{Sr}^{2+}$ and $\mathrm{Ca}^{2+}$ carriers, $\mathrm{Fe}^{3+}$ hold back carrier and ${ }^{85} \mathrm{Sr}$ tracer were added to 1067 the sample before separation. The leachate was then neutralized to $\mathrm{pH} 8-9$, all transit 1068 metals (e.g. Fe, Co, Eu, etc.) and actinides were precipitated and removed from calcium 1069 and strontium. The supernatant containing calcium and strontium was used for further 1070 separation of ${ }^{41} \mathrm{Ca}$ and ${ }^{90} \mathrm{Sr}$.

$1071 \mathrm{Na}_{2} \mathrm{CO}_{3}$ solution was added to the supernatant, which was heated to $95{ }^{\circ} \mathrm{C}$ and keeping 1072 for 1 hour. The formed precipitate of $\mathrm{Ca}$ and $\mathrm{Sr}$ as carbonate was separated by centrifuge. 1073 The precipitate was dissolved with $\mathrm{HCl}$, and $2 \mathrm{mg} \mathrm{of} \mathrm{Fe}^{3+}, \mathrm{Co}^{2+}$, and $\mathrm{Eu}^{3+}$ were added, 1074 and then the $\mathrm{NaOH}$ was added to adjust $\mathrm{pH}$ to 8-9. The $\mathrm{Fe}(\mathrm{OH})_{3}$ precipitate was removed 1075 by centrifuging, $6 \mathrm{~mol} / 1 \mathrm{NaOH}$ was added to the supernatant to $0.5 \mathrm{~mol} / \mathrm{l} \mathrm{NaOH}$, and the 1076 precipitate of $\mathrm{Ca}(\mathrm{OH})_{2}$ was separated by centrifuging. The supernatant was used for the 1077 separation of ${ }^{90} \mathrm{Sr}$. The $\mathrm{Ca}(\mathrm{OH})_{2}$ precipitate was dissolved with $\mathrm{HCl}, 2 \mathrm{mg}$ of $\mathrm{Fe}^{3+} . \mathrm{Co}^{2+}$ 1078 and $\mathrm{Eu}^{3+}$ were added and $\mathrm{pH}$ adjusted to 8-9 using $\mathrm{NaOH}$ again. The precipitate was 1079 removed by centrifuge, and $6 \mathrm{~mol} / \mathrm{l} \mathrm{NaOH}$ was added to the supernatant to $0.5 \mathrm{~mol} / 1$ of $1080 \mathrm{NaOH} . \mathrm{Ca}(\mathrm{OH})_{2}$ precipitate was then separated by centrifuging. This dissolution and 1081 precipitation step were repeated. The final obtained $\mathrm{Ca}(\mathrm{OH})_{2}$ precipitate was dissolved 1082 using $\mathrm{HCl}$. The chemical yield was measured by determination of stable calcium in the 1083 final solution and the solution before separation. ${ }^{41} \mathrm{Ca}$ in the final solution was measured 1084 by LSC counting [54]. An overall recovery of more than $85 \%$ was obtained, and 1085 decontamination factors to all interfering radionuclides were more than $5 \times 10^{4}$. Fig. 20 1086 shows the analytical procedure for ${ }^{41} \mathrm{Ca}$ in concrete.

1087 To the supernatant from the first $\mathrm{Ca}(\mathrm{OH})_{2}$ precipitation step, $\mathrm{HCl}$ is added to adjust $\mathrm{pH} 2$. 1088 The chemical yield of strontium was measured by gamma counting of ${ }^{85} \mathrm{Sr}$ in the 
1089 solution. After addition of $\mathrm{Y}^{3+}$ carrier, the solution was kept 3 weeks for in-growth of $1090{ }^{90} \mathrm{Y}$. Afterwards, $\mathrm{Na}_{2} \mathrm{SO}_{4}$ was then added to precipitate $\mathrm{Sr}$ as well as $\mathrm{Ra}$, and $\mathrm{Ba}$ as 1091 sulphate. ${ }^{90} \mathrm{Y}$ ingrown from ${ }^{90} \mathrm{Sr}$ and remained in the supernatant was then separated by $1092 \mathrm{Y}(\mathrm{OH})_{3}$ precipitation after addition $\mathrm{NH}_{4} \mathrm{OH}$ to $\mathrm{pH}$ to $8-9$ and centrifuging. The 1093 precipitate was then dissolved using $\mathrm{HCl}, \mathrm{H}_{2} \mathrm{C}_{2} \mathrm{O}_{4}$ was added to the solution to precipitate 1094 yttrium as $\mathrm{Y}_{2}\left(\mathrm{C}_{2} \mathrm{O}_{4}\right)_{3}$, and the chemical yield of ${ }^{90} \mathrm{Y}$ was measured by weighing the dried $1095 \mathrm{Y}_{2}\left(\mathrm{C}_{2} \mathrm{O}_{4}\right)_{3}$ precipitate or by ICP-OES after ${ }^{90} \mathrm{Y}$ measurement. ${ }^{90} \mathrm{Y}$ in the precipitate was 1096 measured by beta counting using a low background GM counter (Risø Multi-counter), $1097{ }^{90} \mathrm{Sr}$ in the samples was calculated from the measured ${ }^{90} \mathrm{Y}$ with correction for chemical 1098 yield of strontium and yttrium, as well as the in-growth time of ${ }^{90} \mathrm{Y}$ from ${ }^{90} \mathrm{Sr}$ [10].
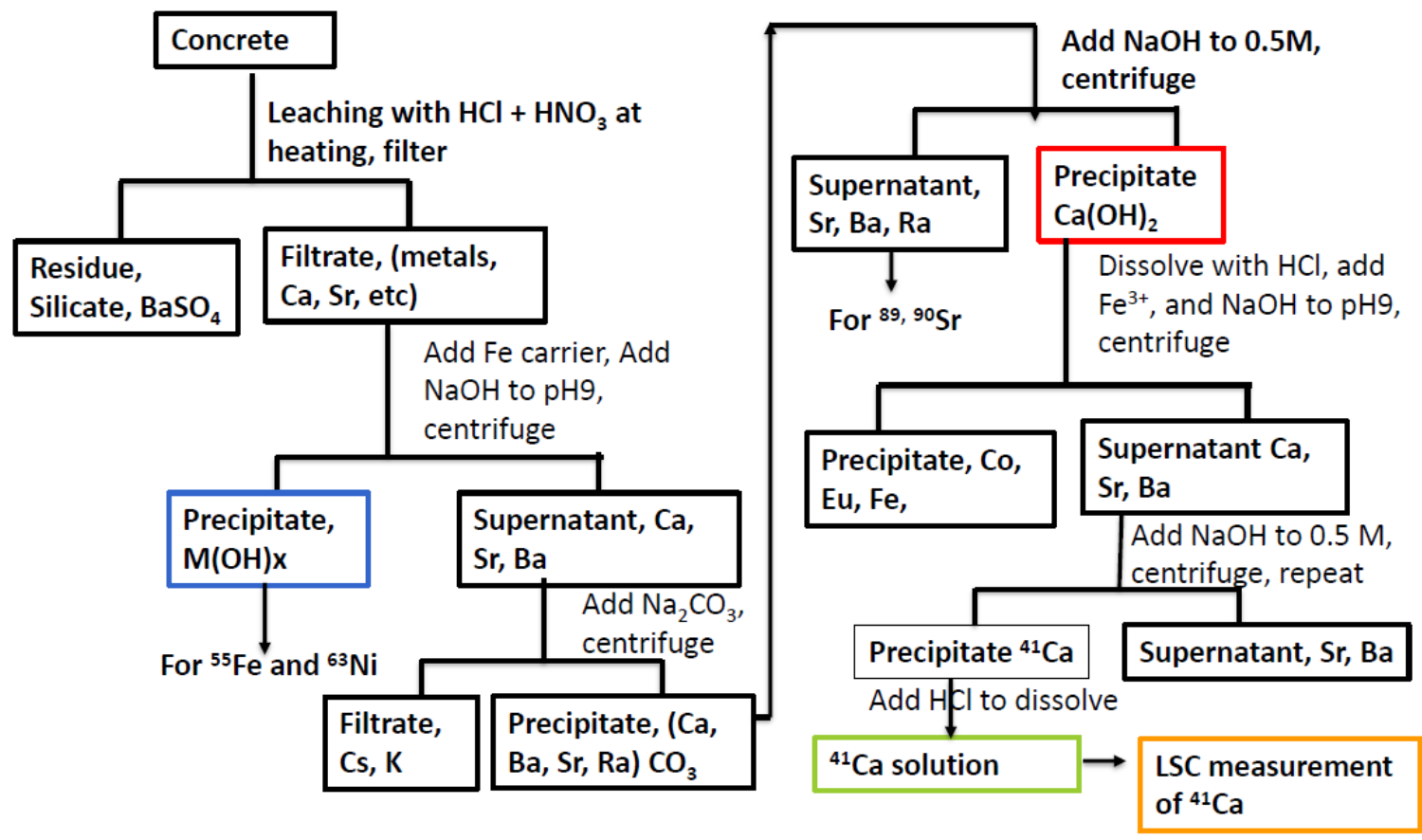

1101 Fig. 20 Schematic diagram of analytical procedure for ${ }^{41} \mathrm{Ca}$ 
1104 The major isotopes of plutonium in the environment and decommissioning waste are

$1105{ }^{238} \mathrm{Pu}{ }^{239} \mathrm{Pu},{ }^{240} \mathrm{Pu}$ and ${ }^{241} \mathrm{Pu}$, they are the important alpha and beta emitters and have to be 1106 determined in the decommissioning of nuclear facilities. Separation of plutonium mainly 1107 relies on the formation of anion complexes of $\mathrm{Pu}^{4+}$ with $\mathrm{NO}_{3}^{-}$and $\mathrm{Cl}^{-}$in high 1108 concentration of $\mathrm{HNO}_{3}$ or $\mathrm{HCl}$, and no such anion is formed for $\mathrm{Pu}^{3+}$, and less anion 1109 complexes of other valence sates of plutonium are formed in $\mathrm{HCl}$ and $\mathrm{HNO}_{3}$. Therefore, 1110 adjustment of valence state of plutonium is critical in the separation of plutonium. For 1111 acidified water sample or acid leachate of samples, ${ }^{242} \mathrm{Pu}$ and ${ }^{243} \mathrm{Am}$ as yield tracers and $1112 \mathrm{Fe}^{3+}$ as carrier were spiked. $\mathrm{NaOH}$ was then added to adjust $\mathrm{pH} 8-9$ to separate plutonium 1113 as co-precipitate with $\mathrm{Fe}(\mathrm{OH})_{3}$. The co-precipitate was dissolved with $\mathrm{HCl}$, and $\mathrm{KHSO}_{3}$ 1114 solution was added to reduce plutonium to $\mathrm{Pu}^{3+}$, then $\mathrm{NaOH}$ was added to adjust $\mathrm{pH}$ to 811159 to precipitate $\mathrm{Pu}(\mathrm{OH})_{3}$ with $\mathrm{Fe}(\mathrm{OH})_{2}$. The precipitate was dissolved with concentrated $1116 \mathrm{HCl}$, and then concentrated $\mathrm{HNO}_{3}$ was added, $\mathrm{Pu}^{3+}$ was oxidized to $\mathrm{Pu}^{4+}$ by $\mathrm{NO}_{2}{ }^{-}$in the 1117 concentrated $\mathrm{HNO}_{3}$. The sample solution was prepared in $8 \mathrm{~mol} / \mathrm{L} \mathrm{HNO}_{3}$ medium and 1118 loaded to an anion exchange column ( $\mathrm{AG} 1 \times 4, \mathrm{Cl}^{-}$form). The column was rinsed with 8 $1119 \mathrm{~mol} / 1 \mathrm{HNO}_{3}$, the effluent and washes were combined and collected for the determination 1120 of ${ }^{241} \mathrm{Am}$ and ${ }^{242,}{ }^{244} \mathrm{Cm}$. The column was rinsed with $9 \mathrm{~mol} / \mathrm{l} \mathrm{HCl}$, and plutonium 1121 adsorbed on the column was finally eluted using $0.05 \mathrm{~mol} / 1 \mathrm{NH}_{2} \mathrm{OH} \cdot \mathrm{HCl}-2 \mathrm{M} \mathrm{HCl}$ 1122 solution. In this case, $\mathrm{Pu}^{4+}$ on the column was reduced to $\mathrm{Pu}^{3+}$, which could not form 1123 anion complex and eluted from the column. The eluate was evaporated to dryness, 1124 concentrated $\mathrm{HNO}_{3}$ was added and heated to decompose the $\mathrm{NH}_{2} \mathrm{OH} \cdot \mathrm{HCl}$, and the 1125 solution was evaporated to dryness again. The residue was dissolved with $0.5 \mathrm{~mol} / 1$ $1126 \mathrm{HNO}_{3}$, one aliquot was used for ICP-MS measurement of ${ }^{239} \mathrm{Pu},{ }^{240} \mathrm{Pu}$ and ${ }^{241} \mathrm{Pu}$, another 1127 aliquot was evaporated to dryness again and dissolved with $0.5 \mathrm{~mol} / 1 \mathrm{H}_{2} \mathrm{SO}_{4}$ for alpha 1128 spectrometry measurement of ${ }^{238} \mathrm{Pu}$ after electrodeposition on a stainless steel disk [14, 1129 55]. With this procedure, a high chemical yield up to 98\% could be obtained.

$1130{ }^{241} \mathrm{Am}$ and ${ }^{243,244} \mathrm{Cm}$ are the major radioisotopes of americium and curium in the 1131 decommissioning waste due to their relative long half-lives and high production in the 1132 nuclear reactors. The chemical properties of americium and curium are similar, and 1133 therefore could be separated together. The energies of alpha particles of ${ }^{243} \mathrm{Cm}$ and ${ }^{244} \mathrm{Cm}$ 1134 are too close to be discriminated in the alpha spectrometry, and therefore were measured 
1135 together and reported as ${ }^{243} \mathrm{Cm}+{ }^{244} \mathrm{Cm}\left({ }^{243,244} \mathrm{Cm}\right)$. Americium and curium are often 1136 presented as $\mathrm{Am}^{3+}$ and $\mathrm{Cm}^{3+}$, they cannot form anion complexes with $\mathrm{HNO}_{3}$ and $\mathrm{HCl}$ in 1137 aqueous solution due to the small ion radius and strongly bound water molecules, but 1138 could form anion complexes in non-aqueous media. To the effluent from the ion 1139 exchange separation of $\mathrm{Pu}, \mathrm{Fe}^{3+}$ was added, and $\mathrm{NH}_{3}$ was added to $\mathrm{pH} 8-9$ to form co1140 precipitates of $\mathrm{Am}$ and $\mathrm{Cm}$ hydroxides with $\mathrm{Fe}(\mathrm{OH})_{3}$. The precipitate was dissolved 1141 using concentrated $\mathrm{HNO}_{3} .30 \% \mathrm{H}_{2} \mathrm{O}_{2}$ was added and the solution stirred for 2 minutes. $1142 \mathrm{CH}_{3} \mathrm{OH}$ was added to the solution to prepare the sample in $93 \% \mathrm{CH}_{3} \mathrm{OH}-1.0 \mathrm{~mol} / 1 \mathrm{HNO}_{3}$ 1143 solution. The solution was then loaded to an anion exchange column ( $\mathrm{AG} 1 \times 4, \mathrm{Cl}^{-}$form). 1144 The column was rinsed with $1.0 \mathrm{~mol} / 1 \mathrm{HNO}_{3}-93 \% \mathrm{CH}_{3} \mathrm{OH}$ and $0.1 \mathrm{~mol} / 1 \mathrm{HCl}-0.5 \mathrm{~mol} / 1$ $1145 \mathrm{NH}_{4} \mathrm{SCN}-80 \% \mathrm{CH}_{3} \mathrm{OH}$, followed by $1.0 \mathrm{~mol} / 1 \mathrm{HNO}_{3}-93 \% \mathrm{CH}_{3} \mathrm{OH}$ to remove interfering 1146 radionuclides and lanthanides. Am and $\mathrm{Cm}$ on the column were finally eluted using 1.5 $1147 \mathrm{~mol} / 1 \mathrm{HCl}-86 \% \mathrm{CH}_{3} \mathrm{OH}$ solution. The eluate was evaporated to dryness, concentrated $1148 \mathrm{HNO}_{3}$ was added to the residue and digested for $30 \mathrm{~min}$ on a hotplate and then 1149 evaporated to dryness. The residue was dissolved with $10 \mathrm{ml}$ of $0.05 \mathrm{M} \mathrm{H}_{2} \mathrm{SO}_{4}$, and the 1150 solution was transferred to an electrodeposition cell to electrodeposit $\mathrm{Am}$ and $\mathrm{Cm}$ on a 1151 stainless steel disk. ${ }^{241} \mathrm{Am}$ and ${ }^{244} \mathrm{Cm}$ on the disc were finally measured by alpha 1152 spectrometry. ${ }^{243} \mathrm{Am}$ on the disc was also measured and used as chemical yield tracer for 1153 correction of the measured concentration of ${ }^{241} \mathrm{Am}$ and ${ }^{234,244} \mathrm{Cm}[14]$

1154 A new analytical procedure using extraction chromatography was developed in our lab 1155 for separation of plutonium, americium and curium in the nuclear waste samples (Fig. 1156 21). The sample solution was first acidified using $\mathrm{HCl},{ }^{242} \mathrm{Pu}$ and ${ }^{243} \mathrm{Am}$ tracers, $\mathrm{Fe}^{3+}$ 1157 carriers were spiked, and then $\mathrm{NaHSO}_{3}$ was added to reduce plutonium to $\mathrm{Pu}^{3+} . \mathrm{NaOH}$ 1158 was added to the sample solution to adjust $\mathrm{pH} 8-9$ to co-precipitate $\mathrm{Pu}^{3+}, \mathrm{Am}^{3+}$ and $\mathrm{Cm}^{3+}$ 1159 hydroxides with $\mathrm{Fe}(\mathrm{OH})_{2}$. The precipitate was dissolved with $\mathrm{HCl}$ and concentrated $1160 \mathrm{HNO}_{3}$ was added to oxidize $\mathrm{Pu}^{3+}$ to $\mathrm{Pu}^{4+}$. The sample solution was prepared in $4 \mathrm{~mol} / 1$ $1161 \mathrm{HNO}_{3}$ medium, and loaded to two sequential connected columns of TEVA and DGA, the 1162 columns were then rinsed with $4 \mathrm{~mol} / 1 \mathrm{HNO}_{3} \cdot \mathrm{Pu}\left(\mathrm{NO}_{3}\right)_{2}{ }^{-}$was adsorbed on TEVA 1163 column, while $\mathrm{Am}^{3+}$ and $\mathrm{Cm}^{3+}$ passed through the TEVA column, and adsorbed on DGA 1164 column by forming complex with the functional group of tetra-n-octyldiglycolamide on 
1165 the DGA column. Afterwards, the two columns were disconnected, TEVA column was 1166 used for separation of plutonium, and DGA column was used for separation Am and Cm.

1167 The TEVA column was rinsed with $6 \mathrm{~mol} / 1 \mathrm{HCl}$, and plutonium on the column was then 1168 eluted using $0.5 \mathrm{~mol} / 1 \mathrm{NH}_{2} \mathrm{OH} \cdot \mathrm{HCl}-2 \mathrm{~mol} / \mathrm{l} \mathrm{HCl}$ solution. The DGA column was rinsed 1169 with $0.2 \mathrm{~mol} / 1 \mathrm{HCl}$, and $\mathrm{Am}$ and $\mathrm{Cm}$ were eluted using $0.5 \mathrm{M} \mathrm{HCl}$. The separated 1170 plutonium and $\mathrm{Am}+\mathrm{Cm}$ fractions were prepared using the same method described above 1171 for the determination of plutonium isotopes using ICP-MS and alpha spectrometry for $1172{ }^{238} \mathrm{Pu},{ }^{241} \mathrm{Am}$, and ${ }^{2433}{ }^{244} \mathrm{Cm}$.

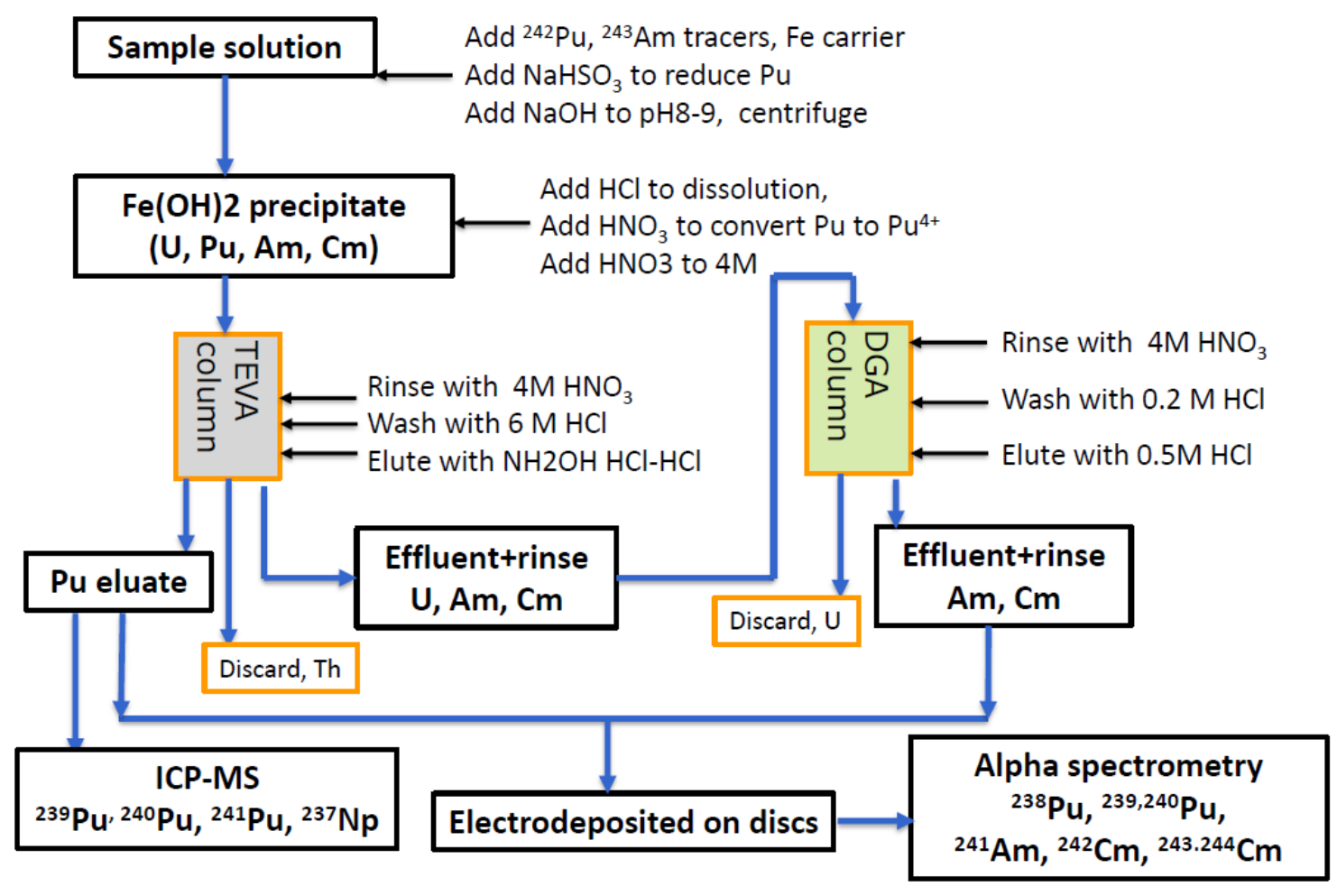

1175 Fig. 21 Schematic diagram of analytical procedure for determination of isotopes of 1176 plutonium, americium and curium using extraction chromatography 
1179 In our laboratory, the methods for the determination of ${ }^{93} \mathrm{Mo}$, ${ }^{94} \mathrm{Nb}$, and ${ }^{135} \mathrm{Cs}$ in the 1180 decommissioning wastes were also developed, and the methods for the determination of 1181 other radionuclides, such as ${ }^{79} \mathrm{Se},{ }^{93} \mathrm{Zr},{ }^{126} \mathrm{Sn}$, and ${ }^{151} \mathrm{Sm}$ are under development. Although 1182 the concentrations of these radionuclides are very low in most of decommissioning waste, 1183 but their long half-lives make them also important in view of waste repository.

1184 The separation of ${ }^{93} \mathrm{Mo}$ and ${ }^{94} \mathrm{Nb}$ was implemented using ion exchange chromatography 1185 followed by a purification using alumina column. After spiked the yield tracers of stable $1186 \mathrm{Mo}, \mathrm{Nb}$ and $\mathrm{Zr}$ and hold-back carriers, such as stable $\mathrm{Co}$, $\mathrm{Ni}$ and $\mathrm{Eu}$, the sample was 1187 prepared in $0.02 \mathrm{~mol} / \mathrm{l} \mathrm{HF}$ and loaded to a strong acidic cation exchange chromatographic 1188 column. $\mathrm{Mo}, \mathrm{Zr}$ and $\mathrm{Nb}$ present as anions $\mathrm{MoO}_{4}{ }^{2-}, \mathrm{ZrF}_{6}{ }^{2-}$ or $\mathrm{NbF}_{6}-$ passed through the 1189 column, while cations including transition metals, alkali and alkaline earth metals were 1190 adsorbed on the column and removed. The effluent from the column was then loaded to a 1191 TEVA column, $\mathrm{MoO}_{4}{ }^{2-}, \mathrm{ZrF}_{6}{ }^{2-}$ and $\mathrm{NbF}_{6}-$ were adsorbed on the column. After rinsing 1192 with $0.02 \mathrm{~mol} / 1 \mathrm{HF}$ solution, $\mathrm{Zr}$ was first eluted using $7 \mathrm{~mol} / 1 \mathrm{HCl}-0.5 \mathrm{~mol} / 1 \mathrm{HF}$ solution, 1193 Mo was eluted with $4 \mathrm{~mol} / \mathrm{l} \mathrm{HF}$ solution, and $\mathrm{Nb}$ was eluted with $1 \mathrm{~mol} / 1 \mathrm{HNO}_{3}$ solution.

1194 The $\mathrm{Nb}$ fraction was directly used for measurement of ${ }^{94} \mathrm{Nb}$ by gamma spectrometry after 1195 evaporated to $<5 \mathrm{ml}$. $\mathrm{Zr}$ fraction can be used for determination of ${ }^{93} \mathrm{Zr}$ after a further 1196 purification. The Mo fraction was evaporated to dryness and converted to $\mathrm{HNO}_{3}$ medium 1197 by addition of $\mathrm{HNO}_{3}$ and evaporated to dryness, and the residue was dissolved in 1.0 $1198 \mathrm{~mol} / 1 \mathrm{HNO}_{3}$ solution. The prepared solution was then loaded to an alumina column, after 1199 rinsing the column with $1.0 \mathrm{~mol} / 1 \mathrm{HNO}_{3}, 0.1 \mathrm{~mol} / 1 \mathrm{HNO}_{3}$, water and $0.01 \mathrm{~mol} / 1 \mathrm{ammonia}$. $1200 \mathrm{MoO}_{4}{ }^{2-}$ adsorbed on the column was finally eluted with $25 \%$ ammonium. The eluate was 1201 evaporated to dryness and the residue was dissolved in water, which was transferred to a $120220 \mathrm{ml}$ vial for LSC measurement of ${ }^{93} \mathrm{Mo}$. The chemical yield was obtained by 1203 measurement of stable $\mathrm{Mo}$ and $\mathrm{Nb}$ in the separation sample and the spiked sample 1204 solution using ICP-OES.

1205 For the determination of ${ }^{135} \mathrm{Cs}$, the sample solution was prepared in a neutral or slight 1206 acidic medium. Ammonium molybdophosphate (AMP) powder was added and mixed 1207 with the sample solution, AMP powder adsorbed cesium was separated by filtration. 1208 Cesium on the AMP powder was then leached out with $5 \mathrm{~mol} / 1 \mathrm{NH}_{4} \mathrm{Cl}$ solution. By this 
1209 way, most of radionuclides can be removed because of the specific adsorption of cesium 1210 on the AMP powder. The leachate was then loaded to a cation exchange chromatographic 1211 column (e.g. Bio-Rad AG $1 \times-50), \mathrm{Cs}^{+}$was adsorbed on the column. After rinsing with $1212 \mathrm{H}_{2} \mathrm{O}$ and $0.1 \mathrm{~mol} / 1 \mathrm{HNO}_{3}, \mathrm{Cs}^{+}$was eluted with $1.0 \mathrm{~mol} / 1 \mathrm{HNO}_{3}$. In this step, most of Ba 1213 was removed. The eluate was then evaporated to dryness and prepared in $5 \mathrm{ml}$ of 0.5 $1214 \mathrm{~mol} / 1 \mathrm{HNO}_{3}$ for ICP-MS of ${ }^{135} \mathrm{Cs}$ using a triple-quadrupole ICP-MS (Agilent 8800) with $1215 \mathrm{~N}_{2} \mathrm{O}$ as reaction gas to eliminate the interferences including isobar (e.g. ${ }^{135} \mathrm{Ba}^{+}$). 1216 Meanwhile, ${ }^{137} \mathrm{Cs}$ can be also measured by ICP-MS. In this case, no external chemical 1217 yield tracer is needed, ${ }^{137} \mathrm{Cs}$ can be used as an internal yield tracer. ${ }^{137} \mathrm{Cs}$ in the samples 1218 was first measured using gamma spectrometry, the concentration of ${ }^{135} \mathrm{Cs}$ was calculated 1219 using the measured ${ }^{135} \mathrm{Cs} /{ }^{137} \mathrm{Cs}$ ratio by ICP-MS and the ${ }^{137} \mathrm{Cs}$ concentration in the 1220 sample measured by gamma spectrometry. For the sample containing high level 1221 radioactivity of other radionuclides (e.g. ${ }^{60} \mathrm{Co}$ ), ${ }^{137} \mathrm{Cs}$ can be determined by measurement 1222 of the AMP powder adsorbed cesium from the sample, in which ${ }^{60} \mathrm{Co}$ and many other 1223 radionuclides were removed.

1224 The methods presented in this work have been successfully used for the characterization 1225 of various radioactive wastes from the decommissioning of research reactors in Denmark 1226 (DR-1, DR-2 and DR-3) and Australia, nuclear power reactors in Barsebäck, Sweden, 1227 and other nuclear facilities such as hot cells in Denmark. Meanwhile they were also used 1228 for characterization of radioactive waste from the operation of nuclear power plants (e.g. 1229 concentrate, ion exchange resin, etc.) in Finland. Table 2 list the sample amount required 1230 for analysis and the minimum detectable activity (MDA) of our methods for the difficult1231 to measure radionuclides. This is mainly for the clearance samples (less contaminated). 1232 For the samples directly exposed to neutrons or highly contaminated ones, e.g. graphite, 1233 metals from reactor tank or first circulation system, ion exchange resin for purification of 1234 reactor water, small sample (0.05- $0.5 \mathrm{~g})$ is required depending on the radioactive level, 1235 while the MDAs for the corresponding radionuclides (in unit of $\mathrm{Bq} / \mathrm{mBq}$ ) are similar as 1236 listed in the table. 
1238 Table 2 Minimum detectable activity (MDA) for the concerned radionuclides

\begin{tabular}{|c|c|c|c|}
\hline Sample type & Nuclides & Measurement method & MDA $(\mathrm{Bq} / \mathrm{g}) \#$ \\
\hline \multirow{16}{*}{$\begin{array}{l}\text { concrete, } \\
\text { soil, } \\
\text { sediment, } \\
\text { vegetation, } \\
\text { animal } \\
\text { tissues }\end{array}$} & ${ }^{3} \mathrm{H}$ & LSC & $0.1 \mathrm{~Bq} / \mathrm{g}$ \\
\hline & ${ }^{14} \mathrm{C}$ & LSC & $0.05 \mathrm{~Bq} / \mathrm{g}$ \\
\hline & ${ }^{55} \mathrm{Fe}$ & LSC & $0.05 \mathrm{~Bq} / \mathrm{g}$ \\
\hline & ${ }^{63} \mathrm{Ni}$ & LSC & $0.01 \mathrm{~Bq} / \mathrm{g}$ \\
\hline & ${ }^{36} \mathrm{Cl}$ & LSC & $0.01 \mathrm{~Bq} / \mathrm{g}$ \\
\hline & ${ }^{129} \mathrm{I}$ & LSC/AMS & $0.01 \mathrm{~Bq} / \mathrm{g}, 0.1 \mu \mathrm{Bq} / \mathrm{g}(\mathrm{AMS})$ \\
\hline & ${ }^{41} \mathrm{Ca}$ & LSC & $0.15 \mathrm{~Bq} / \mathrm{g}$ \\
\hline & ${ }^{90} \mathrm{Sr}$ & Beta counting & $0.01 \mathrm{~Bq} / \mathrm{g}$ \\
\hline & ${ }^{99} \mathrm{Tc}$ & Beta counter /ICP-MS & $0.01 \mathrm{~Bq} / \mathrm{g}$ \\
\hline & ${ }^{94} \mathrm{Nb}$ & $\gamma$-spectrometry & $0.5 \mathrm{~Bq} / \mathrm{g}$ \\
\hline & ${ }^{238} \mathrm{Pu}$ & $\alpha$-spectrometry & $0.1 \mathrm{mBq} / \mathrm{g}$ \\
\hline & ${ }^{239} \mathrm{Pu}$ & $\alpha$-spectrometry /ICP-MS & $0.1 \mathrm{mBq} / \mathrm{g}$ \\
\hline & ${ }^{240} \mathrm{Pu}$ & $\alpha$-spectrometry /ICP-MS & $0.1 \mathrm{mBq} / \mathrm{g}$ \\
\hline & ${ }^{241} \mathrm{Pu}$ & ICP-MS & $0.03 \mathrm{~Bq} / \mathrm{g}$ \\
\hline & ${ }^{241} \mathrm{Am}$ & $\alpha$-spectrometry & $0.1 \mathrm{mBq} / \mathrm{g}$ \\
\hline & ${ }^{244} \mathrm{Cm}$ & $\alpha$-spectrometry & $0.1 \mathrm{mBq} / \mathrm{g}$ \\
\hline \multirow[t]{16}{*}{ Water } & ${ }^{3} \mathrm{H}$ & LSC & $0.05 \mathrm{~Bq} / \mathrm{ml}$ \\
\hline & ${ }^{14} \mathrm{C}$ & LSC & $0.02 \mathrm{~Bq} / \mathrm{ml}$ \\
\hline & ${ }^{55} \mathrm{Fe}$ & LSC & $0.01 \mathrm{~Bq} / \mathrm{ml}$ \\
\hline & ${ }^{63} \mathrm{Ni}$ & LSC & $0.002 \mathrm{~Bq} / \mathrm{ml}$ \\
\hline & ${ }^{36} \mathrm{Cl}$ & LSC & $0.002 \mathrm{~Bq} / \mathrm{ml}$ \\
\hline & ${ }^{129} \mathrm{I}$ & LSC/AMS & $\begin{array}{l}0.002 \mathrm{~Bq} / \mathrm{ml}, \\
0.1 \mu \mathrm{Bq} / \mathrm{g}(\mathrm{AMS})\end{array}$ \\
\hline & ${ }^{41} \mathrm{Ca}$ & LSC & $0.02 \mathrm{~Bq} / \mathrm{ml}$ \\
\hline & ${ }^{90} \mathrm{Sr}$ & Beta counting & $0.002 \mathrm{~Bq} / \mathrm{ml}$ \\
\hline & ${ }^{99} \mathrm{Tc}$ & Beta counter /ICP-MS & $0.002 \mathrm{~Bq} / \mathrm{ml}$ \\
\hline & ${ }^{94} \mathrm{Nb}$ & $\gamma$-spectrometry & $0.1 \mathrm{~Bq} / \mathrm{ml}$ \\
\hline & ${ }^{238} \mathrm{Pu}$ & $\alpha$-spectrometry & $0.1 \mathrm{mBq} / \mathrm{ml}$ \\
\hline & ${ }^{239} \mathrm{Pu}$ & $\alpha$-spectrometry /ICP-MS & $0.1 \mathrm{mBq} / \mathrm{ml}$ \\
\hline & ${ }^{240} \mathrm{Pu}$ & $\alpha$-spectrometry /ICP-MS & $0.1 \mathrm{mBq} / \mathrm{ml}$ \\
\hline & ${ }^{241} \mathrm{Pu}$ & ICP-MS & $0.01 \mathrm{~Bq} / \mathrm{ml}$ \\
\hline & ${ }^{241} \mathrm{Am}$ & $\alpha$-spectrometry & $0.1 \mathrm{mBq} / \mathrm{ml}$ \\
\hline & ${ }^{244} \mathrm{Cm}$ & $\alpha$-spectrometry & $0.1 \mathrm{mBq} / \mathrm{ml}$ \\
\hline
\end{tabular}

\# The value was estimated by using $20 \mathrm{~g}$ solid samples $\left(1 \mathrm{~g}\right.$ for ${ }^{3} \mathrm{H}$ and $\left.{ }^{14} \mathrm{C}\right)$ and $100 \mathrm{ml}$

1241 for water samples. * For metal samples exposed to the neutrons or direct contaminated,

$12420.1-0.5 \mathrm{~g}$ is required depending on the radioactivity level, and the MDAs are 1243 corresponding to the sample amount. . 


\section{Conclusions}

1245 This paper presents the progress in the development of Radioanalytical methods for 1246 determination of radionuclides in ultra-low level samples in the environment, and 1247 analytical methods for the characterization of radioactive waste from decommissioning of 1248 nuclear facilities, the main achievements are briefly summarized below.

1249 1) A series of radioanalytical methods have been developed and updated for 1250 determination of low-level anthropogenic and naturally occurring radionuclides in 1251 various environmental and biological samples for environmental radioactivity investigation, environmental process and oceanographic tracing.

2) A number of highly selective pre-concentration methods using AMP powder adsorption and $\left.\mathrm{K}_{2} \mathrm{CuFe}(\mathrm{CN})_{6}\right)$ impregnated cartridge filtration were developed and applied for separation of cesium from 100-1000 liter water for determination of low-level ${ }^{134} \mathrm{Cs}$ and ${ }^{137} \mathrm{Cs}$ using gamma spectrometry. With further purification using ion exchange chromatography combined with triple quadrupole ICP-MS and $\mathrm{N}_{2} \mathrm{O}$ as reaction gas, a method was also developed for determination of ${ }^{135} \mathrm{Cs}$ in environmental samples.

3) A simple method was developed for separation of strontium from large volume of environmental water samples (up to $100 \mathrm{~L}$ ) and more than $20 \mathrm{~g}$ soil by precipitation without using highly toxic fuming nitric acid and chromate. By removal of $\mathrm{Sr}$ and $\mathrm{Ra}$ by sulfate precipitation and separation of yttrium as oxalate, ${ }^{90} \mathrm{Sr}$ was determination by measurement of its decay daughter of ${ }^{90} \mathrm{Y}$. A rapid method based on extraction chromatography using Sr-resin was also developed for determination of ${ }^{89} \mathrm{Sr}$ and ${ }^{90} \mathrm{Sr}$ in samples of low strontium content, especially decommissioning samples, both ${ }^{89} \mathrm{Sr}$ and ${ }^{90} \mathrm{Sr}$ were determined using Cherenkov counting and LSC.

4) The stability of technetium in separation processes were investigated, a method was developed to separate technetium from large size environmental samples using co-precipitation. Ultra-low level ${ }^{99} \mathrm{Tc}$ in various environmental samples was 
determined by completely eliminating the isobaric and molecule ions interferences of Ru and Mo and sensitive measurement using ICP-MS.

5) A method based on pre-concentration using co-precipitation and ion exchange chromatographic separation was developed for simultaneous separation of plutonium and neptunium from large environmental samples based on the precisely control of the valence states of two elements. Ultra-low level ${ }^{239} \mathrm{Pu}$, ${ }^{240} \mathrm{Pu},{ }^{237} \mathrm{~Np}$ in environmental samples were determined using ICP-MS.

6) A series of analytical methods for determination of ${ }^{129} \mathrm{I}$ in various environmental samples, such as water, air, aerosol, soil, sediment, vegetation, animal tissue, etc. have been developed. The separation of iodine was mainly implemented by using a specifically designed combustion system, it allows rapid separation of iodine from various solid samples with a chemical yield up to $100 \%$. A carrier free separation method was developed using co-precipitation to separate iodine from environmental samples and to prepare measurement target without addition of any extra iodine carrier, this is useful for the determination of natural level ${ }^{129} \mathrm{I}$. A number of separation methods were developed for speciation analysis of iodine in air, aerosol, water, soil and sediment, iodide, iodate, gaseous organic iodine, gaseous inorganic iodine, iodine associated with different components were separated using these methods. These methods have been successfully applied in the investigation of environmental processes.

7) A number of innovative mass-spectrometric methods have been developed for measurement of ultra-low level radionuclides, including ${ }^{99} \mathrm{Tc},{ }^{129} \mathrm{I},{ }^{236} \mathrm{U},{ }^{239} \mathrm{Pu}$, ${ }^{240} \mathrm{Pu}$, and ${ }^{237} \mathrm{~Np}$. AMS measurement methods were developed for accurate determination of ultra-low level ${ }^{129}$ I down to $10^{6}-10^{7}$ atom level. Combined with carrier free iodine separation, an AMS measurement method was developed to measure ${ }^{129} \mathrm{I}$ in $\mathrm{AgI}-\mathrm{AgCl}$ target with microgram level iodine $(<5 \mu \mathrm{g})$. A direct AMS measurement method without chemical separation of iodine was developed for rapid determination of ${ }^{129} \mathrm{I}$ in environmental samples, with this method, 40 samples can be analyzed within 5 hours and the detection limit is still 2-3 orders 
of magnitude lower than conventional radiometric methods. New ICP-MS methods using triple-quadrupole ICP-MS and collision/reaction gas have been developed for determination of ${ }^{239} \mathrm{Pu},{ }^{240} \mathrm{Pu},{ }^{237} \mathrm{~Np}$, and ${ }^{236} \mathrm{U}$. With this method, the interference of uranium hydrides, and tailing of ${ }^{238} \mathrm{U}$ and ${ }^{235} \mathrm{U}$ can be significantly suppressed by using $\mathrm{NH}_{3}-\mathrm{He}$ and $\mathrm{CO}_{2}-\mathrm{He}$ as reaction gasses and two quadrupole mass separators, which enable to measure ${ }^{239} \mathrm{Pu}$ in a sample with $\mathrm{Pu} / \mathrm{U}$ atomic ratio lower than $10^{-11}$ by combining this measurement technique and chemical separation.

8) A series of analytical methods have been developed for the determination of difficult to measure radionuclides (e.g. ${ }^{3} \mathrm{H},{ }^{14} \mathrm{C},{ }^{36} \mathrm{Cl},{ }^{41} \mathrm{Ca},{ }^{55} \mathrm{Fe},{ }^{63} \mathrm{Ni},{ }^{90} \mathrm{Sr},{ }^{93} \mathrm{Mo}$, ${ }^{94} \mathrm{Nb},{ }^{129} \mathrm{I},{ }^{135} \mathrm{Cs}$, and isotopes of $\mathrm{Pu}, \mathrm{Np}, \mathrm{Am}$ and $\mathrm{Cm}$ ) in various radioactive waste for decommissioning of nuclear facilities and waste repository. Special efforts were given to ensure reliability in the determination of volatile radionuclides (e.g. ${ }^{3} \mathrm{H},{ }^{14} \mathrm{C},{ }^{36} \mathrm{Cl},{ }^{99} \mathrm{Tc},{ }^{129} \mathrm{I}$ ), simple operation and rapid separation for reducing the radiation exposure and analytical time. Some sequential analytical procedures were proposed to determine all required radionuclides in one sample, to further reduce the analytical time, the sample amount, and consequently the radiation exposure. These methods have been successfully used in the characterization of decommissioning waste from the research and power reactors in Denmark and Sweden.

\section{Acknowledgements}

1323 The author thanks the colleagues and students in Radioecology and Tracer Studies (RAS) 1324 group in the Center for Nuclear Technologies, Technical University of Denmark, Dr. 1325 Sven P. Nielsen, Mr. Qingjiang Chen, Dr. Per Roos, Dr. Jixin Qiao, Dr. Szabolcs Osváth, 1326 Mr. Liuchao Zhu for their contributions in the development of the analytical methods 1327 summarized in this papers. Dr. Keliang and Prof. Wangsuo in Lanzhou University are 1328 appreciated for their contributions in the development of some methods and suggestions 
1329 to this paper. The author is grateful to Dr. Luyuan Zhang, Ms. Yanyun Wang, Dr. Ning 1330 Chen, Dr. Qi Liu, Dr. Weichao Zhang, Dr. Maoyi Luo, Dr. Shan Xing, Dr. Yukun Fan 1331 and prof. Weijian Zhou for their contribution in the development of the analytical 1332 methods for ${ }^{129} \mathrm{I}$ and its chemical species in environmental samples and AMS 1333 measurement methods for ${ }^{129} \mathrm{I}$. The author also likes to thank prof. Zhifang Chai, prof. 1334 Jan Kucera, prof. Nora Vajda, prof. Phil Warwick, and prof. Amares Chatt for their great 1335 and continuous support and collaboration. This work was partly supported by NKS, the

1336 Ministry of Science and Technology of China (No. 2015FY110800), the National Natural 1337 Science Foundation of China (No. 11875261, 91643206, 11605206, 41603125), Chinese 1338 Academy of Sciences (132B61KYSB20180003), and National Research Program for Key 1339 Issues in Air Pollution Control (DQGG0105-02).

\section{$1341 \quad$ References}

1342 1. IAEA, Power Reactor Information System (PRIS), https://www.iaea.org/pris/

1343 2. UNSCEAR (2000) Sources, Effects and Risk of Ionizing Radiation. UNSCEAR 13442000 Report to the General Assembly, Annex C: Exposures from Man-made Sources 1345 of Radiation (New York): 195-204

1346 http://www.unscear.org/docs/publications/2000/UNSCEAR_2000_Annex-C$1347 \quad$ CORR.pdf

1348 3. UNSCEAR (2013) Sources, Effects and Risk of Ionizing Radiation. UNSCEAR 1349 2013, Volume I, Report to the General Assembly, Scientific Annex A: Level and 1350 effect of radiation exposure due to the nuclear accident after the 2011 great east1351 Japan earthquake and Tsunami. New York 2014, 1352 http://www.unscear.org/docs/reports/2013/13-85418_Report_2013_Annex_A.pdf

1353 4. Gray J, Jones SR, Smith AD (1995). Discharge to the environment from the 1354 Sellafield site, 1952-1992., J. Radiol. Prot., 15 (1995), 99-131 
Journal of Radioanalytical and Nuclear Chemistry

1355 5. IRRIN (1999), Inventaire des rejets radioactifs des installation nuceairs, Groupe $1356 \quad$ Radioecologie Bord Contentin, Vol.1

1357 6. Hou XL, Hansen V, Aldahan A, Possnert G, Lind OC, Lujaniene G (2009)

1358 Speciation of Iodine-129 in the Environment. Anal Chim Acta. 632:181-196

1359 7. Xu Y, Gu P, Zhao J, Wang L, Xiao XZ, Zhang GH, Han F (2017) Comprehensive 1360 evaluation of cesium removal by $\mathrm{CuFC}$ adsorption: the effects of initial 1361 concentration, CuFC dosage and co-existing ions in solution. J Radioannal Nucl 1362 Chem Lett. 311:531-540. DOI:10.1007/s10967-016-5049-1

1363 8. Park JH, Chang BU, Kim YJ, Seo JS, Choi SW, Yun JY (2008) Determination of 1364 low ${ }^{137} \mathrm{Cs}$ concentration in seawater using ammonium 12-molybdophosphate 1365 adsorption and chemical separation method. J Environ Radioact. 99:1815-1818. 1366 doi:10.1016/j.jenvrad.2008.07.006

1367 9. Olatunji MA, Khandaker MU, Mahmud HNME, Amin YM (2015) In fluence of 1368 adsorption parameters on cesiumuptake from aqueous solutions- a brief review. RSC $1369 \quad$ Advances. DOI: 10.1039/c5ra10598f

1370 10. Chen QJ, Hou XL, Nielsen SP, Dahlgaard H, Yu Y (2002) Separation of Sr from Ca, $1371 \mathrm{Ba}$ and $\mathrm{Ra}$ in the determination of radiostrontium by means of simple precipitation 1372 using $\mathrm{Ca}(\mathrm{OH})_{2}, \mathrm{Ba}(\mathrm{Ra}) \mathrm{Cl}_{2}$ or $\mathrm{Ba}(\mathrm{Ra}) \mathrm{SO}_{4}$. Anal Chim Acta. 466 (1): 109-116

1373 11. Shi KL, Hou XL, Roos P, Wu WS (2011) Determination of Technetium-99 in 1374 environmental samples: a review. Anal Chim Acta. 709:1-20

1375 12. Shi K, Hou XL, Roos P, Wu WS (2012) Stability of technetium and 1376 decontamination of $\mathrm{Ru}$ and $\mathrm{Mo}$ in determination of ${ }^{99} \mathrm{Tc}$ in environmental solid 1377 samples by ICP-MS. Anal Chem. 84:2009-2016

1378 13. Chen QJ, Dahlgaard H, Nielsen SP (1994) Determination of ${ }^{99} \mathrm{Tc}$ in seawater at 1379 ultra-low level. Anal Chim Acta. 285:177-180 
1380

1381

1382

1383

1384

1385

1386

1387

1388

1389

1390

1391

1392

1393

1394

1395

1396

1397

1398

1399

1400

1401

1402

1403

1404

1405

1406

14. Chen QJ, Aarkrog A, Nielsen SP, Dahlgaard H, Lind B, Kolstad AK, Yu YX (2001)

Procedures for determination of $\mathrm{Pu}, \mathrm{Am}, \mathrm{Np}, \mathrm{U}, \mathrm{Th},{ }^{99} \mathrm{Tc},{ }^{210} \mathrm{Po}^{210}{ }^{210}$ in environmental materials, Risø report, Risø-R-1263, 2001.

http://130.226.56.153/rispubl/NUK/nukpdf/ris-r-1263.pdf

15. Shi K, Qiao JX, Roos P, Wu WS, Hou XL (2012) Rapid determination of technetium-99 in large volume seawater samples using sequential injection extraction chromatographic separation and ICP-MS measurement. Anal Chem., 2012, 84(15)6783-6789

16. Hou XL, Jansen M, Nielsen SP (2007) Use of ${ }^{99 m} \mathrm{Tc}$ from a Commercial ${ }^{99} \mathrm{Mo} /{ }^{99 \mathrm{~m}} \mathrm{Tc}$ Generator as Yield Tracer for the Determination of $9^{9} \mathrm{Tc}$ at Low Levels. Applied Radiation and Isotopes. 65:610-618

17. Qiao JX, Hou XL, Miró M, Roos P (2009). Determination of plutonium isotopes in waters and environmental solids: A review, Analytica Chimica Acta. 652: 66-84

18. Qiao JX, Hou XL, Miró M, Roos P (2010) Rapid and simultaneous determination of neptunium and plutonium isotopes in environmental samples by extraction chromatography using sequential injection analysis and ICP-MS Journal of Analytical Atomic Spectrometry. 25(11):1769-1779

19. Wang ZT, Yang GS, Zhang J, Cao LG, Yu HJ, Zhu YB, Tagami K, Uchida S (2015) Effect of ashing temperature on accurate determination of plutonium in soil samples. Anal Chem. 87:5511-5515. DOI: 10.1021/acs.analchem.5b01472

20. Luo MY, Xing S, Yang YG, Song LJ, Ma Y, Wang YD, Dai XX, Happel S. (2018) Sequential analyses of actinides in large-size soil and sediment samples with total sample dissolution. J Environ Radioact. 187:73-80. https://doi.org/10.1016/j.jenvrad.2018.01.028

21. Vajda N, Kim CK (2011) Determination of transuranium isotopes ( $\mathrm{Pu}, \mathrm{Np}, \mathrm{Am})$ by radiometric techniques: A review of analytical methodology. Anal Chem. 83:46884719. DOI: $10.1021 / \mathrm{ac} 2008288$ 
22. Chen QJ, Dahlgaard H, Nielsen SP, Aarkrog A (2002) Pu-242 as tracer for simultaneous determination of $\mathrm{Np}-237, \mathrm{Pu}-239, \mathrm{Pu}-240$ in environmental samples. $\mathrm{J}$ Radioanal Nuc Chem. 253:451-458

23. Qiao JX, Hou XL, Miró M, Roos P (2011) Reliable determination of ${ }^{237} \mathrm{~Np}$ in environmental samples using ${ }^{242} \mathrm{Pu}$ as a potential tracer. Talanta. 84(2):494-500

1412 24. Qiao JX, Hou XL, Miró M, Roos P (2011) High throughput sequential injection method for simultaneous determination of plutonium and neptunium in environmental solids using microporous anion exchange chromatography, followed by ICP-MS detection, Anal Chem. 83(1):374-381

25. Qiao JX, Hou XL, Miró M, Roos P (2013) Method for Determination of Neptunium in Large-Sized Urine Samples Using Manganese Dioxide Coprecipitation and ${ }^{242} \mathrm{Pu}$ as Yield Tracer. Anal Chem. 85:1889-1895

26. Wang ZT, Zheng J, Ni Y, Men W, Tagami K, Uchida S (2017) High performance method for rapid determination of $\mathrm{Pu}$ isotopes in soil and sediment samples by sector field inductively coupled plasma mass spectrometry. Anal Chem. 89:2221-2226

27. Hou XL, Zhang DX (2018) Determination of I-129 in environmental solid samples using pyrolysis separation and accelerator mass spectrometry measurement. J. Radioanal Nucl Chem. 317:487-499

28. Hou XL, Wang YY (2016) Determination of ultra-low level ${ }^{129}$ I in vegetation using pyrolysis for iodine separation and accelerator mass spectrometry measurement. $\mathrm{J}$ Anal At Spectrom. 31:1298-1310

29. Hou XL, Dahlgaard H, Rietz B, Jacobsen U, Nielsen SP, Aarkrog A (1999) Determination of iodine-129 in seawater and some environmental materials by neutron activation analysis. Analyst. 124:1109-1114 sequential extraction and mass spectrometry detection. Anal Chem. 87(13):69376944 
1434 31. Hou XL, Zhou WJ, Chen N, Zhang LY, Liu Q, Luo MY, Fan YK, Liang WG, Fu YC (2010) Determination of Ultralow Level ${ }^{129} I^{127} I$ in Natural Samples by 1436 Separation of Microgram Carrier Free Iodine and Accelerator Mass Spectrometry 1437 Detection, Anal Chem. 82(18):7713-7721

1438 32. Dang HJ, Hou XL, Roos P, Nielsen SP (2012) Release of iodine from organic matter in natural water by $\mathrm{K}_{2} \mathrm{~S}_{2} \mathrm{O}_{8}$ oxidation for ${ }^{129} \mathrm{I}$ determination. Anal Method. DOI:10.1039/c2ay25958c

33. Luo MY, Hou XL, He CH, Liu Q, Fan YK (2013) Speciation analysis of ${ }^{129}$ I in seawater by carrier free $\mathrm{AgI}-\mathrm{AgCl}$ coprecipitation and AMS measurement. Anal Chem. 85(7):3715-3722 JC, McFiggans G, Saunders RW (2012) Atmospheric chemistry of iodine. Chemical Reviews. 112:1773-1804. DOI:10.1021/cr200029u

35. Hou XL, Dahlgaard H, Nielsen SP (2001) Chemical speciation analysis of ${ }^{129}$ I in seawater and a prliminary investigation to use it as a tracer for geochemical cycle study of stable iodine. Mar Chem. 74:145-155 circulation and marine environment in the Antarctic traced by speciation of ${ }^{129} \mathrm{I}$ and ${ }^{127}$ I. Sci Rep. 7:7726, DOI:10.1038/s41598-017-07765-w

1453 37. Liu D, Hou XL, Du JZ, Zhang LY, Zhou WJ (2016) I-129 and its species in the East 1454 China Sea: level, distribution, sources and tracing water masses exchange and 1455 movement. Sci Rep. 6; 36611, DOI: 10.1038/srep36611

1456 38. Hou XL, Fogh CL, Kucera J, Andersson KG, Dahlgaard H, Nielsen SP (2003) 1457 Iodine-129 and Cesium-137 in Chernobyl Contaminated Soil and Their Chemical 1458 Fractionation. Sci Total Environ. 308(1-3):97-109 
39. Qiao JX, Hansen V, Hou XL, Aldahan A, Possnert G (2012) Speciation analysis of ${ }^{129} \mathrm{I},{ }^{137} \mathrm{Cs},{ }^{232} \mathrm{Th},{ }^{238} \mathrm{U},{ }^{239} \mathrm{Pu}$ and ${ }^{240} \mathrm{Pu}$ in environmental soil and sediment. Applied Radiation and Isotopes. 70(8):1698-1708

40. Luo MY, Hou XL, Zhou WJ, He CH, Chen N, Liu Q, Zhang LY (2013). Speciation and migration of ${ }^{129} \mathrm{I}$ in soil profiles. J Environ Radioact 118:30-39

1464 41. Englund E, Aldahan A, Hou XL, Petersen R, Possnert G (2010) Speciation of iodine $\left({ }^{129} \mathrm{I}\right.$ and $\left.{ }^{127} \mathrm{I}\right)$ in lake sediments, Nucl Instr Method B. 268(7-8):1102-1105

42. Hou XL, Roos P (2008) Critical Comparison of Radiometric and Mass Spectrometric Methods for the Determination of Radionuclides in Environmental, Biological and Nuclear Waste samples. Anal Chim Acta. 608:105-139

43. Hou XL (2018) Liquid scintillation counting for determination of radionuclides in environmental and nuclear application. J Radioanal Nucl Chem. 318:1597-1628.

44. Xing S, Zhang WC, Qiao JX, Hou XL (2018) Determination of ultra-low level plutonium isotopes $\left({ }^{239} \mathrm{Pu},{ }^{240} \mathrm{Pu}\right)$ in environmental samples with high uranium, Talanta 187:357-364

45. Liu Q, Hou XL, Zhou WJ, Fu YC (2015) Accelerator mass spectrometry analysis of ultra-low-level ${ }^{129} \mathrm{I}$ in carrier-free $\mathrm{AgI}-\mathrm{AgCl}$ sputter targets. Journal of the American

46. Liu Q, Zhao XL, Hou XL, Burr G, Zhou WJ, Fu YC, Chen N, Zhang LY (2016) Preliminary Investigation on the Rapid and Direct AMS Measurement of I-129 in

47. Hou XL (2005) Determination of ${ }^{14} \mathrm{C}$ and ${ }^{3} \mathrm{H}$ in Reactor Graphite and Concrete for Environmental Samples without Chemical Separation. Radiocarbon. 58:147-156

1482 48. Hou XL (2011) Analysis of Urine for Pure Beta Emitters: Methods and Application, 1483 Health Phys. 101(2):159-169 
1484 49. Hou XL (2007) Radiochemical analysis of radionuclides difficult to measure. J 1485 Radioanal Nucl Chem. 273:43-48

1486 50. Hou XL (2018) Tritium and ${ }^{14} \mathrm{C}$ in the Environment and Nuclear Facilities: Sources 1487 and Analytical Methods. J. Nucl. Fuel Cycle Waste Technol. 2018, 16: 1738-1894.

1488 51. Hou XL, Østergaard LF, Nielsen SP (2007) Determination of ${ }^{36} \mathrm{Cl}$ in Nuclear Waste 1489 from Reactor Decommissioning, Anal Chem. 79:3126-3134

1490 52. Hou XL (2005) Determination of ${ }^{63} \mathrm{Ni}$ and ${ }^{55} \mathrm{Fe}$ in nuclear waste and environmental $1491 \quad$ samples. Anal Chim Acta. 535:297-307

1492 53. Hou XL, Olsson M, Togneri L, Englund S, Vaaramaa K, Askeljung GC, 1493 Gottfridsson O, Hirvonen H, Öhlin H, Forsström M, Anders F, Lampen M, Hatakka A (2016) Present status and perspective of radiochemical analysis of radionuclides in Nordic countries. J Radioanal Nucl Chem 309(3):1283-1319

1496 54. Hou XL (2005) Radiochemical determination of ${ }^{41} \mathrm{Ca}$ in reactor concrete for decommissioning. Radiochim Acta. 93:611-617

1498 55. Chen QJ, Nielsen SP, Aarkrog A, Dahlgaard H, Duniec S (1993) Distribution of 1499 plutonium isotopes in cooling water from a PWR. J Nucl Sci Technol. 30:164-170 